SABRINA ZBÓRIL

Diagnóstico da síndrome da disfunção cognitiva em cães idosos após procedimento cirúrgico-anestésico

São Paulo

2015 


\section{SABRINA ZBÓRIL}

Diagnóstico da síndrome da disfunção cognitiva em cães idosos após procedimento cirúrgico-anestésico

Dissertação apresentada ao Programa de Pós-Graduação em Clínica Cirúrgica Veterinária da Faculdade de Medicina Veterinária e Zootecnia da Universidade de São Paulo para obtenção do título de Mestre em Ciências

Departamento:

Cirurgia

Área de concentração:

Clínica Cirúrgica Veterinária

Orientadora:

Profa. Dra. Silvia Renata Gaido

Cortopassi 
Autorizo a reprodução parcial ou total desta obra, para fins acadêmicos, desde que citada a fonte.

\section{DADOS INTERNACIONAIS DE CATALOGAÇÃO-NA-PUBLICAÇÃO}

(Biblioteca Virginie Buff D’Ápice da Faculdade de Medicina Veterinária e Zootecnia da Universidade de São Paulo)

Zbóril, Sabrina

Diagnóstico da síndrome da disfunção cognitiva em cães idosos após procedimento cirúrgico-anestésico / Sabrina Zbóril. -- 2015.

97 f. :il.

Dissertação (Mestrado) - Universidade de São Paulo. Faculdade de Medicina Veterinária e Zootecnia. Departamento de Cirurgia, São Paulo, 2015.

Programa de Pós-Graduação: Clínica Cirúrgica Veterinária. Área de concentração: Clínica Cirúrgica Veterinária.

Orientador: Profa. Dra. Silvia Renata Gaido Cortopassi.

1. Anestesia. 2. Cães. 3. Déficit cognitivo. 4. Geriatria. 5. NSE. 6. S100ß. I. Título. 


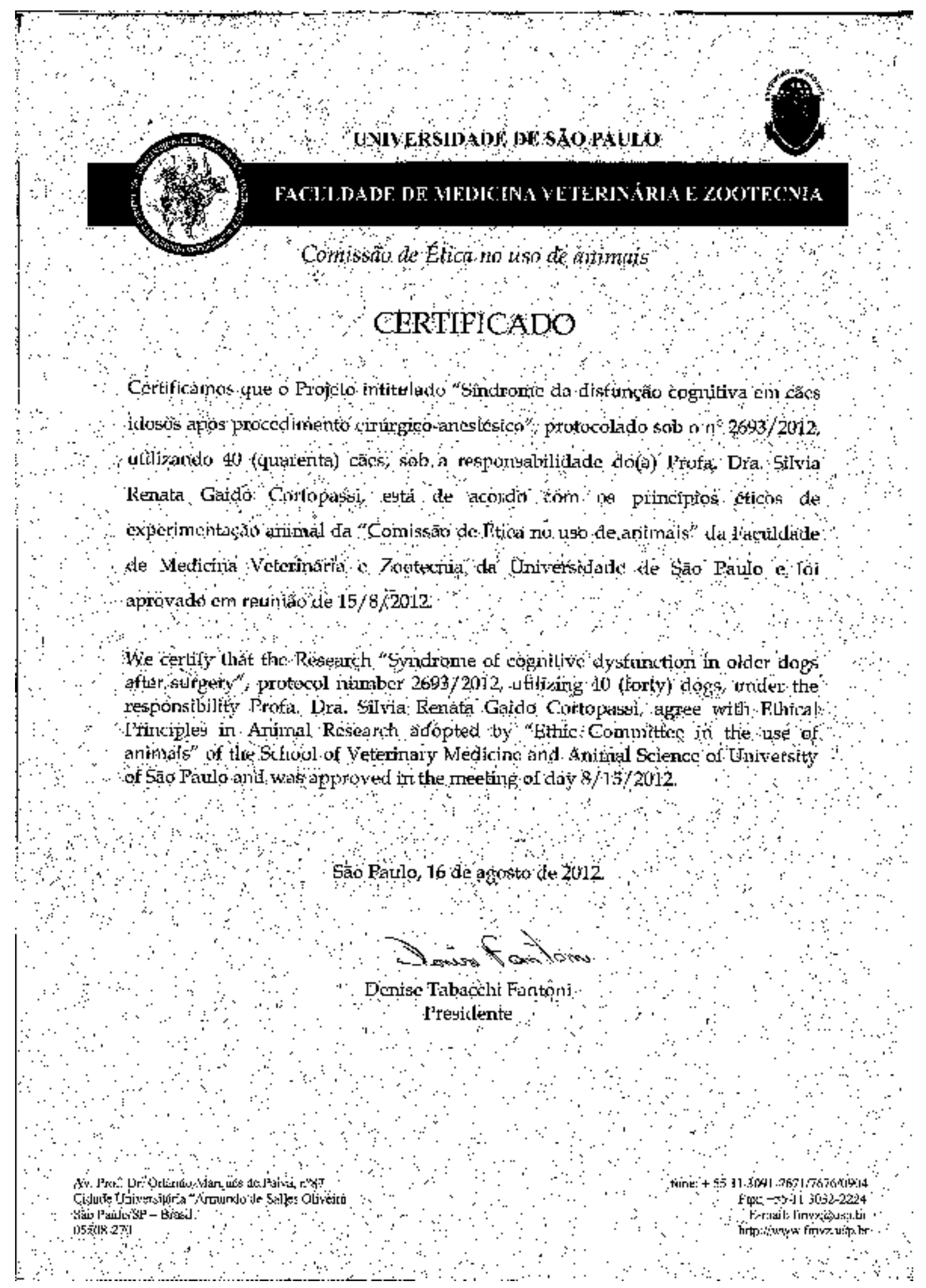


Autor: ZBÓRIL, Sabrina

Título: Diagnóstico da síndrome da disfunção cognitiva em cães idosos após procedimento cirúrgico-anestésico.

Dissertação apresentada ao Programa de Pós-Graduação em Clínica Cirúrgica Veterinária da Faculdade de Medicina Veterinária e Zootecnia da Universidade de São Paulo para obtenção do título de Mestre em Ciências

Data:

\section{Banca Examinadora}

Prof. Dr.:

Instituição: Julagamento:

Prof. Dr.:

Instituição: Julagamento:

Prof. Dr.:

Instituição: Julagamento: 


\section{DEDICATÓRIA}

Dedico esse trabalho aos meus queridos pais, Mauricio de Abreu Zbóril e Vera Márcia Moraes Zbóril.

A minha irmã Fernanda Zbóril, ao meu sobrinho Otávio Zbóril.

E ao meu marido e amigo Felipe Milagres Drumond Amorim. 


\section{AGRADECIMENTOS ESPECIAIS}

A minha amiga querida e orientadora Profa. Silvia Renata Gaido Cortopassi e ao amigo Dr. André Prato Schimidt agradeço a oportunidade e a confiança a que me foi depositada .

Pelo apoio e ajuda constante na confecção deste estudo.

Foi uma honra e um provilégio trabalhar ao lado de pessoas execepcionais como vocês. 


\section{AGRADECIMENTOS}

Ao meu marido e amigo Felipe Milagres Drumond Amorim, por todo o apoio e compreensão, por estar sempre ao meu lado nas horas dificeis.

A minha mãe Vera Márcia Moraes Zbóril, ao meu pai Mauricio de Abreu Zbóril e a minha irmã Fernanda Zbóril pelo amor e educação a que me foi dada.

Ao amigo Prof. Dr. Rodrigo Luiz Marucio, pelos ensinamentos e pelas oportunidades.

Ao meu amigo e companheiro de profissão Luis Augusto Linz Sansoni, pelo grande auxilio neste projeto

As amigas e companheiras de profissão Patrícia Bonifácio Flor e Geni Cristina Fonseca, pela coloboração na realização desse projeto.

As amigas e companheiras de profissão Bruna Dezzorzi, Danielle Amazonas e Fernanda Devito pelo apoio e colaboração desse projeto.

A equipe do Laboratório de Odontologia Comparada da FMVZ-USP-SP, em especial a Mariana, Cintia e Nicole pela ajuda com os animais durante o projeto.

Aos enfermeiros, Jesus dos Anjos Viera, José Miron de Oliveira da Silva e Otávio Rodrigues dos Santos.

A todos os cães que participaram desse projeto.

A Fundação de Amparo a Pesquisa do Estado de São Paulo pelo apoio financeiro ao projeto. 


\section{RESUMO}

ZBÓRIL, S. Diagnóstico da síndrome da disfunção cognitiva em cães idosos após procedimento cirúrgico-anestésico. [Diagnostic of the syndrome of cognitive dysfunction in older dogs after surgery]. 2015. 97f. Dissertação (Mestrado em Ciências) - Faculdade de Medicina Veterinária e Zootecnia, Universidade de São Paulo, São Paulo, 2015.

A disfunção cognitiva é definida como alterações dos processos mentais e sua detecção é feita com auxílio de testes neuropsicológicos. Pesquisas vem sendo realizadas na tentativa de estabelecer prováveis marcadores neurobioquímicos precoces para estimar morte neuronal. O presente estudo avaliou 24 cães distribuídos em dois grupos: GC - grupo controle (até 8 anos) ( $n=10)$ e $\mathrm{Gl}$ - grupo idoso (acima de 8 anos) $(n=14)$. Todos os animais foram submetidos ao tratamento periodontal sob anestesia geral e avaliados previamente quanto à presença de outras doenças sistêmicas. Para tal foram submetidos a teste neurológico completo, exame cardiológico e à colheita de sangue venoso periférico para realização de hemograma completo, perfil renal e hepático. Os animais foram avaliados quanto a cognição com auxílio de duas escalas neuropsicológicas (ARCAD e CCDR) e à avaliação dos valores séricos das proteínas marcadoras de danos neuronais (NSE e $\mathrm{S} 100 \beta)$, nos períodos pré e pós-operatórios. Constatou-se aumento significativo da proteína $S 100 \beta$ no $\mathrm{Gl}$ em relação ao $\mathrm{GC}(\mathrm{p}=0,014)$ no momento pré-operatório, e também entre os momentos pós-extubação nos animais do $G C(p=0,04)$. Por meio das escalas comportamentais empregadas, não foi possível detectar a disfunção cognitiva no pós-cirúrgico de cães idosos submetidos a procedimento cirúrgicoanestésico. Os valores obtidos da proteína $S 100 \beta$ sugerem que os animais idosos possuem possível neuroinflamação pré-operatória, ocasionada por inflamação sistêmica ou mesmo central; entretanto não foi possível correlacionar com as escalas comportamentais empregadas.

Palavras-chave: Anestesia. Cães. Déficit cognitivo. Geriatria. NSE. S100ß. 


\begin{abstract}
ZBÓRIL, S. Diagnostic of the syndrome of cognitive dysfunction in older dogs after surgery. [Diagnóstico da síndrome da disfunção cognitiva em cães idosos após procedimento cirúrgico-anestésico]. 2015. 97f. Dissertação (Mestrado em Ciências) - Faculdade de Medicina Veterinária e Zootecnia, Universidade de São Paulo, São Paulo, 2015.
\end{abstract}

Cognitive dysfunction is defined as changes in mental processes and it detection is performed with the aid of neuropsychological tests. Recently research has been conducted in attempt to establish early neuro biochemicals markers to estimate neuronal death. This study evaluated 24 dogs that were distributed into two groups: CG - control group (up to 8 years old) $(n=10)$ and $E G$ - elderly group (over 8 years) $(n=14)$. All animals underwent periodontal treatment under general anesthesia and were previously evaluated to detect the presence of systemic diseases. A complete neurological and cardiac examination were performed in all animals and also a peripheral venous blood samples were collected for blood count, kidney and liver profile. The animals were assessed for cognition by using two neuropsychological scales (ARCAD and CCDR) and the assessment of serum levels of protein markers of neuronal damage (NSE and S100ß) pre and postoperatively. A significant increase in $S 100 \beta$ protein in $E G$ compared to the $C G(p=0.014)$ in the preoperative period was observerd and also between the post-extubation times in the animals of CG ( $p=$ 0.04). Through behavioral scales used it was not possible to detect cognitive dysfunction in the postoperative elderly dogs underwent surgical - anesthetic procedure. The values of $S 100 \beta$ protein suggest that elderly animals may have preoperative neuroinflammation caused by systemic or central inflammation; however we could not correlate with the behavioral scales.

Key-words: Anesthesia. Cognitive deficit. Dogs. Geriatrics. NSE. S100ß. 


\section{LISTA DE TABELAS}

Tabela 1 - Informações gerais sobre os cães dos grupos controle (CG) e tempo transoperatório (min-minutos) - São Paulo - 2013/2014

Tabela 2 - Informações gerais sobre os cães do grupo idoso (Gl) e tempo transoperatório (min-minutos) - São Paulo - 2013/2014

Tabela 3 - Valores da somatória das escalas de avaliação de cognição, ARCAD e CCDR no período pré-operatório e sete dias após procedimento cirúrgico-anestésico no grupo controle (CG) - São Paulo - 2013/2014 . 38

Tabela 4 - Valores da somatória das escalas de avaliação da cognição ARCAD e CCDR no período pré-operatório e sete dias após procedimento anestésico-cirúrgico nos cães do grupo idoso (GI)- São Paulo 2013/2014

Tabela 5 - Valores médios e desvio-padrão das variáveis: frequência cárdica (FC-batimentos por minuto), pressão arterial sistólica (PAS - mmHg), pressão arterial média (PAM - $\mathrm{mmHg}$ ) e pressão arterial diastólica (PAD-mmHg) nos grupos controle (GC) e idoso (Gl) nos diferentes momentos de avaliação - São Paulo - 2013/2014

Tabela 6 - Valores médios e desvio-padrão das variáveis: frequência respiratória (FR-movimentos respiratórios por minuto), concentração expirada de dióxido de carbono (ETCO2 - mmHg ), concentração expirada de isofluorano (Iso exp - \%) e temperatura retal (TR - Celsius) dos animais dos grupos controle (GC) e idoso (GI) nos diferentes momentos de avaliação - São Paulo - 2013/2014

Tabela 7 - Valores médios e desvio-padrão do pH arterial, pressão parcial de dióxido de carbono ( $\mathrm{PaCO} 2-\mathrm{mmHg}$ ), pressão parcial de oxigênio (PaO2 - $\mathrm{mmHg}$ ), saturação da oxihemoglobina no sangue arterial ( $\mathrm{SaO} 2$ - \%), bicarbonato plasmático $\left(\mathrm{HCO}_{3}{ }^{-}-\mathrm{mEq} / \mathrm{L}\right)$ e déficit de base (BE) - São Paulo - 2013/2014

Tabela 8 - Valores médios e desvio-padrão dos marcadores neurobioquímicos: S100B e NSE $(\mu \mathrm{g} / \mathrm{ml})$ nos momentos basal $(\mathrm{Mb})$ e pós-extubação (Mpe) - São Paulo - 2013/2014 
Tabela 9 - Número de pacientes com complicações, hipotermia leve e moderada e hipotensão arterial sistêmica no período transoperatório nos grupo controle (GC) e grupo idoso (Gl) - São Paulo - 2013/2014 53 


\section{LISTA DE FIGURAS}

Figura 1 - Representação gráfica demonstrando valores médios e respectivos desvios-padrão da concentração expirada de isofluorano (\%) dos cães dos grupos controle (GC) e idoso (Gl) nos diferentes momentos de avaliação - São Paulo - 2013/2014

Figura 2 - Representação gráfica demonstrando valores médios e respectivos desvios-padrão da temperatura retal (graus Celsius) dos cães dos grupos controle (GC) e idoso (Gl) nos diferentes momentos de avaliação - São Paulo - 2013/2014.

Figura 3 - Representação gráfica demonstrando valores médios e respectivos desvios-padrão da pressão parcial de oxigênio no sangue arterial $(\mathrm{mmHg})$ dos animais dos grupos controle (GC) e idoso (Gl) nos diferentes momentos de avaliação - São Paulo - 2013/2014 48

Figura 4 - Representação gráfica demonstrando valores médios e respectivos desvios-padrão do marcador neurobioquímico S100B dos cães dos grupos controle (GC) e idoso (Gl) nos diferentes momentos de avaliação - São Paulo - 2013/2014 


\section{LISTA DE ABREVIATURAS E SIGLAS}

$\begin{array}{ll}\text { ARCAD } & \text { Evaluation of age-related cognitive and affective disorders } \\ \mathrm{CCDR} & \text { Escala de Classificação da Disfunção Cognitiva em Cães } \\ \mathrm{bpm} & \text { batimentos por minuto } \\ \mathrm{ETCO}_{2} & \text { fração de dióxido de carbono no final da expiração } \\ \mathrm{FC} & \text { frequência cardíaca } \\ \mathrm{FR} & \text { frequência respiratória } \\ \mathrm{GC} & \text { grupo controle } \\ \mathrm{Gl} & \text { grupo idoso } \\ \mathrm{HCO}_{3}{ }^{-} & \text {concentração plasmática de bicarbonato } \\ \mathrm{ISPOCD} \text { I } & \text { Study of Postoperative Cognitive Dysfunction I } \\ \mathrm{ISPOCD} \text { II } & \text { Study of Postoperative Cognitive Dysfunction II } \\ \mathrm{kg} & \text { quilograma } \\ \mu \mathrm{mg} & \text { microgramas } \\ \mathrm{mg} & \text { miligrama } \\ \mathrm{ml} & \text { mililitros } \\ \mathrm{min} & \text { minuto } \\ \mathrm{mrm} & \text { movimentos respiratórios por minuto } \\ \mathrm{NSE} & \text { enzima glicolítica enolase } \\ \mathrm{PaCO} & \text { pressão parcial de dióxido de carbono no sangue arterial } \\ \mathrm{PaO} & \text { pressão parcial de oxigênio no sangue arterial } \\ \mathrm{PAD} & \text { pressão arterial diastólica } \\ \mathrm{PAM} & \text { pressão arterial média } \\ \mathrm{PAS} & \text { pressão arterial sistólica } \\ \mathrm{pH} & \text { potencial hidrogeniônico } \\ \mathrm{SaO} & \text { saturação de oxigênio na hemoglobina do sangue arterial } \\ \mathrm{TR} & \text { temperatura retal } \\ \% & \text { porcentagem } \\ & \end{array}$




\section{SUMÁRIO}

INTRODUÇÃO .16

$2.1 \quad$ ENVELHECIMENTO VERSUS COGNIÇÃO …................................18

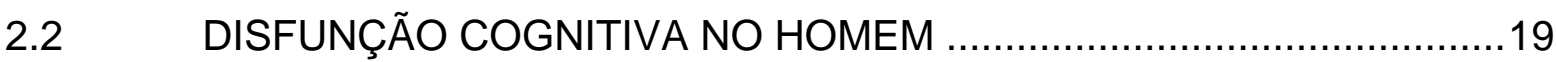

2.3 DISFUNÇÃO COGNITIVA PÓS-OPERATÓRIA …..............................20

2.4 DISFUNÇÃO COGNITIVA PÓS-OPERATÓRIA VERSUS ANESTESIA INALATÓRIA

2.5 MARCADORES DE INJÚRIA NO SNC - PROTEÍNAS S100ß E ENZIMA

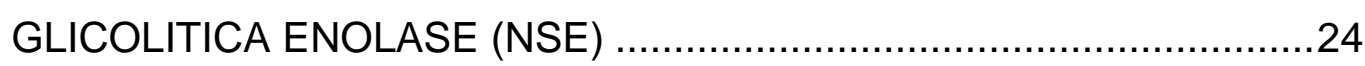

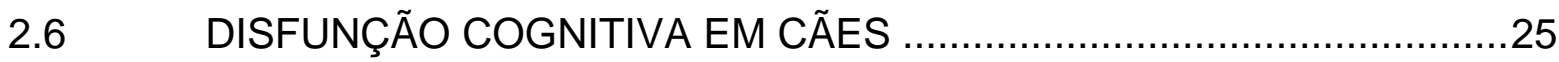

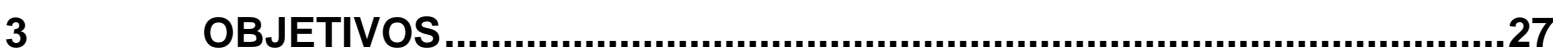

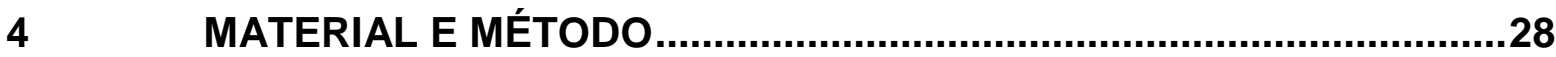

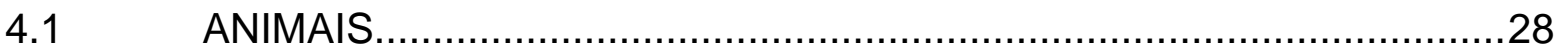

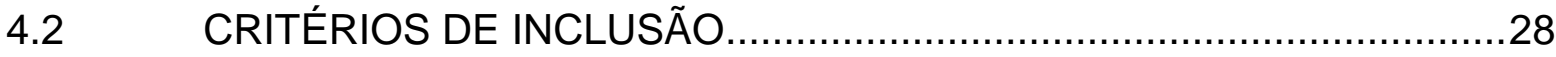

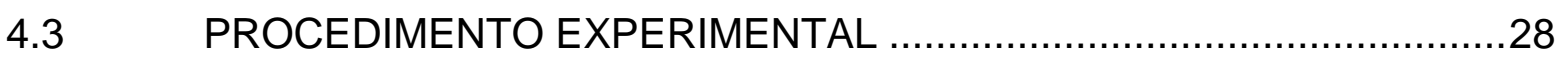

4.4 AVALIAÇÃO DO PROCEDIMENTO ANESTÉSICO …........................30

4.4.1 Frequência cardíaca e ritmo cardíaco ..............................................30

4.4.2 Pressão arterial sistólica, média e diastólica .......................................31

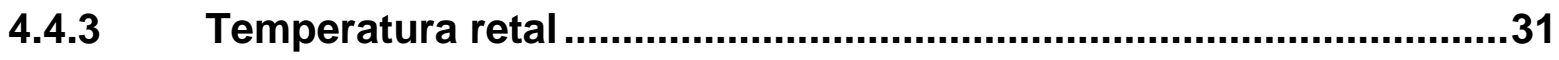

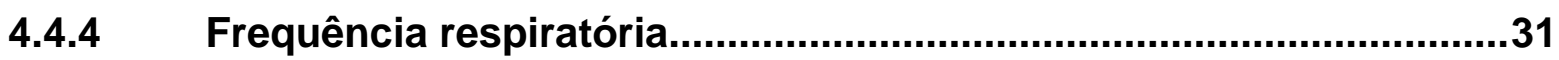

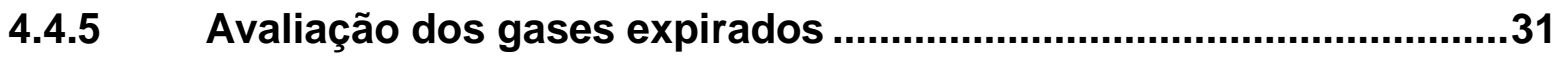

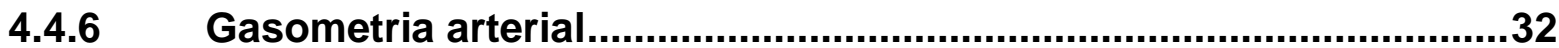

4.5 DELINEAMENTO EXPERIMENTAL …............................................

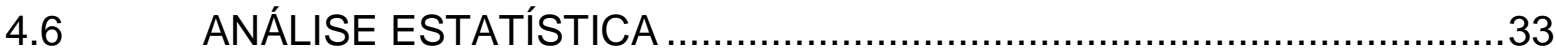

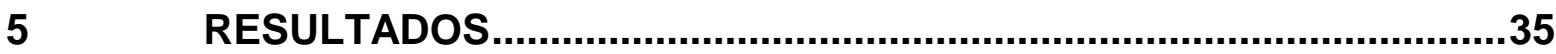

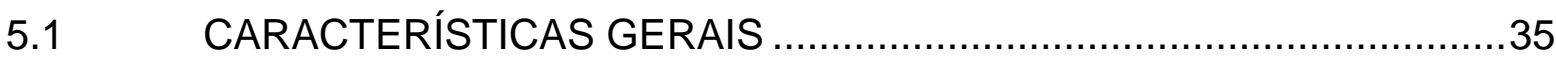

5.2 ESCALAS DAS AVALIAÇÕES DE COMPORTAMENTO - ARCAD E CCDR

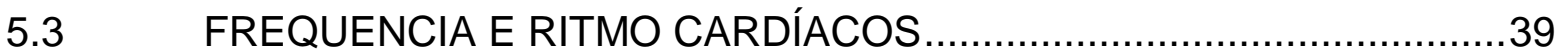

5.3.1 Frequência Cardíaca ............................................................................. 


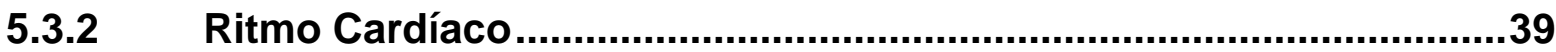

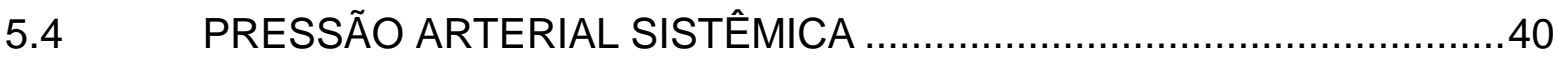

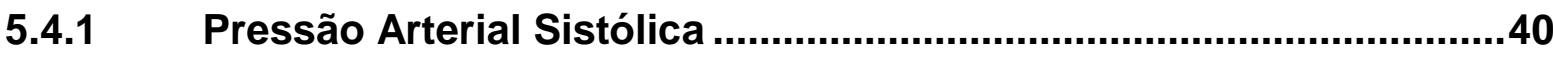

5.4.2 Pressão Arterial Média ..........................................................................

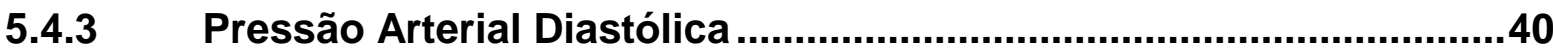

5.5 FREQUENCIA RESPIRATÓRIA E CONCENTRAÇÃO EXPIRADA DE

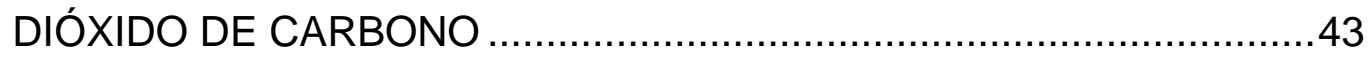

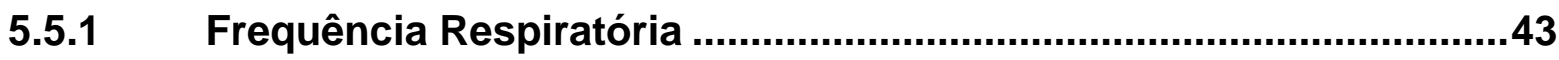

5.5.2 Concentração expirada de dióxido de carbono...................................43

5.6 CONCENTRAÇÃO EXPIRADA DE ISOFLUORANO ...........................44

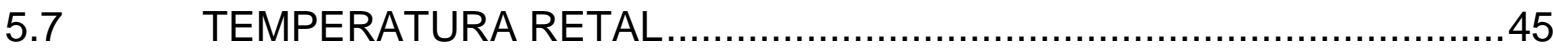

5.8 AVALIAÇÃO DA HEMOGASOMETRIA ARTERIAL ...........................47

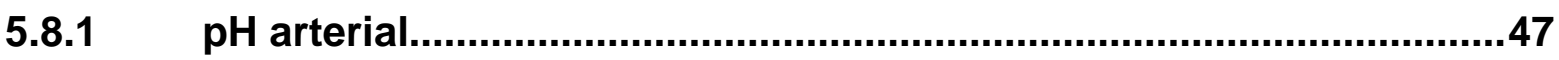

5.8.2 Pressão parcial de dióxido de carbono no sangue .............................47

5.8.3 Pressão parcial de oxigênio no sangue ...........................................47

5.8.4 Saturação da oxihemoglobina no sangue arterial..............................49

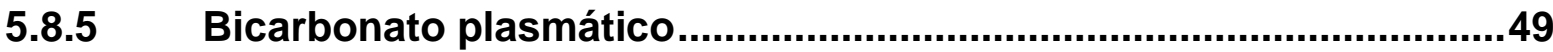

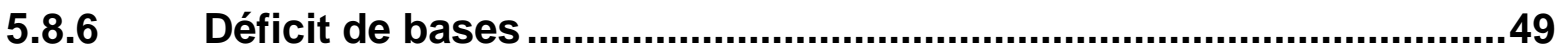

5.9 MARCADORES NEUROBIOQUIMICOS - S100ß E NSE séricos ..........51

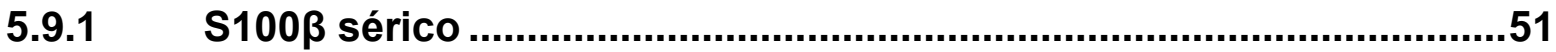

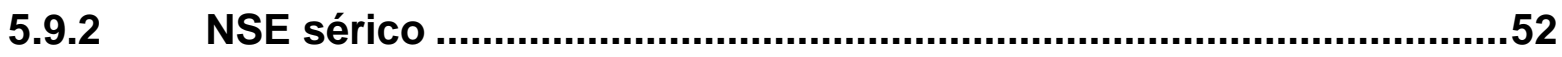

5.10 CORRELAÇÃO ENTRE OS MARCADORES NEUROBIOQUÍMICOS E

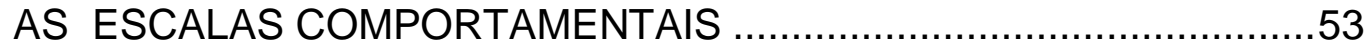

5.11 COMPLICAÇÕES PERIOPERATÓRIAS ….......................................53

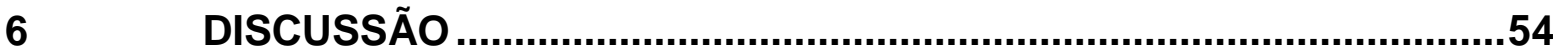

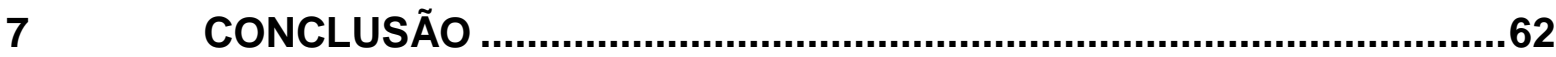

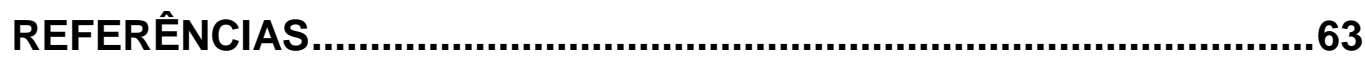

ANEXOS

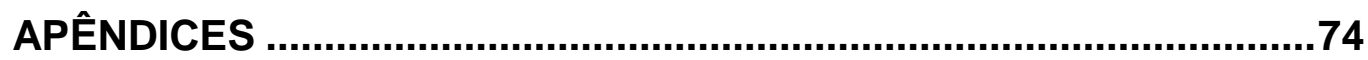




\section{INTRODUÇÃO}

O processo de envelhecimento acarreta alterações morfológicas, fisiológicas e bioquímicas ao sistema nervoso central, prejudicando muitas vezes as suas funções (CULLEY; MONK; CROBY, 2008).

O aumento da longevidade no último século ocasionou um acréscimo no número de idosos na população mundial, acarretando maior incidência de doenças ligadas ao envelhecimento patológico do cérebro (ARAUJO et al., 2005).

Os avanços tecnológicos e da medicina também ocasionaram aumento no número de idosos entre os animais de estimação. Tendo em vista que há um paralelo entre as alterações patológicas do sistema nervoso central em homens e cães idosos, os animais vêm sendo utilizados em estudos experimentais sobre doenças cognitivas no homem (ADAMS et al., 2000; LANDSBERG; HUNTHASUEN; ACKERMAN, 2003; ARAUJO et al., 2005).

A disfunção cognitiva ocorre por meio de alterações dos processos mentais de memória e percepção que auxiliam o indivíduo nos mecanismos de aprendizagem, sendo diagnosticada por meio de testes neuropsicológicos e da exclusão de outras doenças de base (HANNING, 2005).

Há décadas se observa que humanos idosos submetidos a procedimento cirúrgico-anestésico apresentam disfunção cognitiva no pós-cirúrgico que pode se estender desde semanas até anos após o procedimento. Diversos estudos vêm sendo realizados a fim de estabelecer as causas desta disfunção (BEDFORD; 1955; RASMUSSEN, 2006; DEINER; SILVERSTEIN, 2009; RAMAIAH; LAM, 2009; MONK; PRICE; 2011).

A duração da anestesia, o nível de educação, a utilização de benzodiazepínicos após procedimento e complicações respiratórias e cardíacas no pós-cirúrgico, seriam algumas das causas da disfunção cognitiva no pós-cirúrgico (HANNING, 2005; CULLEY; MONK; CROBY, 2008; WURI et al., 2011).

Com o objetivo de auxiliar o diagnóstico precoce da disfunção cognitiva no pósoperatório nos seres humanos, diversos marcadores neurobioquímicos sanguíneos, como enzima glicolítica enolase (NSE) e a proteína $S 100 \beta$, vem sendo estudados a fim de detectar injúrias ao sistema nervoso central (JOHNSSON et al., 1995; RASMUSSEN et al., 1999). 
Outra possível causa seria a morte neuronal ocasionada pelos anestésicos inalatórios utilizados no procedimento cirúrgico-anestésico (HANNING, 2005; STRATMANN et al., 2010; MONK; PRICE; 2011).

A disfunção cognitiva em cães e gatos é uma afecção comum no animal idoso, mas vem sendo subestimada. Seu diagnóstico é realizado indiretamente com auxílio da aplicação de questionários assim como pela avaliação clínica completa (OSELLA et al., 2007; LANDSBERG, 2006).

Visto que há paralelos entre os processos patológicos envolvendo cães e o homem idoso com disfunção cognitiva, estima-se que os cães também apresentem a disfunção cognitiva após o procedimento anestésico-cirúrgico, como observado no homem.

Para tal objetivou-se neste estudo avaliar a acorrência de disfunção cognitiva no período pós-operatório em cães e sua possível correlação com os marcadores neurobioquímicos. 


\section{REVISÃO BIBLIOGRÁFICA}

\subsection{ENVELHECIMENTO VERSUS COGNIÇÃO}

O envelhecimento é definido como um processo gradual e espontâneo, associado a diminuição das reservas funcionais do organismo e de seu declive de corrente da longevidade (SILVERSTEIN, 2008; RAMAIAH; LAM, 2009).

O processo de envelhecimento no homem acarreta ao sistema nervoso central, em particular ao cérebro, alterações morfológicas, bioquímicas e fisiológicas que invariavelmente afetam a função cerebral. Essas alterações iniciam-se na fase adulta e são aceleradas após os 60 anos (CULLEY; MONK; CROBY, 2008).

As mudanças neurobiológicas normais da senilidade incluem diminuição do peso e do volume cerebral, da expressão gênica neuronal, da função dos neurotransmissores e do número de sinapses, além da deposição de placas amiloides no cérebro e emaranhados neurofibrilares. Há também diminuição do fluxo sanguíneo cerebral em torno de 10 a 20\%; acredita-se que esta diminuição está atrelada a redução do peso e do volume cerebral (CULLEY; MONK; CROBY, 2008).

A função cerebral é afetada diretamente pelo grau das mudanças morfológicas do cérebro, sendo comum o declínio intelectual acompanhar o envelhecimento (SILVERSTEIN, 2008).

Com o aumento da expectativa de vida no último século, ocasionado pelos avanços da medicina e da tecnologia, ocorreu uma elevação no número de idosos na população mundial. $\mathrm{O}$ aumento da longevidade acarretou em maior incidência de doenças ligadas ao envelhecimento patológico do cérebro causado por desordens neurológicas e sistêmicas ou apenas pelo aumento de sinais de degeneração, como os encontrados na doença de Alzheimer (ARAUJO et al., 2005).

Assim como nos seres humanos, houve também um aumento na expectativa de vida em cães e gatos domésticos, assim como de sua população geriátrica (HECKLER; SVICERO; AMORIM, 2011). As alterações normais e patológicas do envelhecimento do sistema nervoso central observadas nos humanos assemelhamse muito às observadas em animais senis. Deste modo, cães e outros mamíferos vêm sendo utilizados como modelos experimentais nas pesquisas sobre disfunções 
cognitivas no homem (ADAMS et al., 2000; LANDSBERG; HUNTHASUEN; ACKERMAN, 2003; ARAUJO et al., 2005).

Essas alterações comumente observadas na disfunção cognitiva no cão e na doença de Alzheimer no homem englobam a presença de deposição beta-amilóide, formação da placa senil e emaranhados neurofibrilares em certas regiões cerebrais (DIMAKOPOULOS; MAYER, 2002; LANDSBERG; HUNTHASUEN; ACKERMAN, 2003).

\subsection{DISFUNÇÃO COGNITIVA NO HOMEM}

A disfunção cognitiva é definida como alterações dos processos mentais de memória e percepção que auxiliam o individuo nos mecanismos de aprendizagem. Os pacientes com déficit nesses processos possuem falhas nas simples tarefas cognitivas, como tarefas mentais que anteriormente eram facilmente executadas (HANNING, 2005).

O diagnóstico da disfunção cognitiva é realizado por meio da exclusão de outras afecções que possam causar alterações na cognição e por testes neuropsicológicos, que visam avaliar a memória, a flexibilidade cognitiva, a velocidade sensorial e motora, além do desempenho motor. O mais utilizado no homem é o Mini-Exame de Estado Mental que é aplicado em dez minutos, gerando ao final uma somatória dos escores avaliados (HANNING, 2005; RAMAIAH; LAM, 2009).

A ressonância magnética e a tomografia computadorizada podem auxiliar no diagnóstico por detectarem mudanças morfológicas no cérebro, como o aumento ventricular, aumento do espaço entre o crânio e a superfície do cérebro e ampliação dos sulcos cerebrais (HANNING, 2005; RAMAIAH; LAM, 2009).

O aumento da população senil estimulou a pesquisa de todas as causas de disfunção cognitiva, incluindo estudos sobre a disfunção cognitiva pós-operatória (ARAUJO et al., 2005; HANNING, 2005). 


\subsection{DISFUNÇÃO COGNITIVA PÓS-OPERATÓRIA}

As alterações cognitivas em idosos submetidos à anestesia geral foram pela primeira vez reportadas por Bedford (1955), em seu trabalho retrospectivo com 1193 pacientes. Desde então diversos estudos relatam a alteração na cognição e buscam as causas de sua origem (RASMUSSEN, 2006; DEINER; RAMAIAH; LAM, 2009; SILVERSTEIN, 2009; MONK; PRICE, 2011).

$\mathrm{Na}$ literatura perquirida, há diversas definições para a disfunção cognitiva pósoperatória, mas de um modo geral, pode ser definida como declínio nas funções intelectuais, em especial da memória, concentração e processamento da informação, por semanas, meses ou anos após o procedimento cirúrgico-anestésico (RASMUSSEN, 2006; DEINER; SILVERSTEIN, 2009; MONK; PRICE, 2011).

Os sintomas variam de uma perda leve de memória à dificuldade de concentração e de processamento das informações, o que muitas vezes faz com que ela passe despercebida (RASMUSSEN, 2006; MONK; PRICE, 2011).

A detecção do declínio cognitivo é realizada por testes neuropsicológicos, bem como aqueles utilizados para detecção do déficit cognitivo anteriormente citado (HANNING, 2005; RASMUSSEN, 2006; MONK; PRICE, 2011).

A incidência da disfunção cognitiva pós-cirúrgica varia enormemente, principalmente por não possuir um critério nos testes aplicados, assim como pela existência de variação metodológica entre os trabalhos publicados. Essa variação inclui o período no qual ocorre a avaliação do paciente no pós-cirúrgica e a falta de um grupo controle para comparação em relação ao grupo estudado (RASMUSSEN, 2006; CULLEY; MONK; CROBY, 2008; MONK; PRICE, 2011). Além disso, a maioria dos estudos publicados possui número reduzido de pacientes analisados e geralmente são retrospectivos (CULLEY; MONK; CROBY, 2008).

Inicialmente acreditava-se que a disfunção cognitiva pós-operatória ocorria somente em pacientes idosos após cirurgias cardíacas, causada pela circulação extracorpórea. Tentou-se durante décadas comprovar a existência dessa disfunção pós-cirúrgica em pacientes idosos submetidos a cirurgias não cardíacas (RASMUSSEN, 2006). Somente em 1995, a mesma foi reportada em um estudo com 231 pacientes idosos submetidos à cirurgia de joelho, onde $5 \%$ apresentaram a disfunção 6 meses após o procedimento cirúrgico (WILLIAMS-RUSSO et al., 1995). 
Acredita-se que como a disfunção cognitiva nas cirurgias não cardíacas é pouco pronunciada, a bateria de testes neuropsicológicos eram pouco específicos para esse diagnóstico (RASMUSSEN, 2006).

Em vista disto, no final dos anos 90 foi formado um grupo de estudos multicêntricos, coordenado pela Universidade de Copenhagen que publicou um estudo prospectivo com 1218 pacientes com idade acima de 60 anos submetidos a cirurgias de grande porte não cardíacas. Este grupo é conhecido como ISPOCD I (Study of Postoperative Cognitive Dysfunction), formado com intuito de investigar as causas e a incidência da disfunção cognitiva pós-cirúrgica (MOLLER et al., 1998; RASMUSSEN, 2006).

O estudo utilizou um grupo controle de 176 voluntários saudáveis, e uma bateria de testes neuropsicológicos completos com maior sensibilidade que foi aplicada ao grupo controle e ao grupo estudado, antes do procedimento cirúrgicoanestésico, a fim de excluir portadores de algum déficit cognitivo prévio. Além disso, foram excluídos do estudo, pacientes que utilizavam determinados medicamentos (tranquilizantes ou antidepressivos) e com certas doenças pré-existentes (doenças do sistema nervoso central, problemas visuais e de auditivos), em razão de possuírem maior tendência a apresentar disfunção cognitiva no pós-cirúrgico (MOLLER et al., 1998). As avaliações ocorreram uma semana e três meses após o procedimento anestésico cirúrgico, onde se observou disfunção cognitiva em 25,8\% e $8,8 \%$ dos pacientes, respectivamente (MOLLER et al.,1998).

Em 2000, o mesmo grupo publicou um estudo, onde foi avaliado um novo grupo de pacientes idosos, com idade média de 69 anos, submetidos a procedimento cirúrgico anestésico de grande porte não cardíaco. A avaliação neuropsicológica no período pós-cirúrgico ocorreu, desta vez, entre um e dois anos após o procedimento cirúrgico. Este foi o primeiro estudo que avaliou, a longo prazo, a incidência da disfunção cognitiva no período pós-cirúrgico. O resultado do estudo demostrou que aproximadamente $1 \%$ dos pacientes avaliados tiveram a persistência da disfunção (ABILDSTROM et al., 2000).

Os estudos do grupo ISPOCD elucidaram alguns possíveis fatores de risco que contribuem para o aparecimento da disfunção cognitiva no pós-cirúrgico. Acredita-se que a idade seja o fator mais importante, pois no estudo realizado em 1998, Moller et al. observaram que a incidência de disfunção cognitiva dobrou quando os pacientes possuíam idade acima de 69 anos, em comparação à faixa 
etária de 60 a 69 anos. Outros fatores com diferença significante incluem a duração da anestesia, nível de educação a utilização de benzodiazepínicos após procedimento e complicações respiratórias e cardíacas no pós-cirúrgico (MOLLER et al., 1998; RASMUSSEN, 2006).

As causas da disfunção cognitiva pós-cirúrgica são desconhecidas e acreditase multifatorial. Além dos fatores já expostos anteriormente, o estresse fisiológico da cirurgia (por meio da liberação de mediadores pró-inflamatórios e do mecanismo de neutralização da secreção de cortisol liberado pelo estresse), e fatores genéticos também estariam envolvidos (HANNING, 2005; CULLEY; MONK; CROBY, 2008; WURI et al., 2011).

Especula-se que o trauma cirúrgico poderia acarretar um aumento nos nível séricos de citocinas inflamatórias tais como as interleucinas (IL-6 e IL-1ß) e fator de necrose tumoral (TNF- $\alpha$ ), que acarretariam direta ou indiretamente a ativação da cascata inflamatória no sistema nervoso central (SUN et al., 2011). Contudo, se há exacerbação na resposta inflamatória central, poderá ocorrer prejuízo na função cogntiva (LI et al., 2012).

Outro potencial mecanismo apontado seria a possível morte neuronal causada pelos anestésicos inalatórios utilizados na maioria dos procedimentos cirúrgicoanestésicos (HANNING, 2005; STRATMANN et al., 2010; MONK; PRICE, 2011).

\subsection{DISFUNÇÃO COGNITIVA PÓS-OPERATÓRIA VERSUS ANESTESIA INALATÓRIA}

Os agentes inalatórios promovem anestesia geral por meio de seus efeitos farmacológicos em diferentes regiões do sistema nervoso central, sendo que seus mecanismos de ação não são ainda completamente compreendidos. São amplamente utilizados nos procedimentos anestésicos sendo que nos últimos cinquenta anos, os anestésicos inalatórios halogenados, como o halotano, isofluorano, sevofluorano e o desfluorano, vem sendo utilizados por serem mais seguros (OLIVA; FANTONI, 2010; HUDSON; HEMMINGS, 2011). 
Estudos experimentais demonstraram que o uso de isofluorano, sevofluorano ou halotano, na presença de hipóxia, em culturas celulares neuronais desencadeou apoptose neuronal e aumento da formação de placas beta-amiloides, semelhantes às observadas na doença de Alzheimer no homem (WEl et al., 2008; DONG et al., 2009).

Entretanto, estudo realizado com ratos transgênicos com doença de Alzheimer, expostos diariamente ao halotano e isofluorano, demonstrou a formação das placas beta-amiloides, porém sem alteração cognitiva (BIANCHI et al., 2008). Outro estudo com ratos expostos ao isofluorano por um período de duas horas constatou aumento da apoptose de células marcadas da região do hipocampo e neo-cortical, decorridas seis horas da exposição ao anestésico; após vinte e quatro horas houve aumento na formação das placas beta-amiloides (XIE et al., 2008).

A fim de encontrar evidências clínicas do envolvimento dos agentes inalatórios no desenvolvimento da disfunção cognitiva pós-cirúrgica em idosos, estudos vem sendo realizados confrontando a utilização da anestesia inalatória e da anestesia regional em pacientes humanos, com o intuito de comprovar menor incidência nos pacientes submetidos apenas à anestesia regional (RASMUNSSEN, 2006).

Até o presente momento, apenas um estudo, que incluiu sessenta pacientes com média de idade de 70 anos submetidos a cirurgia ortopédica, reportou diferença estatística significante entre os grupos submetidos à anestesia geral e à regional. Observou-se a presença da disfunção cognitiva apenas no grupo submetido à anestesia geral após o primeiro dia do procedimento anestésico-cirúrgico (HOLE; TERJESEN; BREIVIK, 1980)

No ano de 2003, um estudo multicêntrico e prospectivo realizado pelo grupo ISPOCD II (Study of Postoperative Cognitive Dysfunction II), incluiu 438 pacientes submetidos a procedimentos cirúrgicos não cardíacos foram distribuídos aleatoriamente em dois grupos, um submetido à anestesia geral e outro à anestesia regional. Não foi observada diferença estatística entre os grupos, tanto no período após uma semana, como após os três primeiros meses, apesar de existir maior incidência no grupo submetido à anestesia geral após uma semana (RASMUNSSEN et al., 2003).

Acredita-se que, assim como ocorre com os demais estudos sobre disfunção cognitiva no procedimento cirúrgico-anestésico não cardíaco, as composições dos testes aplicados para deteç̧ão da disfunção e a análise estatística individual sejam 
fatores que não possibilitem a detecção da diferença entre os grupos estudados (RASMUNSSEN, 2006).

\subsection{MARCADORES DE INJÚRIA NO SNC - PROTEÍNAS S100ß E ENZIMA GLICOLITICA ENOLASE (NSE)}

Com o objetivo de auxiliar o diagnóstico precoce da disfunção cognitiva no pósoperatório, diversos marcadores neurobioquímicos sanguíneos vem sendo estudados nas últimas décadas a fim de detectar injúria ao sistema nervoso central (RASMUSSEN et al., 1999).

A alteração da enzima glicolítica enolase (NSE) e da proteína $S-100 \beta$ no sangue ou no líquido cérebro espinhal é descrita como possível marcador dos efeitos cirúrgico-anestésicos sobre o sistema nervoso central (RASMUSSEN et al., 1999). Os valores desses marcadores se apresentaram elevados também em pacientes humanos e animais que sofreram alguma alteração clínica neurológica (JOHNSSON et al., 1995; SATOH et al., 2007; PANCOTTO et al., 2010).

A $S 100 \beta$ é uma proteina ligada ao cálcio, pertencente a família das proteínas $100 \beta$, sendo produzida e secretada pelos astrócitos e células de Schwann do SNC dos vertebrados (MARENHOLZ; HEIZMANN; FRITZ, 2004; PERRY; CUNNINGHAM; HOLMES, 2007) sendo liberadas na corrente sanguinea imediatamente pós danos cerebrais que acarretem em ativação da células da glia (PERRY; CUNNINGHAM; HOLMES, 2007). Outras subunidades desta família podem estar presentes nos melanócitos, adipócitos e condrócitos, (ANDERSON et al., 2001).

A NSE está presente em concentrações elevadas no citoplasma das células nervosas, sendo secretada somente quando ocorre dano axonal. Trata-se do único marcador que avalia diretamente danos neuronais (CHEN et al., 2014). A NSE é encontrada também em células com propriedades neuroendócrinas (porém em menor quantidade) e nas hemácias; a ocorrência de hemólise pode afetar sua utilização como marcador de injúria neuronal (DE KRUIJK, 2001, CHEN et al., 2014). 


\subsection{DISFUNÇÃO COGNITIVA EM CÃES}

Assim como em seres humanos, a disfunção cognitiva em cães idosos é considerada uma doença progressiva neurodegenerativa e muitas vezes resulta em declínio gradual das funções cognitivas, como memória, aprendizado, consciência e percepção (LANDSBERG; HUNTHASUEN; ACKERMAN, 2003; OSELLA et al., 2007). Alguns autores designam os sinais clínicos pela sigla DISHA (desorientação, alterações de interação sono / vigília, perturbações, presença de dejetos do animal pela casa e mudanças de atividade) (LANDSBERG; HUNTHASUEN; ACKERMAN, 2003).

Além dos sinais descritos anteriormente, há enorme variedade de sinais clínicos que podem ser observados, como confusão, alterações nas relações sociais, ansiedade, depressão e apatia (LANDSBERG; HUNTHASUEN; ACKERMAN, 2003).

A disfunção cognitiva é uma afeç̧ão comum em cães idosos, mas muitas vezes passa despercebida tanto ao proprietário como ao veterinário. Desta maneira estudos vêm sendo realizados com a finalidade de estabelecer escalas de avaliação tendo em vista facilitar a sua detecção precoce (OSELLA et al., 2007).

Landsberg, Hunthasuen e Ackerman (2005) estabeleceram a escala ARCAD (Evaluation of age-related cognitive and affective disorders) para auxílio no diagnóstico da doença, onde o comportamento dos cães foi indiretamente avaliado por questionários.

Salvin et al. (2011) validaram outra escala para auxiliar no diagnóstico da disfunção cognitiva que ficou conhecida como CCDR (Escala de Classificação da Disfunção Cognitiva em Cães). Os autores identificaram 27 alterações comportamentais mais comuns em 957 cães idosos com disfunção cognitiva, selecionando para a escala os 13 mais relevantes.

O diagnóstico da disfunção cognitiva é realizado indiretamente por meio da aplicação de tais questionários assim como pela avaliação clínica completa (exames laboratoriais, neurológicos e de imagem) desses animais a fim de excluir outras afecções que possam acarretar o surgimento de sinais neurológicos (LANDSBERG, 2006). Doenças degenerativas, neoplasias, dor e alterações sensoriais são algumas 
das diversas afecções que podem afetar o comportamento do animal (LANDSBERG; ARAUJO, 2006).

Como não há diagnóstico definitivo in vivo para a doença além da aplicação de questionários, a ressonância magnética e tomografia computadorizada podem auxiliar no diagnóstico diferencial da disfunção cognitiva; a hipertrofia dos ventrículos e a redução no volume cortical e cerebelar são algumas das alterações observadas em tais exames em cães acometidos pela disfunção (SU et al., 1998; LANDSBERG; HUNTHASUEN; ACKERMAN, 2003)

Uma constatação de que a disfunção cognitiva no cão idoso vem sendo subestimada é observada em estudo realizado por Osella et al. (2007), no qual 124 cães idosos (com mais de 7 anos de idade) foram avaliados quanto à presença ou não da disfunção cognitiva, sem prévia avaliação comportamental. O questionário aplicado pelos autores detectou que 74 cães apresentavam sinais suspeitos da afecção. Neste estudo, 20 cães com alterações sensoriais graves e outras doenças sistêmicas foram excluídos do estudo.

Em estudo multicêntrico realizado por Salvin et al. (2010), onde foram avaliados 957 cães idosos de diversas raças e idades, constatou-se que os cães não estão sendo devidamente diagnosticados pelo médico veterinários.

Outro dado relevante deste estudo é que o diagnóstico da doença aumenta exponencialmente com a idade e que não ocorreu prevalência entre o tamanho e raça dos animais estudados.

Como exposto anteriormente, as semelhanças no desenvolvimento da disfunção cognitiva em cães e homens, possibilita a abertura da discussão da presença ou não de tal disfunção em cães idosos submetidos ao procedimento cirúrgico-anestésico, bem como aqueles observados e comprovados nos seres humanos. Até o presente momento não existem relatos na literatura sobre a comprovação desta disfunção em cães. 


\section{OBJETIVOS}

Avaliar a ocorrência da disfunção cognitiva no período pós-cirúrgico de cães idosos submetidos a procedimento cirúrgico-anestésico por meio da utilização de escalas comportamentais.

Correlacionar os dados obtidos nas escalas comportamentais com marcadores neurobioquímicos. 


\section{MATERIAL E MÉTODO}

\subsection{ANIMAIS}

Foram avaliados 28 cães submetidos a procedimento cirúrgico-anestésico no Laboratório de Odontologia Comparada, pertencente ao Departamento de Cirurgia da Faculdade de Medicina Veterinária e Zootecnia da Universidade de São Paulo.

\subsection{CRITÉRIOS DE INCLUSÃO}

Foram incluídos 24 cães, machos ou fêmeas, de raças variadas, de pequeno e médio porte, com variação de peso entre 4,85 e $23,80 \mathrm{~kg}$, com doença periodontal, sem a presença de outras doenças concomitantes.

\subsection{PROCEDIMENTO EXPERIMENTAL}

Todos os animais submetidos ao procedimento cirúrgico-anestésico foram avaliados previamente quanto à presença de outras doenças sistêmicas. Para tal foram submetidos a teste neurológico completo, exame cardiológico e à colheita de sangue venoso periférico para realização de hemograma completo, perfil renal e hepático.

No dia do procedimento, os animais foram testados quanto a presença de disfunção cognitiva utilizando-se a escala ARCAD adaptada (Anexo 1) (LANDSBERG; HUNTHAUSEN; ACKERMAN, 2003) e escala CCDR adaptada (Anexo 2) (SALVIN et al., 2011). Os animais com somatória igual ou maior de 22 na escala ARCAD adaptada foram excluídos do projeto, bem como somatória maior ou igual a 50 na escala CCDR adaptada. 
Logo após a avalição cognitiva, os animais foram submetidos à avaliação préanestésica, que contou com a auscultação cardiorrespiratória, avaliação das frequências cardíaca e respiratória, análise da coloração de mucosas, do tempo de preenchimento capilar e da temperatura retal.

Os cães selecionados foram submetidos à medicação pré-anestésica por via intramuscular contendo um medicamento do grupo opioide (meperidina ${ }^{1}$ na dose de $3,0 \mathrm{mg} / \mathrm{kg}$ ) e um medicamento do grupo dos fenotiazínicos (acepromazina ${ }^{2}$ na dose $0,03 \mathrm{mg} / \mathrm{kg}$ ).

Decorridos 15 min, realizou-se a canulação de uma veia periférica com cateter apropriado e a anestesia foi induzida com propofol ${ }^{3}$ (3,0 a 5,0 mg/kg, i.v.). Uma vez que os animais apresentaram relaxamento mandibular e perda do reflexo laringotraqueal, realizou-se a intubação orotraqueal com sonda apropriada.

Antes da realização da indução anestésica, colheu-se sangue da veia jugular externa para realização dos exames dos marcadores neurobioquímicos $\left(\mathrm{NSE}^{4} \mathrm{e}\right.$ $\left.\mathrm{S} 100 \beta^{5}\right)$.

A manutenção da anestesia foi realizada com isofluorano ${ }^{6}$ em oxigênio a $100 \%$ por meio de circuito com ou sem-reinalação ${ }^{7}$, e os animais permaneceram em ventilação controlada ou espontânea de acordo com os valores da concentração expirada de dióxido de carbono. Durante o período transoperatório os animais receberam, quando necessário, medicação para controle da dor $\left(\right.$ fentanil ${ }^{8}$ ), bradicardia (sulfato de atropina ${ }^{9}$ ) e/ou hipotensão arterial sistêmica (cloridrato de dopamina ${ }^{10}$ ).

No período pós-cirúrgico imediato, os cães receberam anti-inflamatório não esteroidal (meloxicam ${ }^{11}$ na dose $0,2 \mathrm{mg} / \mathrm{kg}$ ou carprofeno ${ }^{12}$ na dose de 2,2 $\mathrm{mg} / \mathrm{kg}$ ), analgésicos dipirona ${ }^{13}$ (na dose $25 \mathrm{mg} / \mathrm{k} \mathrm{g}$ ) e quando necessário opioide tramadol $^{14}$ (na dose $2,0 \mathrm{mg} / \mathrm{kg}$ ), todos administrados por via intravenosa.

\footnotetext{
${ }^{1}$ Cloridrato de Petidina ${ }^{\circledR}$, Cristália, São Paulo, SP, Brasil.

2 Acepran ${ }^{\circledR}$ Vetnil Ind. e Com. de Produtos Veterinários Ltda, Louveira, SP, Brasil.

${ }^{3}$ Propovan®, Cristália, São Paulo, SP, Brasil.

${ }^{4}$ Elecsys-2010®, Roche Diagnostics Corporation, Estados Unidos.

${ }^{5}$ Kit Elisa S100B, Uscn Life Science Inc., Wuhan, Hube, China.

6 Isoflurano® Cristália, São Paulo, SP, Brasil.

${ }^{7}$ Shogum®, Takaoka, São Paulo, SP, Brasil.

8 Fentanest $\AA$ Cristália, São Paulo, SP, Brasil.

${ }^{9}$ Pasmodex®, Isofarma Industrial Farmacêutica Ltda, Eusébio, CE, Brasil.

${ }^{10}$ Cloridrato de Dopamina®, Neo quimica Genéricos, São Paulo, SP, Brasil.

${ }^{11}$ Maxicam $\AA$ Ourofino, São Paulo, SP, Brasil.

12 Rymadilß Pfizer, São Paulo, SP, Brasil.

${ }^{13}$ D-500® Pfizer, São Paulo, SP, Brasil.

14 Tramadon® Cristália, São Paulo, SP, Brasil.
} 
Ao término do procedimento e após a extubação dos animais, realizou-se novamente a colheita de sangue venoso da veia jugular externa para realização dos exames dos marcadores de neurobioquímicos NSE e S100ß.

Após tal procedimento, os mesmos foram encaminhados à sala de recuperação anestésica, onde foram monitorados até o momento da alta hospitalar, feita somente após o animal estar em plena consciência e com as funções vitais normais, com auxílio da escala de Aldrete (Anexo 3), sendo que para alta hospitalar a soma dos pontos da escala deveria ser igual a 10 (ALDRETE; KROULINK, 1970; MARTINS; FANTONI, 2010).

Todos os animais foram reavaliados quanto a sua função cognitiva em um período de sete dias a contar da data do procedimento. A avaliação da cognição foi realizada com auxílio das escalas ARCAD adaptada (LANDSBERG; HUNTHAUSEN; ACKERMAN, 2003) e CCDR adaptada (SALVIN et al., 2011). Os animais com pontuação igual ou superior a 22 pontos na somatória da escala ARCAD e maior que 50 na somatória da escala CCDR foram definidos como possíveis portadores de alteração na cognição.

\subsection{AVALIAÇÃO DO PROCEDIMENTO ANESTÉSICO}

Foram avaliados os seguintes parâmetros:

\subsubsection{Frequência cardíaca e ritmo cardíaco}

A frequência (batimentos por minuto) e ritmo cardíacos foram avaliados por meio da colocação dos eletrodos do eletrocardiógrafo do monitor multiparamétrico ${ }^{15}$ nos coxins dos membros torácicos e pélvicos

${ }^{15}$ GE DASH 4000 - G\&E Helthcare - Lisboa, Portugal. 


\subsubsection{Pressão arterial sistólica, média e diastólica}

As pressões arteriais sistólica, média e diastólica foram mensuradas através do cateter introduzido na artéria metatársica dorsal, conectado ao transdutor de pressão do monitor multiparamétrico ${ }^{15}$ nivelado na altura do coração.

\subsubsection{Temperatura retal}

A temperatura retal foi aferida com auxílio de termômetro clínico.

\subsubsection{Frequência respiratória}

A frequência respiratória foi avaliada pelo analisador de gases ${ }^{16}$ (respirações por minuto), sendo o sensor conectado entre a sonda endotraqueal e o circuito circular valvular ou avalvular do aparelho de anestesia.

\subsubsection{Avaliação dos gases expirados}

A concentração expirada de anestésico (ET $\mathrm{T}_{\text {iso }}$ ) e a concentração expirada de dióxido no final da expiração $\left(\mathrm{ETCO}_{2}\right)$ foram obtidas por meio de analisador gases ${ }^{17}$ do tipo sidestream.

\footnotetext{
${ }^{16}$ Poet IQ2, Criticare Inc, Wisconsin, USA.

17 Dräger Vamos - Draeger Medical UK Ltd.- Hertfordshire, Reino Unido.
} 


\subsubsection{Gasometria arterial}

Realizou-se colheita de sangue arterial para obtenção dos valores de potencial hidrogeniônico no sangue arterial $(\mathrm{pH})$, pressão parcial de dióxido de carbono no sangue arterial $\left(\mathrm{PaCO}_{2}\right)$, pressão parcial de oxigênio no sangue arterial $\left(\mathrm{PaO}_{2}\right)$, concentração plasmática no íon bicarbonato $\left(\mathrm{HCO}_{3}{ }^{-}\right)$e déficit ou excesso de base $(B E)^{18}$. A colheita de sangue arterial foi realizada pelo cateter instalado na artéria femoral.

$\mathrm{O}$ volume de sangue arterial de cada amostra foi de $\mathrm{um} \mathrm{mL}$ em seringa descartável contendo heparina sódica ${ }^{19}$ e colhida do cateter inserido na artéria metatársica dorsal.

A agulha foi vedada com tampa de borracha, a fim de evitar o contato do sangue com o ar ambiente, sendo imediatamente analisado após a colheita.

\subsection{DELINEAMENTO EXPERIMENTAL}

Os cães foram distribuídos segundo sua idade em dois grupos. Os animais com idades igual ou superior a oito anos foram inclusos no grupo idoso (Gl) e os cães com idade inferior a oito anos no grupo controle (GC).

Os valores de pressão arterial, frequência cardíaca, frequência respiratória,

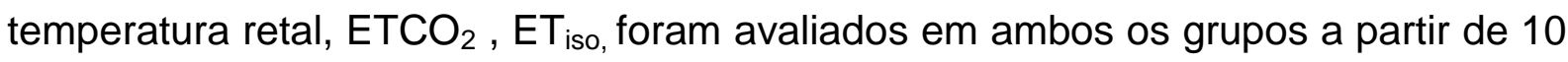
min após a indução da anestesia (M1) até o término do procedimento cirúrgico.

Durante todo o período transoperatório, os animais receberam fluidoterapia intravenosa de solução de Ringer com lactato ${ }^{20}$ na velocidade de $5,0 \mathrm{ml} / \mathrm{kg} / \mathrm{h}$.

As colheitas do sangue arterial foram realizadas a cada 60 minutos a partir da indução da anestesia (M6 e M12).

Estabeleceu-se como hipotensão arterial, valores inferiores a $90 \mathrm{mmHg}$ da pressão arterial sistólica e/ou inferiores a $60 \mathrm{mmHg}$ da pressão arterial média

\footnotetext{
${ }^{18}$ ABL-5 - Radiometer, Copenhagen, Dinamarca

${ }^{19}$ Heparin - Prodotti Laboratório Farmaceutico Ltda., São Paulo, São Paulo, Brasil.

${ }^{20}$ Ringer com Lactato de Sódio, Aster, Sorocaba, São Paulo, Brasil.
} 
inferiores (HASKINS, 2007) Quanto a temperatura retal, considerou-se hipotermia leve quando os valores variaram de a 36,5 a $37,0^{\circ} \mathrm{C}$ e hipotermia moderada quando a temperatura oscilou entre 34,1 e $36,49^{\circ} \mathrm{C}$ (REDONDO et al., 2012).

O sangue venoso para os marcadores neurobioquímicos (NSE e S100ß) foi colhido e armazenado em tubo seco, sendo posteriormente centrifugado por 10 minutos a temperatura de $4^{\circ} \mathrm{C}$, na velocidade de 2500 rotações por minuto.

Ao final, o soro da amostra foi separado em alíquotas de $0,3 \mathrm{ml}$ e congelado a menos $80^{\circ} \mathrm{C}$.

A proteína $S 100 \beta$ foi determinada por um ensaio comercialmente disponível de imunossorvente ligado a enzima S100. Existem duas lacunas de ensaio quantitativo de microplacas ELISA monoclonal em que o último anticorpo adicionado ao sistema de reação é marcado com peroxidase. Após a adição de um substrato de peroxidase, a reação produz um produto de cor final lida por espectrofotometria. Os níveis $\mathrm{S} 100 \beta$ foram expressos em microgramas por mililitros $(\mu \mathrm{g} / \mathrm{ml})$.

Já a proteina NSE foi medida utilizando um ensaio de electroquimioluminescência. Consiste num ensaio duplo-sanduíche que utiliza um anticorpo anti-NSE etiquetado com ruténio, o qual é a molécula luminescente, sendo as mensurações realizadas com o kit específico. Os níveis de NSE foram expressos em microgramas por microgramas por miilitros $(\mu \mathrm{g} / \mathrm{ml})$.

\subsection{ANÁLISE ESTATÍSTICA}

Os resultados estão apresentados em forma de média com seu desvio-padrão. A análise dos dados foi realizada com o pacote estatístico SPSS versão 18.0 e com a planilha eletrônica Microsoft Excel 2010.

A comparação entre as escalas ARCAD e CCRD foi realizada utilizando-se o teste $t$ não pareado, bem como para a comparação entre os grupos em relação ao peso dos animais e para os resultados obtidos pelas proteínas S100ß e NSE Escala nos momentos basal e pós-extubação.

Quanto à comparação entre as idades dos dois grupos foi utilizado o teste qui quadrado. 
Métodos de regressão linear foram utilizados entre os resultados das proteínas S100ß e NSE e as escalas de disfunção cognitiva ARCAD e CCDR.

Para análise das variáveis obtidas durante a anestesia (frequências cardíaca e respiratórias, pressões arteriais, concentração expirada de dióxido de carbono e de isofluorano e temperatura retal) utilizou-se análise de variância para medidas repetidas, seguida do teste de Tukey, objetivando a comparação dos diferentes momentos de observação de um mesmo grupo; para a comparação entre os grupos em cada momento, empregou-se o teste $t$ não pareado. Para a avaliação dos valores da gasometria arterial, utilizou-se o teste $t$ pareado dentro do mesmo grupo e não pareado entre os dois grupos.

O nível de significância estabelecido será de $5 \%$. 


\section{$5 \quad$ RESULTADOS}

Foram avaliados 28 cães, sendo 24 incluídos no estudo e distribuídos em dois grupos, sendo os cães com idade igual ou inferior a oito anos pertencentes ao grupo GC $(n=10)$ e os cães com idade superior a oito anos pertencentes ao grupo Gl $(n=14)$.

\subsection{CARACTERÍSTICAS GERAIS}

Os cães estudados apresentaram valores médios de peso corpóreo

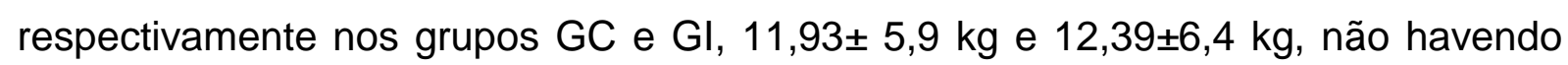
diferença estatística significativa entre os mesmos $(p=0,85)$. Referente à idade, os cães do grupo GC obtiveram o valor médio de 5,2 $\pm 1,9$ anos, e os cães do grupo Gl $10,5 \pm 1,0$ anos, havendo diferença estatística significativa entre grupos $(p<0,001)$ (Tabelas 1 e 2).

Referente ao tempo transoperatório os animais do grupo GC apresentaram valores médios $122 \pm 36,5 \mathrm{~min}$, e os do grupo Gl 116,42 $\pm 30,53 \mathrm{~min}$, não havendo diferença estatística significativa entre os mesmos $(p=0,68)$ (Tabelas 1 e 2$)$. 
Tabela 1 - Informações gerais sobre os cães dos grupos controle (CG) e tempo transoperatório (minminutos) - São Paulo - 2013/2014

\begin{tabular}{cccccc}
\hline Animal & $\begin{array}{c}\text { Idade } \\
(\text { anos })\end{array}$ & $\begin{array}{c}\text { Peso } \\
(\mathrm{kg})\end{array}$ & Sexo & Raça & $\begin{array}{c}\text { Tempo } \\
\text { Transoperatório } \\
(\mathrm{min})\end{array}$ \\
\hline GC01 & 3 & 19,1 & Fêmea & Staffordshire & 100 \\
GC02 & 1 & 6,1 & Fêmea & SRD & 090 \\
GC03 & 7 & 4,9 & Macho & Shih-tzu & 130 \\
GC04 & 6 & 12,3 & Fêmea & SRD & 120 \\
GC05 & 7 & 11,5 & Fêmea & Poodle & 110 \\
GC06 & 7 & 15,7 & Fêmea & SRD & 180 \\
GC07 & 6 & 6,0 & Fêmea & SRD & 140 \\
GC08 & 6 & 14,6 & Macho & Beagle & 070 \\
GC09 & 5 & 22,0 & Fêmea & SRD & 180 \\
GC10 & 4 & 7,1 & Macho & Dachshound & 100 \\
\hline
\end{tabular}

Fonte: (ZBÓRIL, S., 2015)

Tabela 2 - Informações gerais sobre os cães do grupo idoso (GI) e tempo transoperatório (minminutos) - São Paulo - 2013/2014

\begin{tabular}{cccccc}
\hline Animal & $\begin{array}{c}\text { Idade } \\
(\text { anos })\end{array}$ & $\begin{array}{c}\text { Peso } \\
(\mathrm{Kg})\end{array}$ & Sexo & Raça & $\begin{array}{c}\text { Tempo } \\
\text { Transoperatório } \\
(\mathrm{min})\end{array}$ \\
\hline Gl01 & 13 & 6,2 & Macho & Dachshund & 120 \\
GI02 & 10 & 13,5 & Fêmea & Poodle & 100 \\
GI03 & 09 & 8,3 & Fêmea & Yorkshire & 130 \\
GI04 & 12 & 6,5 & Fêmea & Maltes & 110 \\
Gl05 & 10 & 13,5 & Fêmea & SRD & 110 \\
GI06 & 11 & 18 & Fêmea & SRD & 110 \\
GI07 & 10 & 5,5 & Macho & Maltes & 130 \\
GI08 & 10 & 18,7 & Macho & SRD & 160 \\
GI09 & 11 & 11,7 & Fêmea & SRD & 110 \\
Gl10 & 11 & 23,8 & Fêmea & SRD & 180 \\
Gl11 & 10 & 4,85 & Macho & Poodle & 080 \\
Gl12 & 10 & 9,8 & Macho & SRD & 080 \\
Gl13 & 10 & 9,4 & Fêmea & SRD & 070 \\
Gl14 & 11 & 21,8 & Fêmea & SRD & 140 \\
\hline
\end{tabular}

Fonte: (ZBÓRIL, S., 2015) 


\subsection{ESCALAS DAS AVALIAÇÕES DE COMPORTAMENTO - ARCAD E CCDR}

GC: não foi diagnosticada disfunção cognitiva pós-cirúrgica nos cães do grupo, bem como não ocorreu alterações nos valores das escalas ARCAD e CCDR nas avaliações pré-operatória e aos sete dias após o procedimento cirúrgico-anestésico, sendo os valores médios observados de $13,3 \pm 2,9$ para a escala ARCAD, quanto à escala CCDR o valor médio obtido foi de $25 \pm 1,0$ (Tabela 3 ).

GI: não foi diagnosticado disfunção cognitiva pós-cirúrgica nos cães do grupo, porém foi observada alteração pontual no animal Gl7 em ambas as escalas. Os valores médios observados no período pré-cirúrgico foram nas escalas ARCAD e CCDR respectivamente, $12,14 \pm 2,0$ e 25,2 $\pm 0,9$. Já no período de sete dias do pósoperatório foram observados valores médios de 12,35 $\pm 2,2$ para a escala ARCAD, para a escala CCDR foi de $25,5 \pm 0,85$ (Tabela 4 )

GC X GI: não foram observadas diferenças estatísticas nos momentos précirúrgico nas escalas ARCAD $(p=0,26)$ e CCDR $(p=0,61)$, bem como no momento sete dias após a procedimento referente a escala ARCAD $(p=0,37)$ e CCDR $(p=0,21)$. 
Tabela 3 - Valores da somatória das escalas de avaliação de cognição, ARCAD e CCDR no período pré-operatório e sete dias após procedimento cirúrgico-anestésico no grupo controle (CG) - São Paulo - 2013/2014

\begin{tabular}{ccccc}
\hline \multirow{2}{*}{ Animais } & \multicolumn{2}{c}{ Pré-operatório } & \multicolumn{2}{c}{ Sete dias após o procedimento } \\
\cline { 2 - 5 } & ARCAD & CCDR & ARCAD & CCDR \\
\hline GC01 & 10 & 23 & 10 & 23 \\
GC02 & 10 & 25 & 10 & 25 \\
GC03 & 13 & 27 & 13 & 27 \\
GC04 & 10 & 25 & 10 & 25 \\
GC05 & 13 & 25 & 13 & 25 \\
GC06 & 15 & 25 & 15 & 25 \\
GC07 & 15 & 26 & 15 & 26 \\
GC08 & 18 & 25 & 18 & 25 \\
GC09 & 17 & 25 & 17 & 25 \\
GC10 & 12 & 24 & 12 & 24 \\
\hline
\end{tabular}

Fonte: (ZBÓRIL, S., 2015)

Tabela 4 - Valores da somatória das escalas de avaliação da cognição ARCAD e CCDR no período pré-operatório e sete dias após procedimento anestésico-cirúrgico nos cães do grupo idoso (Gl)- São Paulo - 2013/2014

\begin{tabular}{ccccc}
\hline \multirow{2}{*}{ Animais } & \multicolumn{2}{c}{ Pré-operatório } & \multicolumn{2}{c}{$\begin{array}{c}\text { Sete dias após o } \\
\text { procedimento }\end{array}$} \\
\cline { 2 - 5 } & ARCAD & CCDR & ARCAD & CCDR \\
\hline GI01 & 12 & 25 & 12 & 25 \\
GI02 & 10 & 25 & 10 & 25 \\
GI03 & 15 & 25 & 15 & 25 \\
GI04 & 14 & 25 & 14 & 25 \\
GI05 & 14 & 26 & 14 & 26 \\
GI06 & 10 & 25 & 10 & 25 \\
GI07 & 11 & 23 & 15 & 27 \\
GI08 & 12 & 27 & 12 & 27 \\
GI09 & 10 & 25 & 10 & 25 \\
Gl10 & 12 & 25 & 11 & 25 \\
Gl11 & 15 & 25 & 15 & 25 \\
Gl12 & 10 & 25 & 10 & 25 \\
Gl13 & 10 & 25 & 10 & 25 \\
Gl14 & 15 & 27 & 15 & 27 \\
\hline
\end{tabular}

Fonte: (ZBÓRIL, S., 2015) 


\subsection{FREQUENCIA E RITMO CARDÍACOS}

\subsubsection{Frequência Cardíaca}

GC: não foi observada diferença significativa ao longo dos momentos da avaliação do grupo $(p=0,84)$ (Tabela 5 e Apêndice $A)$.

GI: os resultados obtidos em $\mathrm{M} 1$ foram superiores em relação aos momentos M5, M6 ( $p<0,05$ e $p<0,001$, respectivamente) e M7 $(p<0,001)$ (Tabela 5 e Apêndice B).

GC X GI: não foi observada diferença significativa ao longo dos momentos da avaliação do grupo entre os grupos.

\subsubsection{Ritmo Cardíaco}

Um cão do grupo controle (GC9) apresentou arritmias cardíacas (bloqueio átrio-ventricular de primeiro grau e complexo ventricular prematuro) no período perioperatório.

Já no grupo idoso, dois animais (GI6 e GI9) apresentaram arritmia cardíaca (escape ventricular e bloqueio átrio-ventricular do primeiro grau) no período transoperatório. 


\subsection{PRESSÃO ARTERIAL SISTÊMICA}

\subsubsection{Pressão Arterial Sistólica}

GC: não foi observada diferença significativa ao longo dos momentos da avaliação do grupo $(p=0,99)$ (Tabela 5 e Apêndice C).

GI: não houve diferença significativa ao longo dos momentos de avalição do grupo $(p=0,05)$ (Tabela 5 e Apêndice D).

GC X GI: não foi observada diferença significativa ao longo dos momentos da avaliação do grupo entre os grupos.

\subsubsection{Pressão Arterial Média}

GC: não foi observada diferença significativa ao longo dos momentos da avaliação do grupo $(p=0,47)$ (Tabela 5 e Apêndice E).

GI: não houve diferença significativa ao longo dos momentos de avalição do grupo $(p=0,14)$ (Tabela 5 e Apêndice $F)$.

GC X GI: não foi observada diferença significativa ao longo dos momentos da avaliação do grupo entre os grupos.

\subsubsection{Pressão Arterial Diastólica}

GC: não houve diferença significativa ao longo dos momentos de avalição do grupo $(p=0,35)$ (Tabela 5 e Apêndice $G)$. 
GI: não foi constatada diferença significativa ao longo dos momentos de avalição do grupo $(p=0,05)$ (Tabela 5 e Apêndice $H)$.

GC X GI: não foi observada diferença significativa ao longo dos momentos da avaliação do grupo entre os grupos. 


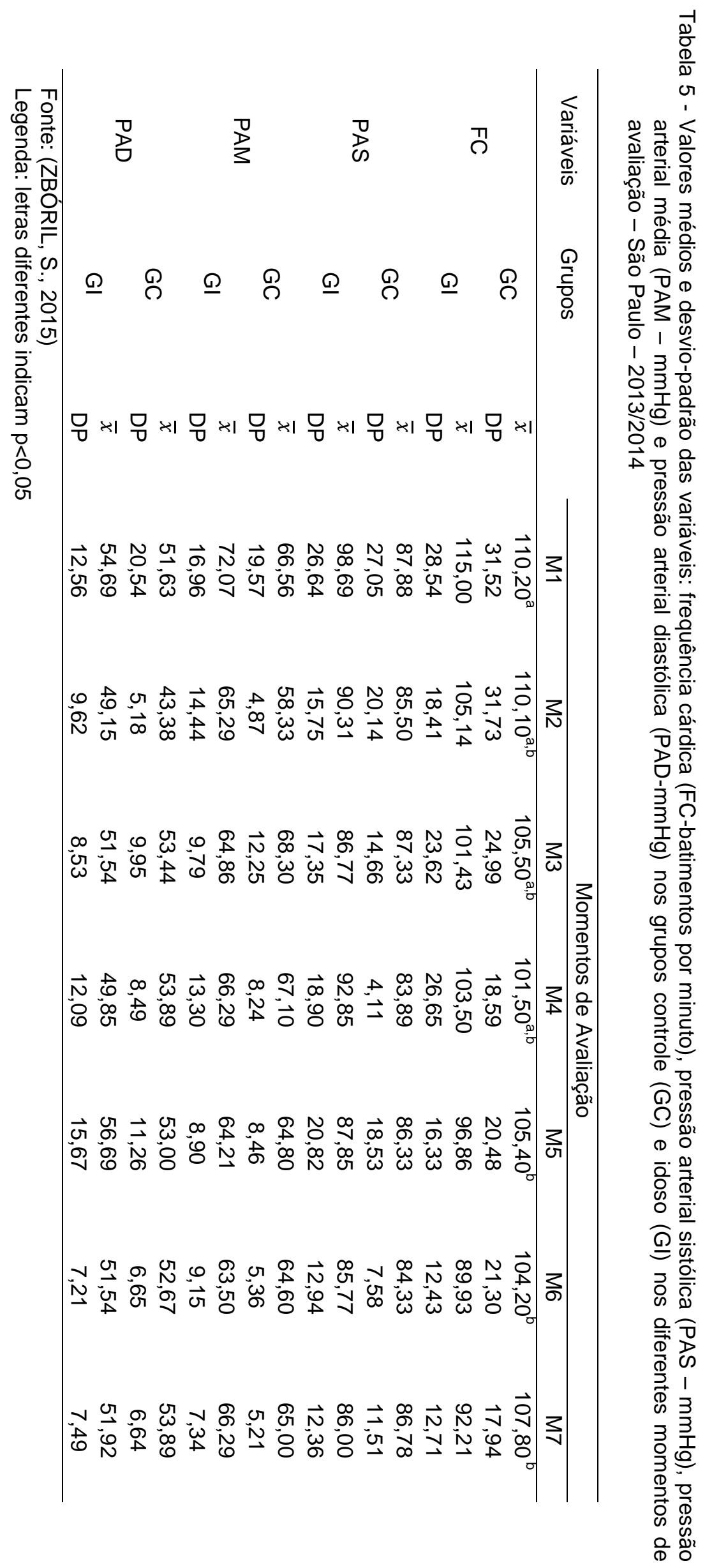




\subsection{FREQUENCIA RESPIRATÓRIA E CONCENTRAÇÃO EXPIRADA DE DIÓXIDO DE CARBONO}

\subsubsection{Frequência Respiratória}

GC: não foi constatada diferença significativa ao longo dos momentos de avalição do grupo ( $p=0,06$ e Apêndice I) (Tabela 6).

GI: não foi observada diferença significativa ao longo dos momentos de avalição do grupo $(p=0,71)$ (Tabela 6 e Apêndice J).

GC X GI: não foi observada diferença significativa ao longo dos momentos da avaliação do grupo entre os grupos.

\subsubsection{Concentração expirada de dióxido de carbono}

GC: não foi observada diferença significativa ao longo dos momentos de avalição do grupo ( $p=0,71$ e Apêndice K) (Tabela 6).

GI: não foi constatada diferença significativa ao longo dos momentos de avalição do grupo $(p=0,14)$ (Tabela 6 e Apêndice $L)$.

GC X GI: não foi observada diferença significativa ao longo dos momentos da avaliação do grupo entre os grupos. 


\subsection{CONCENTRAÇÃO EXPIRADA DE ISOFLUORANO}

GC: não foi constatada diferença significativa ao longo dos momentos de avalição do grupo $(p=0,29)$ (Tabela 6 e Apêndice $M)$.

GI: os resultados obtidos em M1 foram superiores em relação aos momentos M4, M5 ( $p<0,05$ e $p<0,001$, respectivamente) e M6 $(p<0,05)$. Também foram constatados em relação a M2 valores superiores em relação a M4 e M5 ( $p<0,05$ e $p<0,001$, respectivamente) (Tabela 6 e Apêndice $N$ ) .

GC X Gl: observou-se aumento significativo no valor de M2 no grupo Gl em relação à $G C(p<0,05)$ (Figura 1$)$.

Figura 1 - Representação gráfica demonstrando valores médios e respectivos desvios-padrão da concentração expirada de isofluorano (\%) dos cães dos grupos controle (GC) e idoso (Gl) nos diferentes momentos de avaliação - São Paulo - 2013/2014

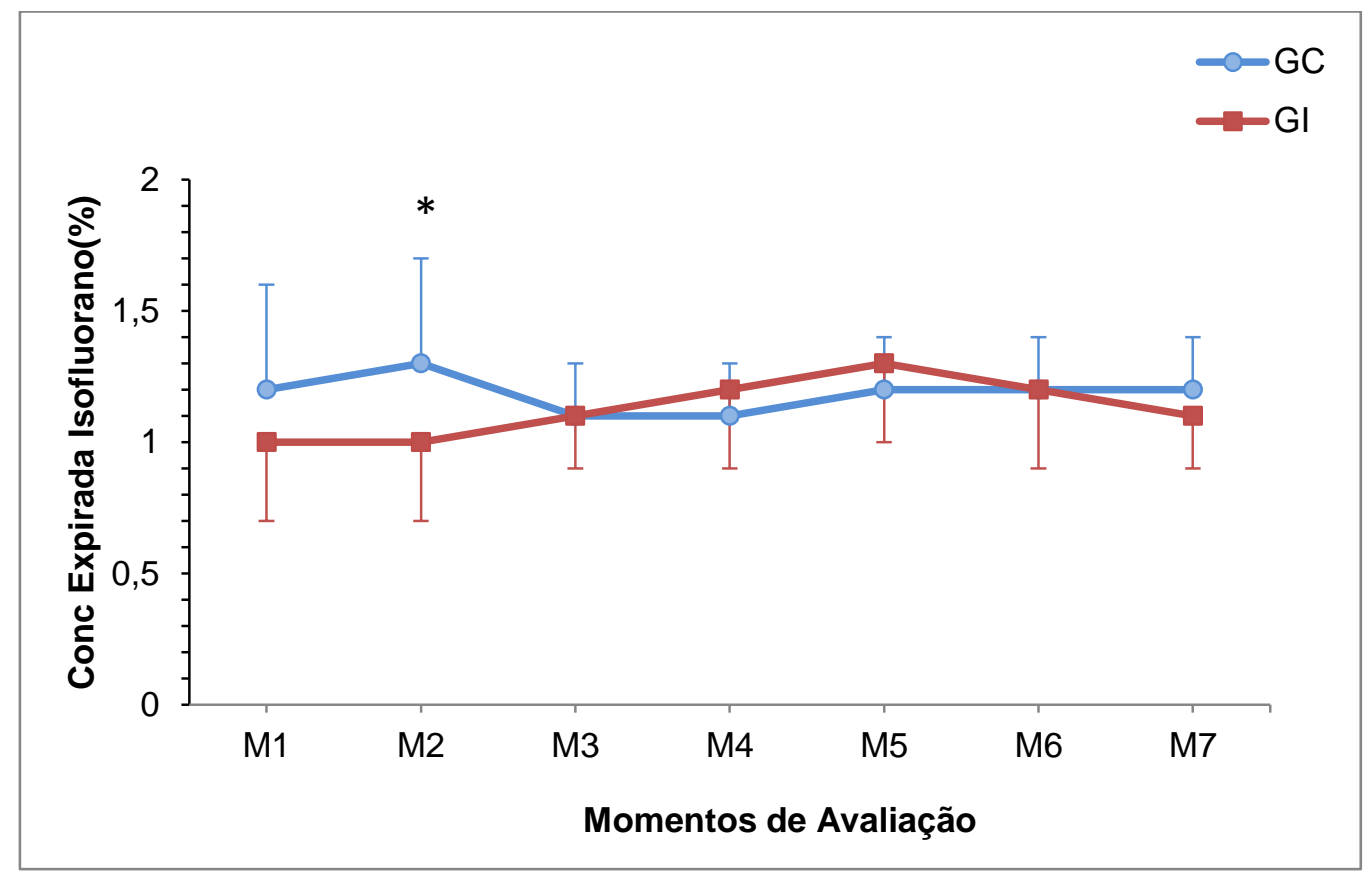

Fonte: (ZBÓRIL, S., 2015)

Legenda: $\left({ }^{*} \mathrm{p}<0,05\right)$ 


\subsection{TEMPERATURA RETAL}

GC: os resultados obtidos em M4 $(p<0,01), M 5, M 6$ e M7 $(p<0,001)$ foram inferiores em relação a momento M1. Também foi constatado que os valores obtidos em M4 ( $p<0,05), M 5, M 6$ e M7 $(p<0,001)$ foram inferiores em relação a M2 e que os momentos M5 $(P<0,01), M 6$ e $M 7 \quad(p<0,001)$ foram inferiores em relação a $M 3$ (Tabela 6 e Apêndice O).

GI: os resultados obtidos em M1 foram superiores em relação aos momentos $M 4, M 5, M 6$ e M7 $(p<0,001)$. Também foram constatados em relação a M2 valor superior em relação a $M 5, M 6$ e $M 7(p<0,001)$, e em M3 em relação $M 5(P<0,01), M 6$ e $M 7(P<0,001)$ (Tabela 6 e Apêndice $P$ ).

GC X GI: não foi observada diferença significativa ao longo dos momentos da avaliação do grupo entre os grupos (Figura 2).

Figura 2 - Representação gráfica demonstrando valores médios e respectivos desvios-padrão da temperatura retal (graus Celsius) dos cães dos grupos controle (GC) e idoso (Gl) nos diferentes momentos de avaliação - São Paulo - 2013/2014

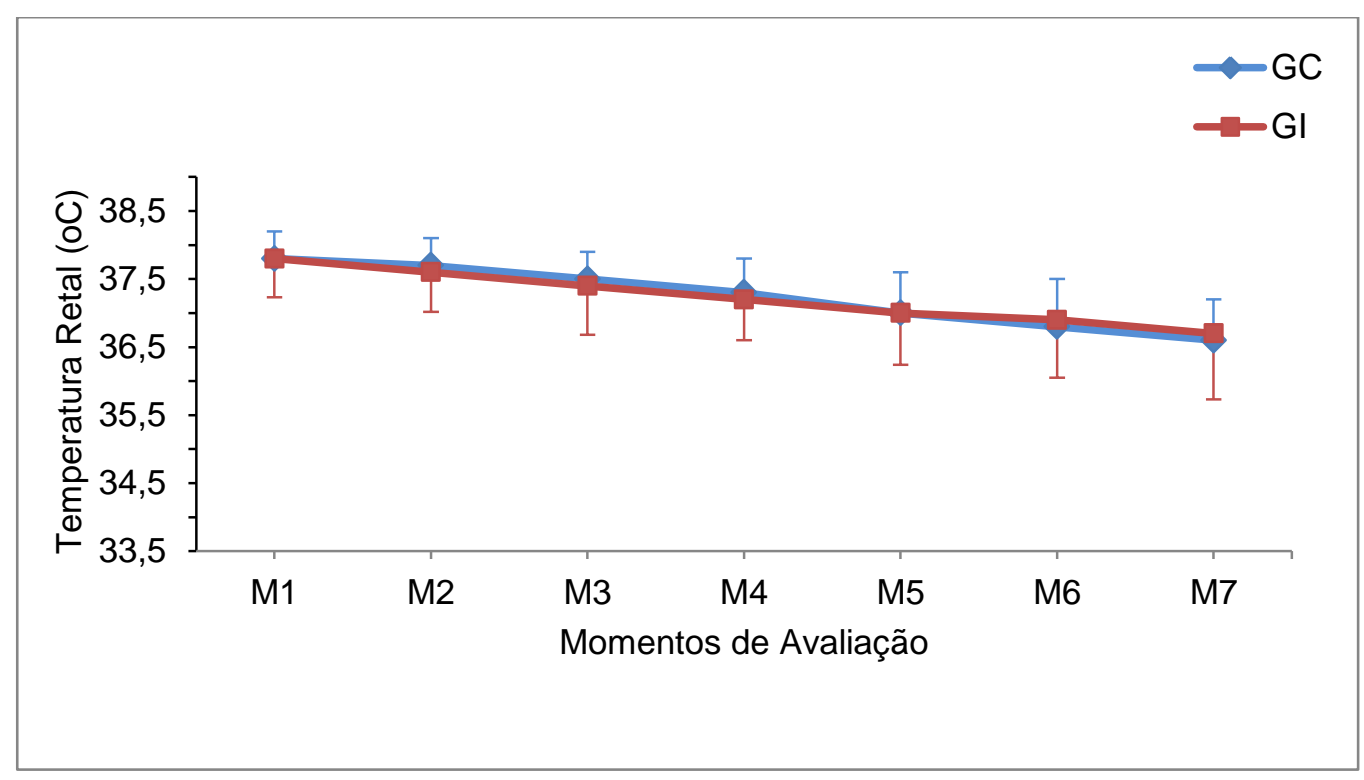

Fonte: (ZBÓRIL, S., 2015) 


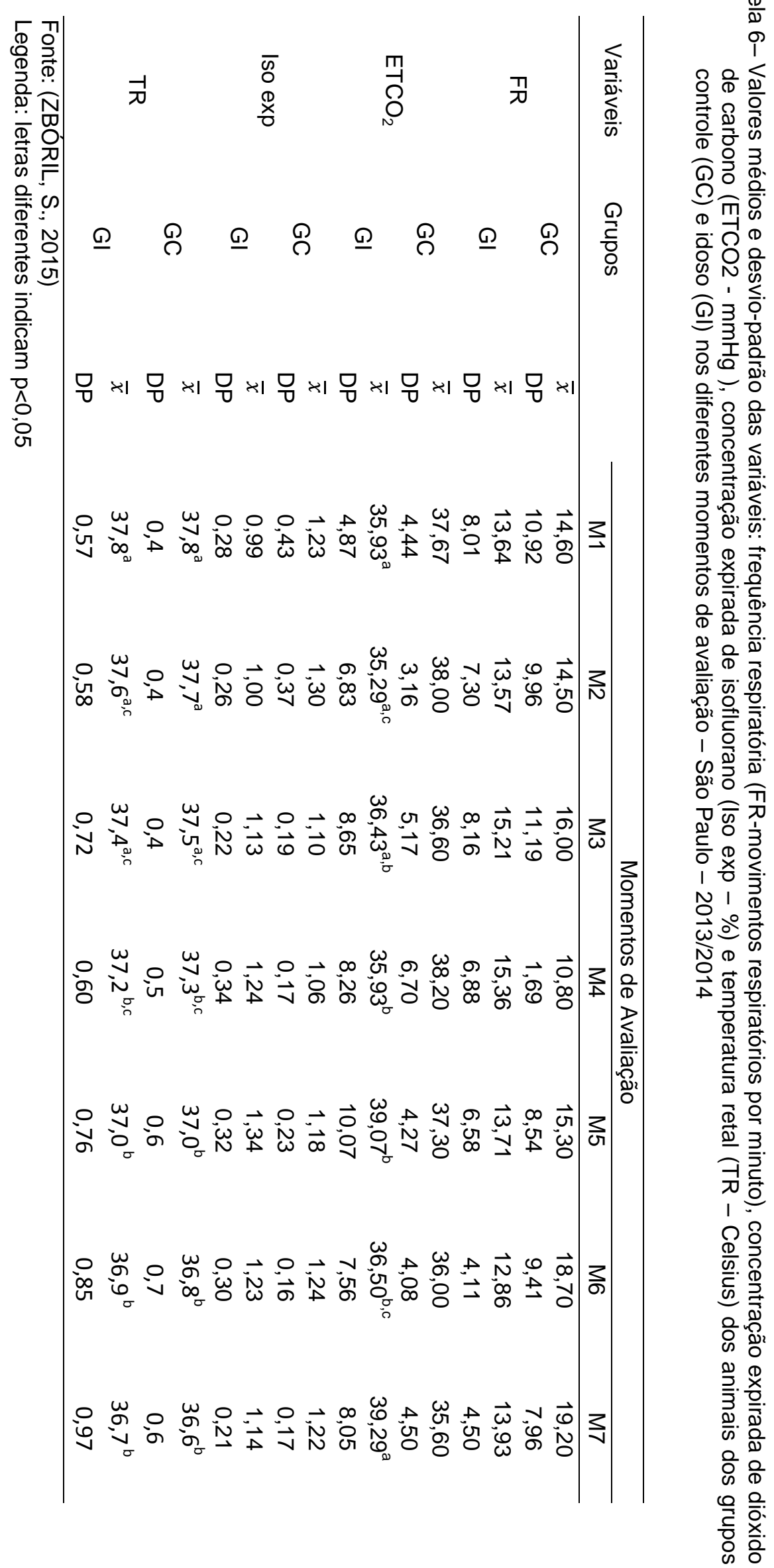




\subsection{AVALIAÇÃO DA HEMOGASOMETRIA ARTERIAL}

\subsection{1 pH arterial}

GC: não foi constatada diferença significativa ao longo dos momentos de avalição do grupo $(p=0,30)$ (Tabela 7 e Apêndices $Q$ e R).

GI: não foi observada diferença significativa ao longo dos momentos de avalição do grupo $(p=0,23)$ (Tabela 7 e Apêndices S e T).

GC X GI: não foi observada diferença significativa ao longo dos momentos da avaliação do grupo entre os grupos.

\subsubsection{Pressão parcial de dióxido de carbono no sangue}

GC: não foi constatada diferença significativa ao longo dos momentos de avalição do grupo $(p=0,73)$ (Tabela 7 e Apêndice $Q$ e R).

GI: não foi observada diferença significativa ao longo dos momentos de avalição do grupo $(p=0,55)$ (Tabela 7 e Apêndice $S$ e T).

GC X GI: não foi observada diferença significativa ao longo dos momentos da avaliação do grupo entre os grupos.

\subsubsection{Pressão parcial de oxigênio no sangue}

GC: não foi constatada diferença significativa ao longo dos momentos de avalição do grupo $(p=0,12)$ (Tabela 7 e Apêndices $Q$ e R). 
GI: não foi observada diferença significativa ao longo dos momentos de avalição do grupo $(p=0,10)$ (Tabela 7 e Apêndices $S$ e T).

GC X GI: foi constatada diferença significativa entre os grupos no momento M6 e M12, sendo os valores do grupo Gl superiores a $G C(p=0,04$ e $p=0,03$, respectivamente) (Figura 3).

Figura 3 - Representação gráfica demonstrando valores médios e respectivos desvios-padrão da pressão parcial de oxigênio no sangue arterial $(\mathrm{mmHg})$ dos animais dos grupos controle (GC) e idoso (Gl) nos diferentes momentos de avaliação - São Paulo - 2013/2014

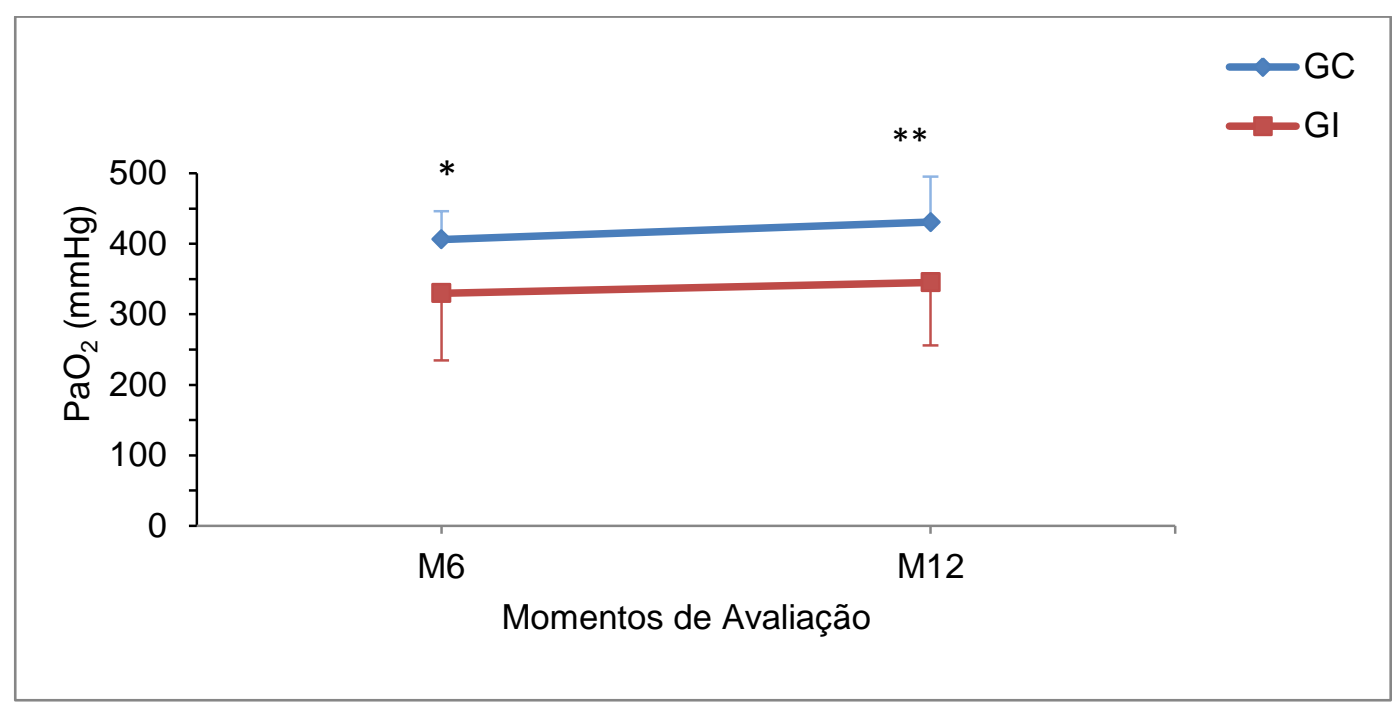

Fonte: (ZBÓRIL, S., 2015)

Legenda: $\left({ }^{*} p=0,04 ;{ }^{* *} p=0,03\right)$ 


\subsubsection{Saturação da oxihemoglobina no sangue arterial}

GC: não foi constatada diferença significativa ao longo dos momentos de avalição do grupo $(p=0,59)$ (Tabela 7 e Apêndices $Q$ e R).

GI: não foi observada diferença significativa ao longo dos momentos de avalição do grupo $(p=0,06)$ (Tabela 7 e Apêndices S e T).

GC X GI: não foi observada diferença significativa ao longo dos momentos da avaliação do grupo entre os grupos.

\subsubsection{Bicarbonato plasmático}

GC: não foi constatada diferença significativa ao longo dos momentos de avalição do grupo $(p=0,41)$ (Tabela 7 e Apêndices $Q$ e R).

GI: não foi observada diferença significativa ao longo dos momentos de avalição do grupo $(p<0,62)$ (Tabela 7 e Apêndices S e T ).

GC X GI: não foi observada diferença significativa ao longo dos momentos da avaliação do grupo entre os grupos.

\subsubsection{Déficit de bases}

GC: não foi constatada diferença significativa ao longo dos momentos de avalição do grupo $(p=0,16)$ (Tabela 7 e Apêndices $Q$ e R). 
GI: não foi observada diferença significativa ao longo dos momentos de avalição do grupo $(p=0,62)$ (Tabela 7 e Apêndices $S$ e T).

GC X GI: não foi observada diferença significativa ao longo dos momentos da avaliação do grupo entre os grupos.

Tabela 7 - Valores médios e desvio-padrão do pH arterial, pressão parcial de dióxido de carbono $\left(\mathrm{PaCO}_{2}-\mathrm{mmHg}\right)$, pressão parcial de oxigênio $\left(\mathrm{PaO}_{2}-\mathrm{mmHg}\right)$, saturação da oxihemoglobina no sangue arterial $\left(\mathrm{SaO} 2\right.$ - \%), bicarbonato plasmático $\left(\mathrm{HCO}_{3}^{-}-\mathrm{mEq} / \mathrm{L}\right)$ e déficit de base (BE) - São Paulo - 2013/2014

\begin{tabular}{|c|c|c|c|c|}
\hline \multirow{2}{*}{ Variáveis } & \multirow{2}{*}{ Grupos } & & \multicolumn{2}{|c|}{ Momentos da Avalição } \\
\hline & & & M6 & M12 \\
\hline \multirow{4}{*}{$\mathrm{pH}$} & \multirow{2}{*}{ GC } & $\bar{x}$ & 7,33 & 7,32 \\
\hline & & DP & 0,04 & 0,05 \\
\hline & \multirow{2}{*}{ Gl } & $\bar{x}$ & 7,31 & 7,31 \\
\hline & & DP & 0,07 & 0,07 \\
\hline \multirow{4}{*}{$\mathrm{PaCO}_{2}$} & \multirow{2}{*}{ GC } & $\bar{x}$ & 39,65 & 0,24 \\
\hline & & DP & 5,27 & 6,17 \\
\hline & \multirow{2}{*}{ Gl } & $\bar{x}$ & 41,72 & 42,24 \\
\hline & & DP & 9,48 & 11,34 \\
\hline \multirow{4}{*}{$\mathrm{PaO}_{2}$} & \multirow{2}{*}{ GC } & $\bar{x}$ & 406,09 & 430,75 \\
\hline & & DP & 40,23 & 64,70 \\
\hline & \multirow{2}{*}{ Gl } & $\bar{x}$ & 339,02 & 345,19 \\
\hline & & DP & 95,19 & 89,19 \\
\hline \multirow{4}{*}{$\mathrm{SaO}_{2}$} & \multirow{2}{*}{ GC } & $\bar{x}$ & 99,95 & 99,95 \\
\hline & & DP & 0,05 & 0,05 \\
\hline & \multirow{2}{*}{ Gl } & $\bar{x}$ & 99,68 & 99,81 \\
\hline & & DP & 0,70 & 0,31 \\
\hline \multirow{4}{*}{$\mathrm{HCO}_{3}^{-}$} & \multirow{2}{*}{ GC } & $\bar{x}$ & 20,50 & 20,24 \\
\hline & & DP & 1,41 & 1,41 \\
\hline & \multirow{2}{*}{ GI } & $\bar{x}$ & 20,58 & 20,69 \\
\hline & & DP & 2,38 & 2,76 \\
\hline \multirow{4}{*}{$\mathrm{BE}$} & \multirow{2}{*}{ GC } & $\bar{x}$ & $-4,88$ & $-5,34$ \\
\hline & & DP & 1,30 & 1,13 \\
\hline & \multirow{2}{*}{ GI } & $\bar{x}$ & $-5,15$ & $-5,05$ \\
\hline & & DP & 2,10 & 1,92 \\
\hline
\end{tabular}

Fonte: (ZBÓRIL, S., 2015) 
5.9 MARCADORES NEUROBIOQUIMICOS - S100ß E NSE séricos

\subsubsection{S100 $\beta$ sérico}

GC: os valores avaliados no momento pós-extubação foram superiores aos avaliados no momento basal, sendo a diferença significativa $(p=0,04)($ Tabela 7 e Apêndice U).

GI: os valores médios observados no grupo diferiram sem significância estatística, sendo o valor médio do momento basal superior ao obtido no momento pós-extubação $(p=0,44)$ (Tabela 7 e Apêndice $V)$.

GC X GI: os valores médios avaliados no momento basal no GC foram inferiores aos obtidos no $G$ I sendo a diferença significativa $(p=0,014)$. No momento pós-extubação, os valores médios obtidos nos grupos não apresentaram diferença estatística $(p=0,50)$ (Figura 4).

Figura 4 - Representação gráfica demonstrando valores médios e respectivos desvios-padrão do marcador neurobioquímico $S 100 \beta(\mu \mathrm{g} / \mathrm{ml}))$ dos cães dos grupos controle $(\mathrm{GC})$ e idoso (GI) nos diferentes momentos de avaliação - São Paulo - 2013/2014

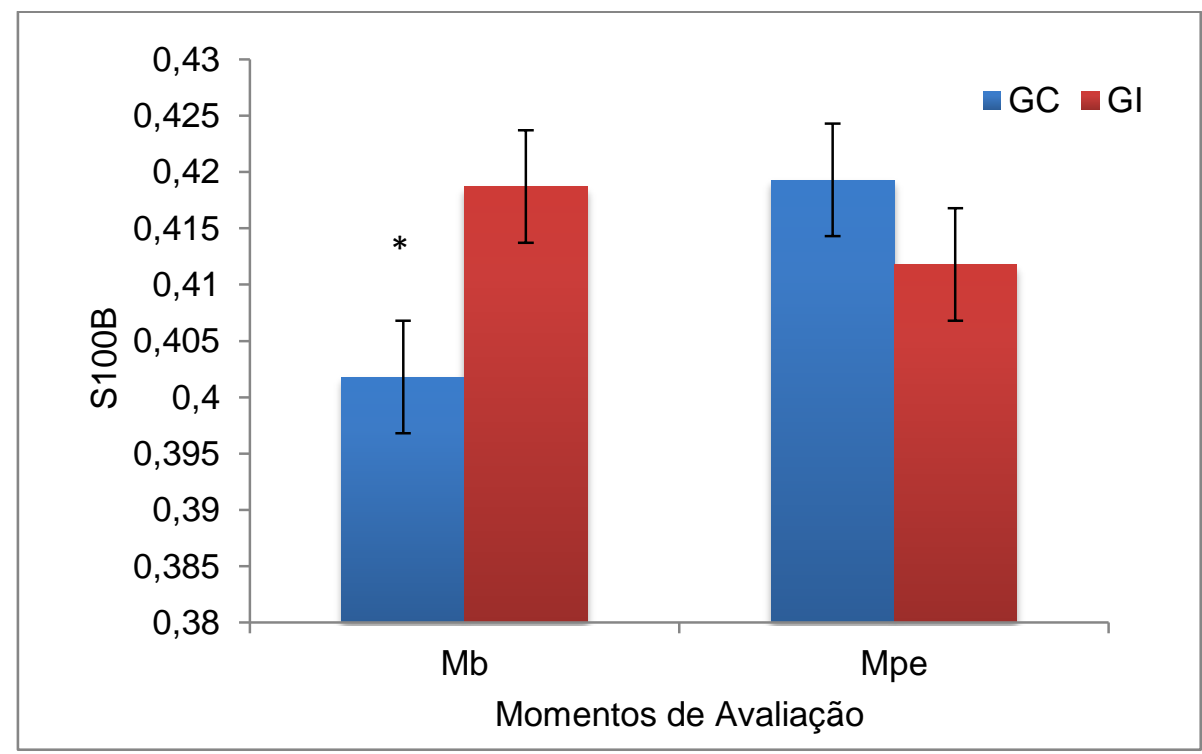

Fonte: (ZBÓRIL, S., 2015)

Legenda: $\left({ }^{*} \mathrm{p}=0,04\right)$ 


\subsubsection{NSE sérico}

GC: os valores médios observados no grupo diferiram, sem significância estatística, sendo o valor médio do momento pós-extubação maior que o basal $(p=0,61)$ (Tabela 8 e Apêndice W).

GI: os valores médios obtidos no grupo diferiram sem significância estatística, sendo o valor médio do momento pós-extubação maior que o basal $(p=0,20)$ (Tabela 8 e Apêndice X).

GC X Gl: os valores observados no momento basal não diferiram significantemente entre os grupo $(p=0,52)$, sendo o valor médio do $C G$ superiores em relação ao grupo Gl. Não houve também significância estatística entre os grupos no momento pós-extubação ( $p=0,74)$, sendo o valor médio do grupo GI maior em comparação ao GC.

Tabela 8 - Valores médios e desvio-padrão dos marcadores neurobioquímicos: S100ß e NSE $(\mu \mathrm{g} / \mathrm{ml})$ nos momentos basal (Mb) e pós-extubação (Mpe) - São Paulo - 2013/2014

\begin{tabular}{|c|c|c|c|c|}
\hline \multirow{2}{*}{ Variáveis } & \multirow{2}{*}{ Grupos } & & \multicolumn{2}{|c|}{ Momentos da Avalição } \\
\hline & & & $\mathrm{Mb}$ & Mpe \\
\hline \multirow{4}{*}{$S 100 \beta$} & \multirow{2}{*}{$\mathrm{GC}$} & $\bar{x}$ & $0,4018^{a}$ & $0,4193^{b}$ \\
\hline & & DP & 0,4083 & 0,4442 \\
\hline & \multirow{2}{*}{ Gl } & $\bar{x}$ & 0,4187 & 0,4118 \\
\hline & & DP & 0,4379 & 0,4395 \\
\hline \multirow{4}{*}{ NSE } & \multirow{2}{*}{ GC } & $\bar{x}$ & 0,9715 & 1,1506 \\
\hline & & DP & 1,6433 & 2,0310 \\
\hline & \multirow{2}{*}{ Gl } & $\bar{x}$ & 0,7901 & 1,3092 \\
\hline & & DP & 1,4732 & 2,6323 \\
\hline
\end{tabular}

Fonte: (ZBÓRIL, S., 2015)

Legenda: letras diferentes indicam $p<0,05$ 


\subsection{CORRELAÇÃO ENTRE OS MARCADORES NEUROBIOQUÍMICOS E AS ESCALAS COMPORTAMENTAIS}

Foi realizada a correlação parcial e total entre os grupos GC e Gl separadamente e as escalas de avaliação comportamental (ARCAD e CCDR) e os marcadores de neurobioquímicos (S100 $\beta$ e NSE) entre cada um dos momentos avaliados. O único cruzamento com significância estatística foi no cruzamento da escala ARCAD sete dias após o procedimento cirúrgico e o marcador NSE no Mpe $(p=0,03)$.

\subsection{COMPLICAÇÕES PERIOPERATÓRIAS}

Observou-se hipotensão arterial sistêmica e hipotermia moderada e leve no período perioperatório em ambos os grupos. A hipotermia leve foi a única das complicações com significância estatística, sendo o número de cães do grupo Gl superior ao do grupo GC $(p=0,001)$.

Tabela 9 - Número de pacientes com complicações, hipotermia leve e moderada e hipotensão arterial sistêmica no período transoperatório nos grupo controle (GC) e grupo idoso (GI) - São Paulo - 2013/2014

\begin{tabular}{ccc}
\hline Complicações & \multicolumn{2}{c}{ Grupos } \\
\cline { 2 - 3 } Transoperatórias & Controle (GD) & Idoso (GI) \\
\hline Hipotermia leve $^{*}$ & 02 & 12 \\
Hipotermia moderada* $^{*}$ & 06 & 07 \\
Hipotensão arterial sistêmica*** $^{*}$ & 10 & 13
\end{tabular}

* abaixo de $37,0 \mathrm{C}^{\circ}$ até $36,5 \mathrm{C}^{\circ}$; ${ }^{\star \star}$ de 36,49 a $34,1 \mathrm{C}^{\circ}$ e ${ }^{\star \star \star} \mathrm{PAS}<90 \mathrm{mmHg}$ e PAM<60 mmHg 


\section{DISCUSSÃO}

Há no meio veterinário uma preocupação crescente quanto aos distúrbios oriundos da idade, visto que, nas últimas décadas, observou-se aumento na expectativa de vida dos animais de estimação (BENNETT, 2012).

O envelhecimento normal do SNC no cão idoso ocasiona pequenos declínios nas atividades diárias comportamentais, sem desencadear alterações no desempenho de suas funções (SALVIN et al., 2010). Entretanto, a disfunção cognitiva em cães é caracterizada por alterações de comportamento, memória e aprendizagem e acomete principalmente 0 animal idoso, causando muitas vezes diminuição na qualidade de vida desses animais (SALVIN et al., 2010).

Estudos demonstram que as alterações estruturais e fisiológicas oriundas do envelhecimento, patológicas ou não, são semelhantes no cérebro canino e de humanos (HEAD, 2011). Isto é confirmado pela utilização de cães como modelo experimental em doenças neurodegenerativas, como Alzheimer, em seres humanos (COTMAN; HEAD, 2008; HEAD, 2011).

Na literatura consultada, diferente da disfunção cognitiva no cão idoso, não há relatos sobre o diagnóstico da disfunção cognitiva pós-cirúrgica em cães. Dessa forma, o estudo objetivou o diagnóstico da afecção no período pós-operatório de cães idosos submetidos a tratamento periodontal.

Foram avaliados 28 cães dos dois grupos estudados, sendo que 17 apresentavam idade superior a 8 anos e 10 foram incluídos no grupo controle. Infelizmente, devido a inúmeros fatores, apenas 14 cães idosos foram incluídos no presente estudo.

Por se tratar de um procedimento cirúrgico que objetiva o tratamento periodontal, não houve prevalência de raça, sendo que dos 14 animais estudados foram avaliados cães das raças Poodle, Maltês, Beagle, Yorkshire, Dachshund e mestiços.

Todos os animais que foram incluídos na análise estatística foram submetidos a exames laboratoriais, cardiológicos e neurológicos. Aqueles, que por ventura não foi possível a realização de todos os exames pré-operatórios, foram descartados.

Três animais foram excluídos do estudo por apresentarem alterações no SNC, distrofia muscular e neoplasia hepática. Aos sete dias de pós-operatório, quando os 
animais eram reavaliados por meio das escalas ARCAD e CCDR, um animal não se apresentou no retorno.

Com o auxílio das duas escalas empregadas não foi possível identificar alterações importantes na cognição dos cães idosos estudados. Apenas um cão do grupo idoso (Gl7) apresentou alterações pontuais nas escalas utilizadas no sétimo dia pós-cirúrgico (alterações de sono e espaciais). Acredita-se que a falta de diagnóstico da disfunção cognitiva pode estar relacionada a vários fatores que incluem desde a variação dos sintomas (de leve a demência), problemas no critério diagnóstico ou a presença de hipotermia perioperatória.

Quanto à variação dos sintomas, é sabido que nos seres humanos, formas sutis de disfunção podem passar despercebidas (BROWN; PURDONT, 2013). Além disso, há inconsistências entre os vários estudos que investigaram a disfunção cognitiva pós-cirúrgica no homem, o que torna difícil a formulação de critérios diagnósticos para a doença (STRØM; RASMUSSEN; SIEBER, 2014).

Sendo assim, é necessária a realização de vários testes neuropsicológicos a fim de avaliar domínios cognitivos individuais, pois atualmente nenhum teste pode medir adequadamente a função cognitiva com sensibilidade aceitável (STRØM; RASMUSSEN; SIEBER, 2014)

Visto que essas complicações são observadas no diagnóstico da disfunção nos seres humanos, acredita-se existir os mesmos paradigmas para o diagnóstico em cães, o que é agravado pelo número limitado de escalas validadas para a avalição da cognição na espécie.

Constatou-se maior facilidade na interpretação da escala CCDR frente a ARCAD pelos proprietários, sendo suas perguntas mais diretas e objetivas. Além disso, os resultados obtidos na escala CCDR são mais diretos quanto a presença ou não da déficits na cognição.

Cabe ressaltar que, como a disfunção cognitiva não ligada a procedimento cirúrgico anestésico é pouco diagnosticada em cães, o mesmo pode ocorrer a aquela ligada ao período pós-operatório. Segundo Salvin et al. (2010), acredita-se que ocorra falta de diagnóstico da doença pelos médicos veterinários; já Landsberg e Araújo (2005) sugerem que os proprietários não relatam as alterações comportamentais indicativas de disfunção. Outro complicador constatado por Oscella et al. (2007) é que os proprietários acreditam que muitas das alterações 
comportamentais oriundas da senilidade em seus cães são normais e não tratáveis. Outras possibilidades quanto ao não diagnóstico da alteração no presente estudo recaem sobre o tipo de procedimento cirúrgico escolhido (considerado de pequeno porte) e ao número reduzido de animais incluídos no estudo.

A escolha do tratamento periodontal objetivou estudar um maior número de animais com menor incidência de comorbidades, além de padronizar o procedimento cirúrgico. Entretanto, durante o período do estudo clínico, a maioria dos cães submetidos ao tratamento cirúrgico periodontal possuía co-morbidades importantes como histórico de neoplasias e alterações neurológicas (cegueira).

É sabido que a incidência da disfunção é maior em cirurgias de grande porte, sendo menor em cirurgias de pequeno porte (RASMUSSEN, 2006). Especulava-se que as cirurgias mais invasivas e prolongadas estavam correlacionadas a um processo inflamatório mais intenso e maior possibilidade da ocorrência da disfunção cognitiva (RASMUSSEN, 2006).

Este fato pode ser comprovado na comparação de dois estudos que utilizaram o mesmo critério de avaliação da disfunção cognitiva, porém em cirurgias de portes diferentes. No estudo multicêntrico realizado pelo ISPOCD1, onde 1.218 pacientes humanos idosos foram submetidos à cirurgia de grande porte não cardíaca (torácicas, abdominais e ortopédicas), foi observada a incidência de $25,8 \%$ de pacientes acometidos pela disfunção aos sete dias de pós-operatório (MOLLER et al., 1998). Já no estudo de Canet et al. (2003), em que 372 pacientes foram submetidos a cirurgias de pequeno porte (um dia de estada no hospital ou procedimentos ambulatoriais), a incidência foi reduzida para $6,8 \%$ após sete dias do procedimento cirúrgico-anestésico.

Os mecanismos que ocasionam o comprometimento cognitivo após procedimento cirurgico-anestésico ainda não foram totalmente elucidados, mas sugere-se um importe papel da resposta imune ao ato cirúrgico (RUNDSHAGEN, 2014). Terrado et al. (2011) demostraram em ratos que a ativação da cascata inflatória periférica deflagrada por procedimento cirúrgico ortédico asséptico pode desencadear declineo cognitivo. O trauma cirúrgico ativa o sistema imune inato que, por meio da liberação de citocinas (como a TNF alfa) afetam a integridade da barreira hematoencefálica, o que facilitaria a migração de macrófagos periféricos 
para a região do hipocampo (região com alta expressão de receptores para citocinas inflamatórias), promovendo, assim, neuroinflamação e alterções na cognição.

A imunorregulação do sistema nervoso central é realizada pelas células da glia como microglia e astrócitos residentes e objetiva propagar os sinais inflamatórios da periferia para o SNC (RANSOHOFF; PERRY, 2009). É sabido que durante o período peri-operatório, por exemplo, a microglia pode liberar citocinas ou realizar atividades de macrófago; isso em associação a uma ação anti-inflamatória prejudicada no idoso, pode gerar uma reação inflamatória exarcebada no cérebro (CORONA; FENN; GODBOUT , 2012).

Além disso, pacientes humanos podem possuir doenças crônicas sistêmicas não diagnosticadas, as quais causariam ativação da imunidade central; sendo assim seriam mais propensos a apresentarem disfunção cognitiva pós-cirúrgica (CORONA; FENN; GODBOUT , 2012;).

A ocorrência de certas doenças vasculares não diagnosticadas no SNC de pacientes que serão submetidos a procedimento cirúrgico-anestésico também pode predispor ao aumento de déficits cognitivos no pós-cirúrgico. Ito et al. (2012) pesquisaram a incidência de infartos centrais não diagnosticados em pacientes que seriam submetidos a revascularização coronariana, e a possivel correlação com maior número de pacientes que apresentavam déficit cogntivo pós-cirurgico. Estudaram quatrocentos e quarenta e nove pacientes que foram submetidos ao exame de ressonância magnética cerebral e angiograma pré-operatório (ITO et al., 2012). Os resultados do estudo mostraram que 35\% desses pacientes possuíam infartos cerebrais não diagnosticados e apresentaram maior ocorrência da disfunção cogntiva pós-cirúrgica em relação aos outros grupos estudados.

Com o intuito de sugerir danos centrais e/ou efeto pós-cirurugico no sistema nervoso central nos animais estutados, foram realizados o exames séricos das proteínas NSE e S100ß, espécificas do sistema nervoso central.

A proteina $S 100 \beta$ é uma proteina primeiramente encontrada nos astrócitos e células de Schwann (PERRY et al., 2007) sendo liberadas na corrente sanguinea imediatamente pós danos cerebrais pela ativação da células da glia. Há uma boa correlação entre o aumento desta proteína com déficits cognitvos em pacientes submetidos a cirurgias cardíacas (RASMUSSEN,1999), cirurgias de pequeno porte 
(ROHAN et al., 2005) ou em ensaios experimentais com indução de doença de Alzheimer em animais (VORONINA et al., 2009).

Em estudo realizado por Li et al. (2012), foram avaliados 42 pacientes idosos submetidos a cirurgia de substituição total de quadril, na tentativa de quantificar os valores séricos da proteína $\mathbf{S 1 0 0 \beta}$ e de citocinas pró-inflamatórias (Interleucinas-6 e $1 \beta$, TNF- $\alpha$ e proteina $C$ reativa) e correlacioná-los a disfunção cognitva pós-cirúrgica. A colheita sanguinea foi realizada no período pré-operatório, e na primeira e sexta hora do pós- operatório; as escalas neuropsicológicas foram aplicadas no primeiro, terceiro e sétimo dias do pós-operatório. Os autores constataram aumento no primeiro dia pós-cirúrgico dos valores séricos da proteína $S 100 \beta$ e da interleucina-6 nos pacientes com alterações na cognição no pós-cirúrgico, sugerindo que a elevação dos valores de S100B estão correlacionados ao déficit cognitivo.

No presente estudo, os valores séricos obtidos da proteína $\mathrm{S100 \beta} B$ no grupo idoso foram superiores aos analisados no grupo controle no momento basal. Isso pode ser decorrente da presença de uma inflamação sistêmica ou de doenças no SNC pré-existentes não diagnosticadas no grupo idoso, tendo em vista que o aumento dos valores de $S 100 \beta$ podem estar correlacionados a insultos causados no sistema central ou fora dele que causam ativação das células glias (LI et al., 2012).

A hipotensão arterial sistêmica e hipoxemia estão entre as complicações perioperatórias mais comumentes observadas no período intra-operatório mas não parecem se relacionadar com a disfunção cognitiva pós-operatória, visto que no estudo ISPOCD1 a correlação entre essas complicações e a incidência de disfunção não foi estatisticamente relevante (MOOLER et al., 1998). O mesmo foi observado no estudo em tela, que constatou elevada incidência de hipotensão arterial sistêmica em seus pacientes em algum momento durante o procedimento cirúrgico, porém os mesmos, frente às escalas avaliadas, não apresentaram alteração de cognição.

É provável que o procedimento cirúrgico pouco invasivo ocasionou momentos de baixa incidência de estímulos dolorosos que, somados a ação hipotensora do isofluorano, deflagrou a grande ocorrência de momentos com hipotensão arterial sistêmica. Cabe ressaltar que a monitoração da pressão arterial transoperatória foi realizada utilizando o padrão ouro para tal aferição, sendo feito por meio da canulação de artéria periférica e utilização de transdutor ligado ao monitor multiparamétrico. Além disso, todos os animais com quadro hipotensivo permanente 
foram submetidos a tratamento com fármacos vasoativos, com o intuito da reversão do quadro.

Além de ser um importante deflagrador da hipotensão arterial, especula-se que os anestésicos inalatórios estariam envolvidos como um fator importante para o desenvolvimento da disfunção cognitiva no período pós-cirúrgico. Xie et al. (2009), ao utilizarem isofluorano na anestesia de camundongos, avaliaram a produção de proteínas precursoras de amiloides a partir das células da glia. Sabe-se que a alteração da produção dessas proteínas está correlacionada ao desenvolvimento da doença de Alzheimer e que o isofluorano estaria envolvido nessa processo.

Porém, em estudo realizado em ratos por Chaparro et al. (2013), observou-se perda neuronal significativa de células do hipocampo em exame histopatológico, duas semanas após serem submetidos a três minutos de hipotensão arterial (20 $\mathrm{mmHg}$ abaixo da basal) por choque hemorrágico. No entanto, não foram observadas alterações nos testes comportamentais nos sobreviventes que foram ressuscitados. Todavia, em estudo similar realizado por Bekker et al. (2009), os resultados obtidos no exame histopatológico do SNC foram semelhantes, porém os animais apresentaram déficit cognitivo (o tempo latência para a execução dos teste de memoria foram maiores em comparação ao grupo controle). Vale ressaltar que os animais foram submetidos a regime de aprendizado em períodos distintos previamente a indução da hipotensão arterial. Chaparro et al. (2013) submeteram os ratos ao regime de aprendizado $24 \mathrm{~h}$ antes da indução da hipotensão arterial. Já Bekker et al. (2009) instituíram o treinamento apenas 3h antes do uso de nitroglicerina, objetivando a hipotensão arterial. A explicação provável para a não ocorrência de déficit cognitivo nos animais do estudo de Chaparro et al. (2013) seria que como apenas a região do hipocampo foi afetada, os animais com treinamento de 24 horas já haviam consolidação de memória (córtex pré-frontal).

A partir destes estudos, é possível sugerir que apesar dos cães do presente estudo terem apresentado hipotensão arterial sistêmica importante e provável dano as células do sistema nervoso central, com aumento significativo dos valores da proteína S100B no grupo controle entre os momentos basal e pós-operatório, não foram observadas alterações de comportamento neste animais. Uma das possíveis causas dessa ausência de alteração relaciona-se às escalas empregadas no presente estudo, uma vez que não foram capazes de avaliar a memória de curto 
prazo. Outro fator correlaciona-se com a ocorrência da hipotermia leve e moderada no período perioperatório. Isso já foi discutido por Alam et al. (2009), ao estudarem 32 em suínos submetidos a hemorragia controlada, sendo que foram distribuídos em direferentes grupos segundo o grau de hipotermia ao qual foram induzidos e um grupo controle normotérmico. Logo após reanimação, as amostras de sangue foram colhidas para avaliação dos marcadores de dano neuronal, S100 $\beta$ e NSE, e avaliados quanto a cognição com base na técnica de condicionamento operante durante um periodo de seis semanas. Os resultados obtidos pelos autores confirmaram a ausência de lesões neuronais na análise histopatológica e déficit neurológico nos animais dos grupo submetidos aos diversos graus de hipotermia, sendo que todos os animais do grupo controle sofreram morte cerebral.

Os exames histopatológicos confirmaram grau importante de alterações isquemicas em astrócitos e neurônios no grupo controle, sendo tais alterações não observadas no grupo hipotérmico. A ausência das lesões nos animais submetidos a hipotermia estaria na diretamente ligada a diminuição do metabolismo desses animais. Porém não foi possivel a correlação entre as proteínas $\$ 100 \beta$ e a NSE, o grau de lesão histopatológica do sistema nervoso central, bem como a avalição clínica desses animais, pois a alterações nos niveis plasmáticos dessas proteinas podem estar ligados a injúria celular de outros tecidos (adiposo, articular por exemplo) ocasionados em caso de pacientes com trauma severo. Outro problema estaria no tempo de colheita da amostragem dos marcadores de dano neuronal, não ocorrendo no momento de pico sérico das proteinas.

A NSE (neurônio específica enolase) é uma enzima localizada preferencialmente no citoplasma dos neurônios, sendo secretada somente quando há dano axonal (CHENG et al., 2014). Em meta-análise realizada por Cheng et al. (2014), constatou-se que valores mais elevados de NSE estão ligados a um prognóstico pior no trauma crânioencefálico, porém o momento ideal de avaliação permanece incerto, pela não padronização dos ensaios quanto ao tempo de correto da colheita sanguinea.

No presente estudo, os valores séricos de NSE não apresentaram diferenças estatísticas em nenhum do momentos de colheita da amostra, sendo essa uma limitação do estudo, pois não foi possível a análise em momentos diferentes do póscirúrgico devido a alta cirúrgica dos animais. Seria interessante que as colheitas 
fossem realizadas em perídos mais prolongados, uma vez que há estudos que relatam picos da NSE entre 12h e 36 h após injúria (RASMUSSEN et al., 2002; CHENG et al., 2014).

Outra limitação importante do estudo relaciona-se à dificuldade diagnóstica de doenças crônicas e neurológicas pré-existentes, apesar da normalidade dos exames perioperatório e neurológico.

É importante que estudos multicêntricos sobre o assunto sejam realizados, incluindo ampliação do número de pacientes idosos, procedimentos cirúrgicos mais invasivos, e maior número de colheitas de amostras para análise dos marcadores neurobioquímicos. 


\section{CONCLUSÃO}

A partir dos resultados obtidos é possível concluir que:

- por meio das escalas comportamentais empregadas, não foi possível detectar a disfunção cognitiva no pós-cirúrgico de cães idosos submetidos a procedimento cirúrgico-anestésico;

- os valores obtidos da proteína $S 100 \beta$ sugerem que os animais idosos possuem possível neuroinflamação pré-operatória, ocasionada por inflamação sistêmica ou mesmo central; entretanto não foi possível correlacionar com as escalas comportamentais empregadas. 


\section{REFERÊNCIAS}

ABILDSTRON, H.; RASMUSSEN, L. S.; RENTOWL, P.; HANNING, C. D.;

RASMUSSEN, H.; KRISTENSEN, P. A.; MOLLER, J. T. Cognitive dysfunction 1-2 years after non-cardiac surgery in the elderly. Acta Anaesthesiologica

Scandinavica, v. 44, n. 10, p.1246-1251, 2000.

ADAMS, B.; CHAN, A.; CALLAHAN, H.; MILGRAM, N. W. The canine as model of human cognitive aging: Recent Developments. Progress in Neuro-

Psychopharmacology and Biological Psychiatry, v. 24, n. 5, p. 675-692, 2000.

ANDERSON, R. E.; HANSSON, L.; NILSSON, O.; LISKA, J.; SETTERGREN, G.; VAAGE, J. Increase in serum S100 A1-B and S100BB during cardiac surgery arises from extracerebral sources. The Annals of Thoracic Surgery, v. 71, n. 5, p. 15121517, 2001.

ALAM, H. S.; CHEN, Z.; AHUJA,N.; CHEN, H; CONRAN, R.; AYUSTE, E.C; TORUNO, K.; ARIABAN, N.; RHEE, P.; NADEL, A.; KOUSTOVA, H. Profound hypothermia protects neurons and astrocytes, and preserves cognitive functions in a swine model of lethal hemorrhage.Journal of Surgical Research, v. 126, n. 2, p. 172-181, 2005.

ALDRETE, J. A.; KROULINK D. A Postanesthetic recovery score. Anesthesia and Analgesia, v. 49, n.6, p. 924-934, 1970.

ARAUJO, J. A.; STUDZINSKI, C. M.; HEAD, E.; COTMAN, C. W. Assessment of nutritional interventions for modification of age-associated cognitive decline using a canine model of humanaging. AGE, v. 27, n. 1, p. 27-37, 2005.

BEDFORD, P. D. Adverse cerebral effects of anaesthesia on old people. Lancet, v. 269, p. 259-263, 1955.

BEKKER, A.; HAILE, M.; LI, Y. S.; GALOYAN, S.; GARCIA, E.; QUARTERMAIN, D.; KAMER, A.; BLANCK, T. Nimodipine prevents memory impairment caused by nitroglycerininduced hypotension in adult mice. Anesthesia and Analgesia, v.109, n. 6, p.1943, 2009.

BIANCHI, S. L.; TRAN, T.; LIU, C.; LIN, S.; LI, Y.; KELLER, J. M.; ECKENHOFF, R. G.; ECKENHOFF, M. F. Brain and behavior changes in 12-month-old Tg2576 and 
non transgenic mice exposed to anesthetics. Neurobiology of Aging, v. 29, n. 7, p. 1002-1010, 2008.

CANET, J.; RAEDER, J.; RASMUSSEN, L. S.; ENLUND, M.; KUIPERS, H. M.; HANNING, C. D.; JOLLES, J.; KORTTILA, K.; SIERSMA, V. D.; DODDS, C.; ABILDSTROM, H.; SNEYD, J. R.; VILA, P.; JOHNSON, T.; MUÑOZ CORSINI, L.; SILVERSTEIN, J. H.; NIELSEN, I. K.; MOLLER, J. T. Cognitive dysfunction after minor surgery in the elderly. Acta Anaesthesiologica Scandinavica, v. 47, n.10, p.1204-1210, 2003.

CHENG, F.; YUAN, Q.; YANG, J.; WANG, W.; LIU, H. The prognostic value of serum neuron-specific enolase in traumatic brain injury: systematic review and metaanalysis. Plos One, v. 9, n. 9, 2014.

CORONA A. W.; FENN; A. M.; GODBOUT, J. P. Cognitive and behavioral consequences of impaired immunoregulation in aging. Journal of Neuroimmune Pharmacology, v. 7, n.1, p. 7-23, 2012.

COTMAN, C. W.; HEAD, E. The canine (dog) model of human aging and disease: dietary, environmental and immunotherapy approaches. Journal of Alzheimer's Disease, v. 15, n. 4, p. 685-707, 2008.

CHAPARRO, R. E.; QUIROGA, C.; BOSCO, G.; ERASSO, D.; RUBINI, A.; MANGAR, D.; PARMAGNANI, A.; CAMPORESI, E. M. Hippocampal cellular loss after brief hypotension. Springerplus, v. 23, n. 2, p. 1-7, 2013.

CULLEY, D. J.; MONK, T. G.; CROSBY, G. Postoperative central nervous system dysfunction. In: SILVERSTEIN, J. H.; ROOKE, G. A.; REVES, J. G.; McLESKEY, C. H. Geriatric anesthesiology. $2^{\text {nd }}$ ed. New York: Spring, 2008. Chap. 09, p. 123136.

DEINER, S.; SILVERSTEIN, J. H. Postoperative delirium and cognitive dysfunction. British Journal of Anaesthesia, v. 103, p. i41-i46, 2009.

DE KRUIJK, J. R.; LEFFERS, P.; MENHEERE, P. P.; MEERHOFF, S.; TWIJNSTRA, A. S-100B and neuron-specific enolase in serum of mild traumatic brain injury patients. A comparison with health controls. Acta Neurologica Scandinavica, v. 103, n. 3, p. 175-179, 2001.

DIMAKOPOULOS, A. C.; MAYER, R. J. Aspects of neurodegeneration in the canine brain. The Journal of Nutrition, v. 132, n. 6, p. 1579S-1582S, 2002. 
DONG, Y.; ZHANG, G.; ZHANG, B.; MOIR, R. D.; XIA, W.; MARCANTONIO, E. R.; CULLEY, D. J.; CROSBY, G.; TANZI, R. E.; XIE, Z. The common inhalational anesthetic sevoflurane induces apoptosis and increases-amyloid protein levels. Archives of Neurology, v. 66, n. 5, p. 620-631, 2009.

HANNING, C. D. Postoperative cognitive dysfunction. British Journal of Anaesthesia, v. 95, p. 82-87, 2005.

HASKINS, S. C. Monitoração de pacientes anestesiados. In: TRANQUILLI, W. J.; THURMON, J. C., GRIMM, K. A. Anestesiologia e analgesia veterinária. 4를 ed. São Paulo: Roca, 2007. Cap.19, p. 582-611.

HECKLER, M. C. T.; SVICERO, D.; AMORIM, R. M. Síndrome da disfunção cognitiva em cães. Clínica Veterinária, n. 90, p. 70-74, 2011.

HOLE, A.; TERJESEN, T.; BREIVIK, H. Epidural versus general anaesthesia for total hip arthroplasty in elderly patients. Acta Anaesthesiologica Scandinavica, v. 24, p. 279-287, 1980.

HUDSON, A. E.; HEMMING JR, H. C. Are anaesthetics toxic to the brain? British Journal of Anaesthesia, v. 107, p. 30-37, 2011.

ITO, A.; GOTO, T.; MAEKAWA, K.; BABA, T.; MISHIMA, Y. Postoperative neurological complications and risk factors for pre-existing silent brain infarction in elderly patients undergoing coronary artery bypass grafting. Journal of Anesthesia, v. 26, n. 3, p. 405-411, 2012.

JOHNSSON, P.; LUNDQVIST, C.; LINDGREN, A.; FERENCZ, I.; ALLING, C.; STÅHL, E. Cerebral complications after cardiac surgery assessed by S-100 and NSE levels in blood. Journal of Cardiothoracic and Vascular Anesthesia, v. 9, n. 6, p. 694-699, 1995.

LANDSBERG, G. M. Therapeutic options for cognitive decline in senior pets. Journal of the American Animal Hospital Association, v. 42, n. 6, p. 407-413, 2006.

LANDSBERG, G. M.; ARAUJO, J. A. Behavior problems in geriatric pets. Veterinary Clinics of North America: small animal practice, v. 35, p. 675-698, 2005.

LANDSBERG, G. M.; HUNTHASUEN, W.; ACKERMAN, L. The effects of aging on the behavior of senior pets. In: LANDSBERG, G. M.; HUNTHASUEN, W.; 
ACKERMAN, L. (Ed.). Handbook of behavior problems of the dog and cat. $2^{\text {nd }}$ ed. Edinburgh: Saunders, 2003. Chap. 12, p. 269-304.

LI, Y. C.; XI , C. H.; AN, W. F.;DONG, W. H.; ZHOU, M. Perioperative inflammatory response and protein $\mathrm{S}-100 \mathrm{~b}$ concentrations - relationship with post-operative cognitive dysfunction in elderly patients. Acta Anaesthesiologica Scandinavica, v. 56, n. 5, p. 595-600, 2012.

MARENHOLZ, I.; HEIZMANN, C.W; FRITZ, G. S100 proteins inmouse and man: from evolution to function and pathology. Biochemical and Biophysical Research Communications, v. 322, n. 4, p. 1111-1122, 2004.

MARTINS, T. M.; FANTONI, D. T. Recuperação pós-anéstesica. In: FANTONI, D. T.; CORTOPASSI, S. R. G. Anestesia em cães e gatos. $2^{\underline{a}}$ ed. São Paulo: Roca, 2010. Cap. 39, p. 591-604.

MOLLER, J. T.; CLUITMANS, P.; RASMUSSEN, L. S.; HOUX, P.; RASMUSSEN, H.; CANET, J.; RABBITT, P.; JOLLES, J.; LARSEN, K.; HANNING, C. D.; LANGERON, O.; JOHNSON, T.; LAUVEN, P. M.; KRISTENSEN, P. A.; BIEDLER, A.; VAN BEEM, H.; FRAIDAKIS, O.; SILVERSTEIN, J. H.; BENEKEN, J. E.; GRAVENSTEIN, J. S. Long-term postoperative cognitive dysfunction in the elderly: ISPOCD1 study. Lancet, v. 351, n. 9106, p. 857-861, 1998.

MONK, T. G.; PRICE, C. C. Postoperative cognitive disorders. Current opinion in critical care, v. 17, p. 376-381, 2011.

OLIVA, V. N. L. S.; FANTONI, D. T. Anestesia inalatória. In: FANTONI, D. T.; CORTOPASSI, S. R. G. Anestesia em cães e gatos. $2^{\underline{a}}$ ed. São Paulo: Roca, 2010. Cap. 16, p. 247-258.

OSELLA, M. C.; RE, G.; ODORE, R.; GIRARDI, C.; BADINO, P.; BARBERO, R.; BERGAMASCO, L. Canine cognitive dysfunction syndrome: Prevalence, clinical signs and treatment with a neuroprotective nutraceutical. Applied Animal Behaviour Science, v. 105, n. 4, p. 297-310, 2007.

PANCOTTO, T.; ROSSMEISL JR., J.; PANCIERA, D.; ZIMMERMAN, K. L. Bloodbrain-barrier disruption in chronic canine hypothyroidism. Veterinary Clinical Pathology, v. 39, n. 4, p. 485-493, 2010. 
PERRY, V. H.; CUNNINGHAM, C.; HOLMES, C. Systemic infections and inflammation affect chronic neurodegeneration. Nature Reviews Immunology, v. 7, p. 161-167, 2007.

RAMAIAH, R.; LAM, A. M. Postoperative cognitive dysfunction in the elderly. Anesthesiology Clinics, v. 27, p. 485-496, 2009.

RASMUSSEN, L. S.; CHRISTIANSEN, M.; HANSEN, P. B.; MOLLER, J. T. Do blood levels of neuron-specific enolase and S-100 protein reflect cognitive dysfunction after coronary artery bypass? Acta Anaesthesiologica Scandinavica, v. 43, n. 5, p. 495500, 1999.

RASMUSSEN, S.; CHRISTIANSEN, M. ; ELIASEN, K.; SANDER-JENSEN, K.; MOLLER, J. T. Biochemical markers for brain damage after cardiac surgery - time profile and correlation with cognitive dysfunction. Acta

Anaesthesiologica Scandinavica, v. 46, p. 547-551, 2002.

RASMUSSEN, L. S. Postoperative cognitive dysfunction: Incidence and prevention. Best Practice \& Research Clinical Anaesthesiology, v. 20, n. 2, p. 315-330, 2006.

RASMUSSEN, L. S.; JOHNSON, t.; KUIPERS, H. M.; KRISTENSEN, D.; SIERSMA, V. D.; VILA, P.; JOLLES, J.; PAPAIOANNOU, A.; ABILDSTROM, H.; SILVERSTEIN, J. H.; BONAL, J. A.; RAEDER, J.; NIELSEN, I. K.; KORTTILA, K.; MUNOZ, L.; DODDS, C.; HANNING, C. D.; MOLLER, J. T.Does anaesthesia cause postoperative cognitive dysfunction? A randomised study of regional versus general anaesthesia in 438 elderly patients. Acta Anaesthesiologica Scandinavica, v. 47, p. 260-266, 2003.

RANSOHOFF, R. M.; PERRY, V. H. Microglial physiology: unique stimuli, specialized responses. Annual Review of Immunology, v. 27, p. 119-145, 2009.

REDONDO, J. I.; SUESTA, P.; SERRA, I.; SOLER, C.; SOLER, G.; GIL, L.; GÓMEZVILLAMANDOS, R. J. Retrospective study of the prevalence of postanaesthetic hypothermia in dogs. Veterinary Record, v. 171, n. 15, 2012.

ROHAN, D.; BUGGY, D. J.; CROWLEY, S.; LING, F. K.; GALLAGHER, H.; REGAN, C.; MORIARTY, D. C. Increased incidence of postoperative cognitive dysfunction 24 $\mathrm{hr}$ after minor surgery in the elderly. Canadian Journal of Anesthesia, v. 52, p. 137-142, 2005. 
RUNDSHAGEN, I. Postoperative cognitive dysfunction. Deutsches Ärzteblatt International, v. 111, n. 8, p. 119-125, 2014.

SATOH, H.; YAMATO, O.; ASANO, T.; YONEMURA, M.; YAMAUCHI, T.; HASEGAWA, D.; ORIMA, H.; ARAI, T.; YAMASAKI, M.; MAEDE, Y. Cerebrospinal fluid biomarkers showing neurodegeneration in dogs with GM1 gangliosidosis: Possible use for assessment of a therapeutic regimen. Brain Research, v. 1133, n. 1, p. 200-208, 2007.

SALVIN, H. E.; MCGREEVY, P. D.; SACHDEV, P. S.; VALENZUELA, M. J. The canine cognitive dysfunction rating scale (CCDR): A data-driven and ecologically relevant assessment tool. The Veterinary Journal, v.188, n. 3, p. 331-336, 2011.

SALVIN, H. E.; MCGREEVY, P. D.; SACHDEV, P. S.; VALENZUELA, M. J. Under diagnosis of canine cognitive dysfunction: A cross-sectional survey of older companion dogs, The Veterinary Journal, v.184, n. 3, p. 277-281, 2010.

SILVERSTEIN, J. H. The pratice of geriatric. In: SILVERSTEIN, J. H.; ROOKE, G. A.; REVES, J. G.; McLESKEY, C. H. Geriatric anesthesiology. 2th ed. New York: Spring, 2008. Chap. 01, p. 03-14.

STRATMANN, G.; SALL, J. W.; BELL, J. S.; ALVI, R. S.; MAY, L. D.; KU, B.; DOWLATSHAHI, M.; SAI, R.; BICKLER, P. E.; RUSSELL, I.; LEE, M. T.; HRUBOS, M. W.; CHIU, C. Isoflurane does not affect brain cell death, hippocampal neurogenesis, or long-term neurocognitive outcome in aged rats. Anesthesiology, v. 112, n. 2, p. 305-315, 2010.

SU, M. Y.; HEAD, E.; BROOKS, W. M.; WANG, Z.; MUGGENBURG, B. A.; ADAM, G. E.; SUTHERLAND, R.; COTMAN, C. W.; NALCIOGLU, O. Magnetic resonance imaging of anatomic and vascular characteristics in a canine model of human aging.

Neurobiology of Aging, v. 19, n. 5, p. 479-485, 1998.

SUN, T.; WANG, X.; LIU, Z.; CHEN, X.; ZHANG, J. Plasma concentration of pro- and anti-inflammatory cytokines and outcome prediction in elderly hip fracture patients.

Injury, v. 42, p. 707-713, 2011.

TERRANDO N.;ERIKSSON, L.I.; RYU J.K., YANG, T.;MONACO C., FELDMANN, M. FAGERLUND,J.M.; CHARO I.F.; AKASSOGLOU;K.; MAZE, M. Resolving postoperative neuroinflammation and cognitive decline. Annals of Neurology, v. 70, p. 986-995, 2011. 
VAN DIJK, D.; SPOO, R. M. Cognitive and cardiac outcomes 5 years after off-pump vs. on-pump coronary artery bypass graft surgery. Journal of the American Medical Association, v. 297, p. 701-708, 2007.

XIE, Z.; CULLEY, D. J.; DONG, Y.; ZHANG, G.; ZHANG, B.; MOIR, R. D.; FROSCH, M. P.; CROSBY, G.; TANZI, R. E. The common inhalation anesthetic isoflurane induces caspase activation and increases amyloid $\beta$-protein level in vivo. Annals of Neurology, v. 64, n. 6, p. 618-627, 2008.

WEI, H.; LIANG, G.; YANG, H.; WANG, Q.; HAWKINS, B.; MADESH, M.; WANG, S.; ECKENHOFF, R. G. The common inhalational anesthetic isoflurane induces apoptosis via activation of inositol 1,4,5-trisphosphate receptors. Anesthesiology, v. 108, n. 2, p. 251-260, 2008.

WILLIAMS-RUSSO, P.; SHARROCK, N. E.; MATTIS, S.; SZATROWSKI, T. P.; CHARLSON, M. E. Cognitive effects after epidural vs general anesthesia in older adults. A randomized trial. The Journal of the American Medical Association, v. 274, n. 1, p. 44-50, 1995.

WURI, G.; WANG, D.-X.; ZHOU, Y.; SHU, S.-N. Effects of surgical stress on longterm memory function in mice of different ages. Acta Anaesthesiologica Scandinavica, v. 55, n. 4, p. 474-485, 2011. 
ANEXO A - ESCALA ARCAD

\section{Parâmetros Emocionais}

\begin{tabular}{|c|c|c|}
\hline Comportamento & Item & Score \\
\hline Alimentação & $\begin{array}{l}\text { Hiperfagia } \\
\text { Anorexia ou hiporexia } \\
\text { Disorexia ( ingere objetos não comestíveis) } \\
\text { Regurgitação } \\
\text { Apetite Normal }\end{array}$ & $\begin{array}{l}5 \\
3 \\
3 \\
2 \\
1\end{array}$ \\
\hline Ingestão de água & $\begin{array}{l}\text { Polidipsia } \\
\text { "Mastigar" a água sem engolir } \\
\text { Normal }\end{array}$ & $\begin{array}{l}4 \\
3 \\
1\end{array}$ \\
\hline $\begin{array}{l}\text { Comportamento } \\
\text { alto estimulatório }\end{array}$ & $\begin{array}{l}\text { Movimentos repetidos de lamber e mordiscar } \\
\text { Mordiscar e perseguindo a cauda repetitivamente } \\
\text { Procura morder-se ou lamber-se } \\
\text { Normal }\end{array}$ & $\begin{array}{l}5 \\
3 \\
2 \\
1\end{array}$ \\
\hline Eliminação de dejetos & $\begin{array}{l}\text { Defeca e urina onde fica (inclusive onde dorme) } \\
\text { Defeca e urina onde fica (poupando onde dorme) } \\
\text { Defeca e urina onde em quantidade pequena e dispersa } \\
\text { Sem alteração }\end{array}$ & $\begin{array}{l}5 \\
4 \\
3 \\
1\end{array}$ \\
\hline Sono & $\begin{array}{l}\text { Inqueto na hora de dormir } \\
\text { Alterna entre insônia e hipersonia ( dorme demais) } \\
\text { Dorme mais que } 15 \text { horas por dia } \\
\text { Sem mudança }\end{array}$ & $\begin{array}{l}5 \\
3 \\
2 \\
1\end{array}$ \\
\hline
\end{tabular}

\section{Parâmetros Cognitivos}

\begin{tabular}{|c|c|c|}
\hline Comportamento & Item & Score \\
\hline $\begin{array}{l}\text { Específicos } \\
\text { comportamentos } \\
\text { aprendidos }\end{array}$ & $\begin{array}{l}\text { Praticamente não responde } \\
\text { Responde randomicamente } \\
\text { Sem mudanças }\end{array}$ & $\begin{array}{l}5 \\
3 \\
1\end{array}$ \\
\hline Auto-Controle & $\begin{array}{l}\text { Tenda generalizar as experiências aversivas } \\
\text { Possui dificuldade em se acalmar após um evento estressante } \\
\text { Não aparenta mudanças }\end{array}$ & $\begin{array}{l}5 \\
3 \\
2\end{array}$ \\
\hline $\begin{array}{l}\text { Comportamento } \\
\text { Social aprendido }\end{array}$ & $\begin{array}{l}\text { Rouba e retém os objetos roubados } \\
\text { Morde sem aviso } \\
\text { Quando repreendido ele não se submete } \\
\text { Sem mudança }\end{array}$ & $\begin{array}{l}5 \\
2 \\
3 \\
1\end{array}$ \\
\hline Capacidade Adaptativa & $\begin{array}{l}\text { Olha indiferente para as mudanças } \\
\text { Incapaz de suportar mudanças na sua rotina } \\
\text { Recusa novas situações } \\
\text { As mudanças tem um interesse normal }\end{array}$ & $\begin{array}{l}5 \\
3 \\
2 \\
1\end{array}$ \\
\hline Escore Cognitivo= & & \\
\hline
\end{tabular}


Interpretação da escala ARCAD

\begin{tabular}{|l|l|}
\hline Interperetação & Score \\
\hline Normal para a idade & 9 a 15 \\
\hline Reavaliação em 6 meses & 16 a 21 \\
\hline Depressão & 22 a 30 \\
\hline Cão idoso Hiperagressivo & 18 a $30^{\star}$ \\
\hline Depressão Involutiva & 31 a 41 \\
\hline
\end{tabular}

* com uma pontuação de 3 ou 4 da aprendizagem social e pontuação de 3 de auto-regulação, em associação com a medição do índice de agressividade.

Fonte: LANDSBERG; HUNTHASUEN; ACKERMAN, 2003. 


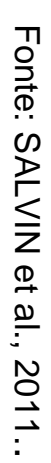

\begin{tabular}{|c|c|c|c|c|c|c|c|c|c|c|c|c|c|c|}
\hline & 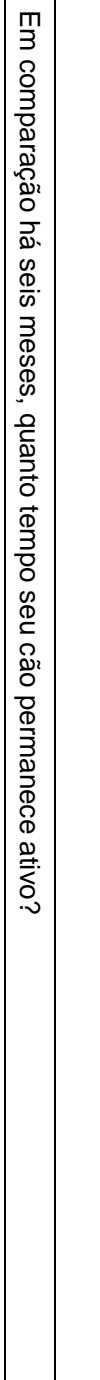 & 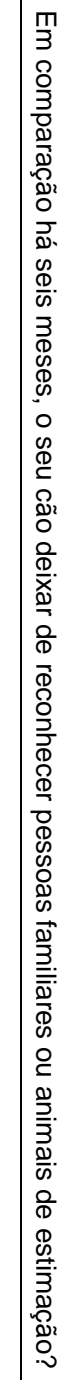 & 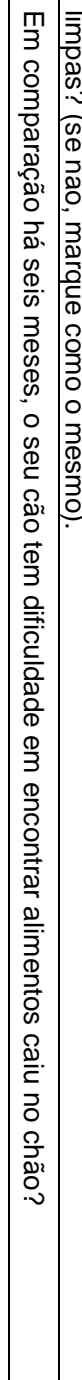 & 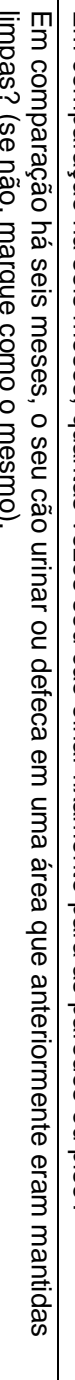 & 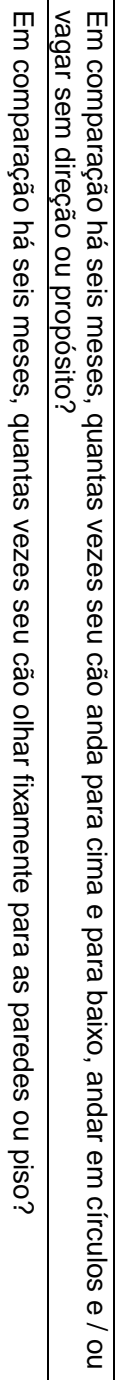 & & 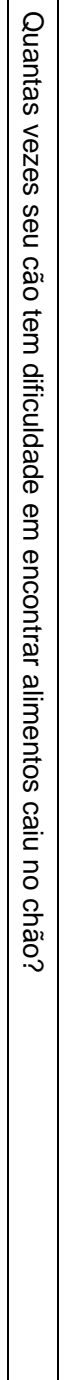 & & 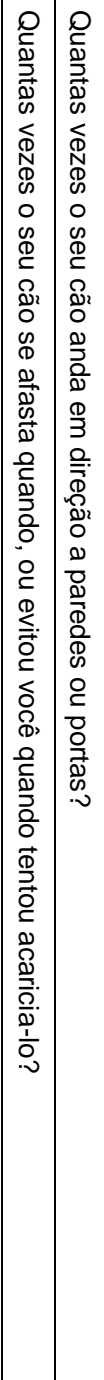 & 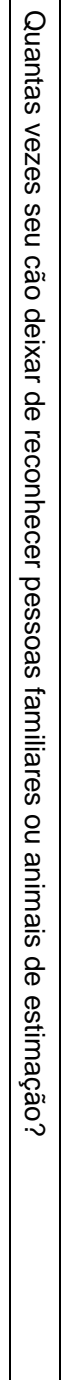 & 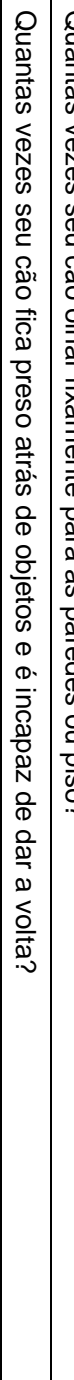 & 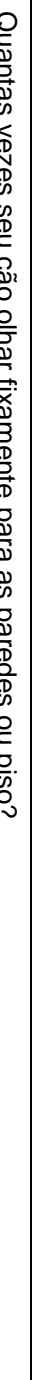 & 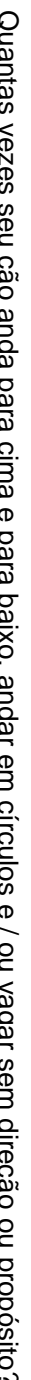 & \\
\hline & $\begin{array}{l}3 \\
\frac{3}{0} \\
3 \\
\frac{0}{\omega} \\
\frac{0}{\omega}\end{array}$ & & & & & 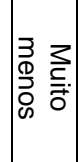 & & $\begin{array}{l}\text { Ż } \\
\text { స్త }\end{array}$ & & & & & & \\
\hline & $\frac{3}{\omega}$ & & & & & 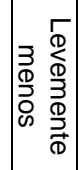 & & 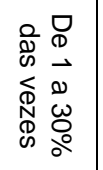 & & & & & & 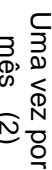 \\
\hline & $\begin{array}{l}0 \\
3 \\
0 \\
0 \\
0 \\
3\end{array}$ & & & & & $\begin{array}{l}0 \\
3 \\
\mathbf{0} \\
0 \\
3 \\
\end{array}$ & & 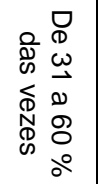 & & & & & & 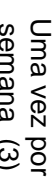 \\
\hline & 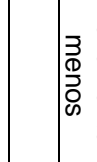 & & & & & $\frac{3}{\frac{3}{\omega}}$ & & 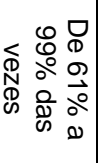 & & & & & & 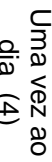 \\
\hline $\begin{array}{l}\text {-1 } \\
\stackrel{-}{1} \\
2\end{array}$ & 商 & & & & & 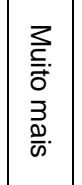 & & $\begin{array}{l}\mathbb{D} \\
\mathbb{1} \\
3 \\
\frac{0}{0} \\
\mathbb{1}\end{array}$ & & & & & & 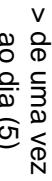 \\
\hline & & & & & & & & & & & & & & \\
\hline
\end{tabular}

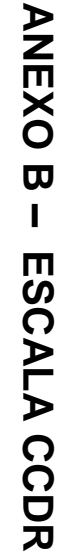




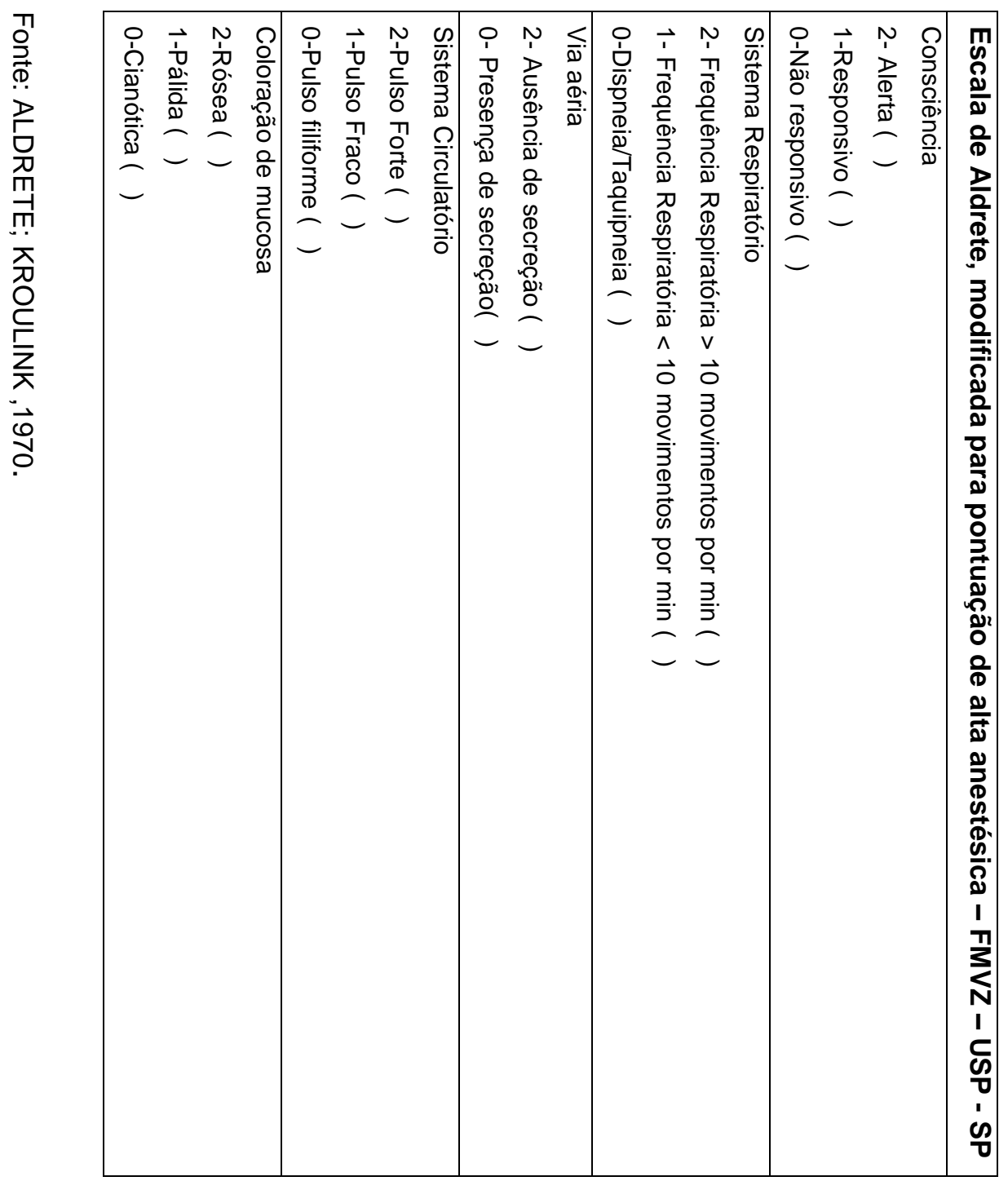

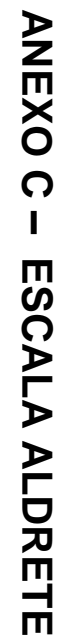




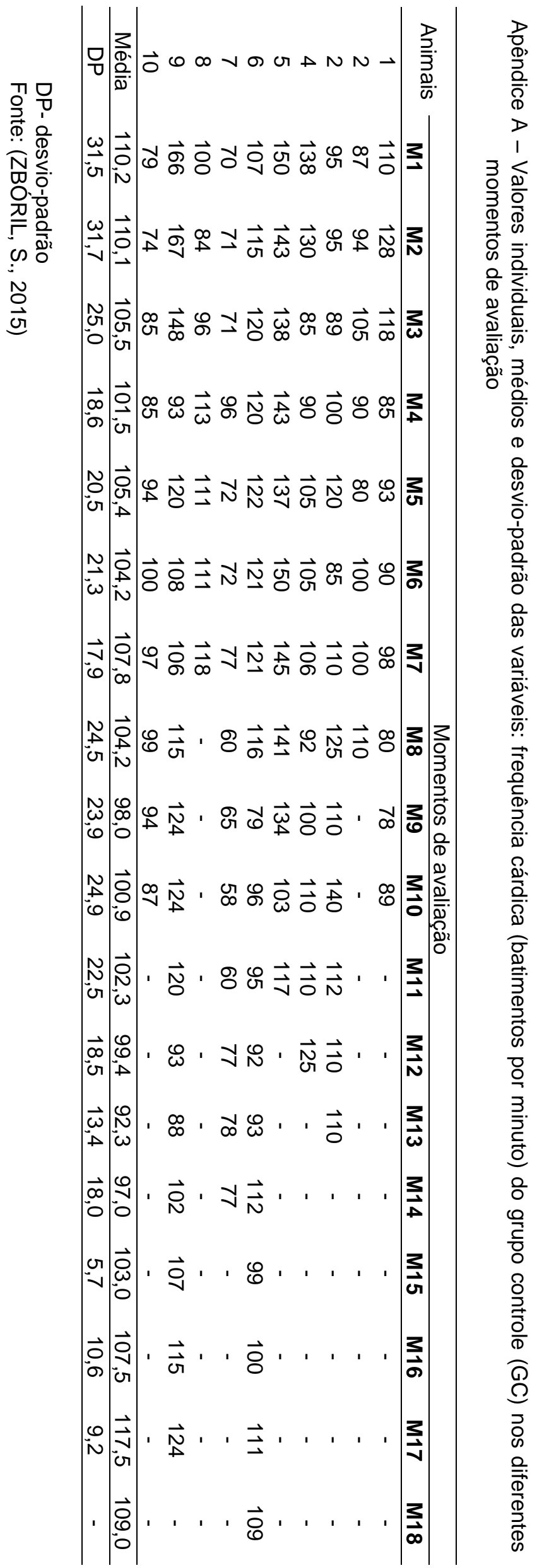




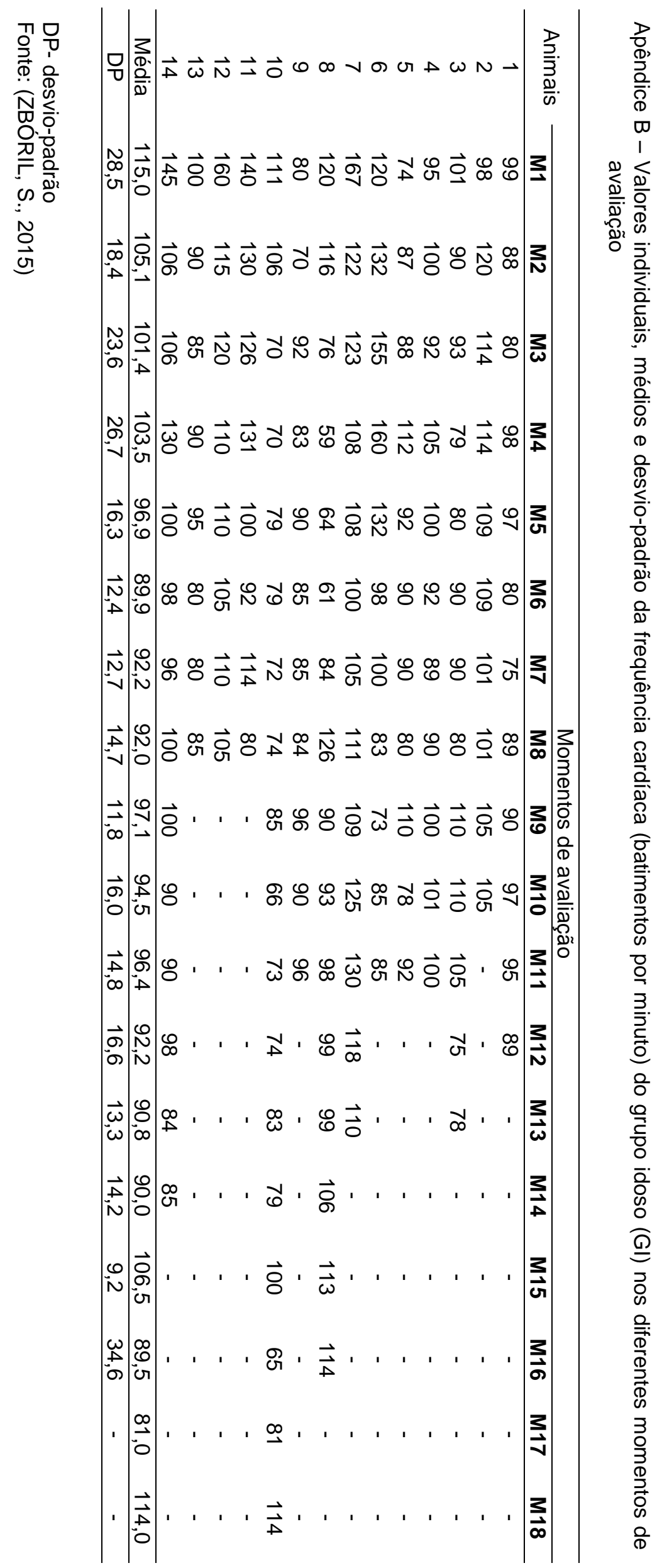




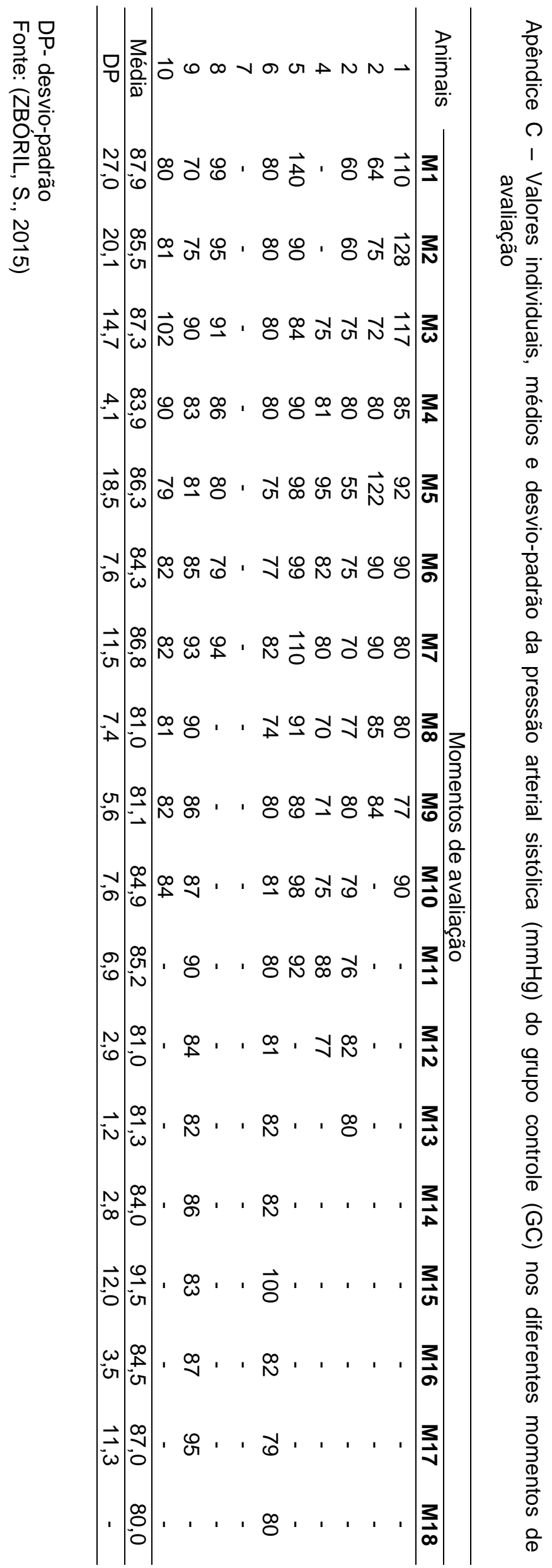




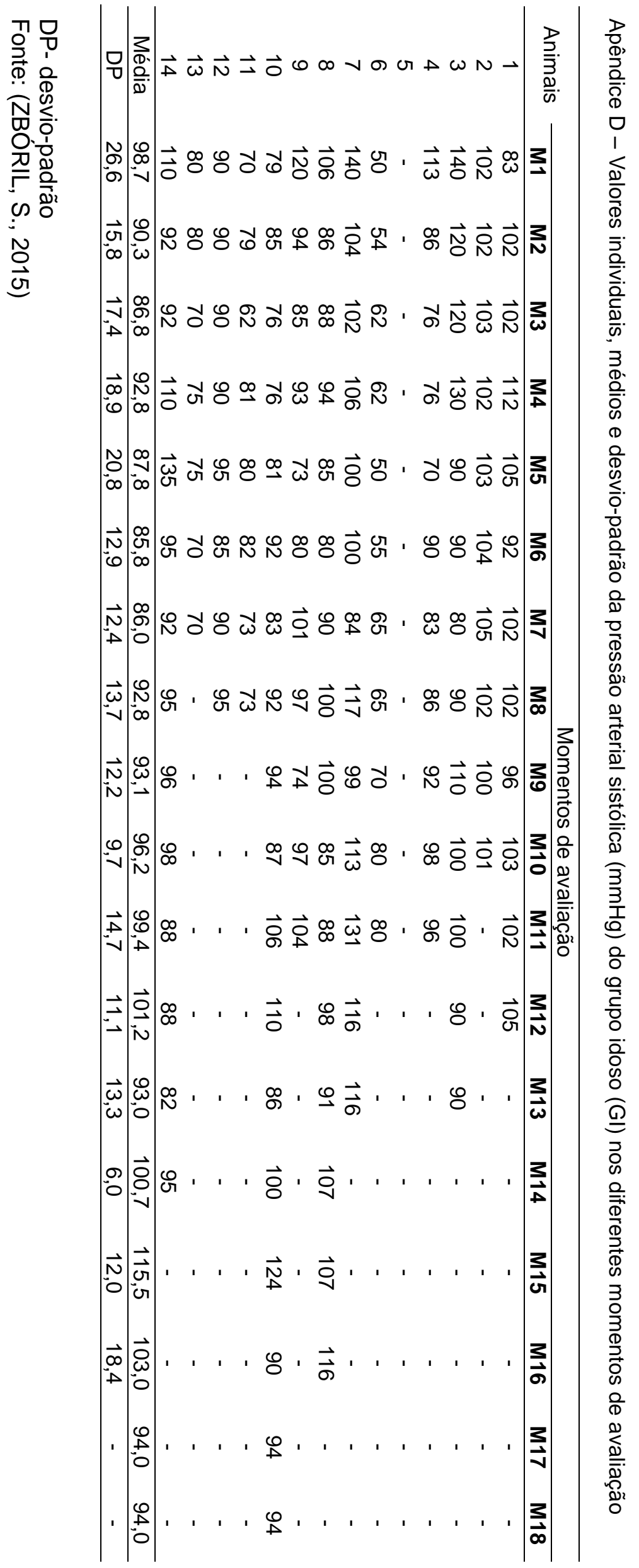




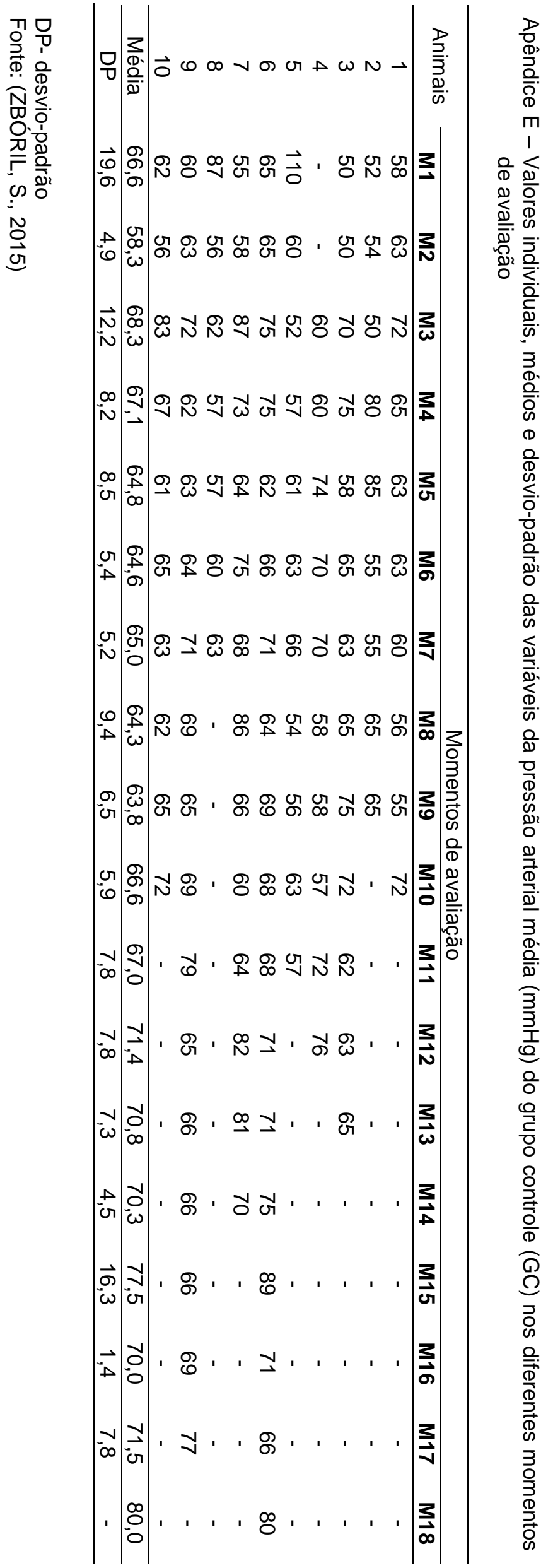




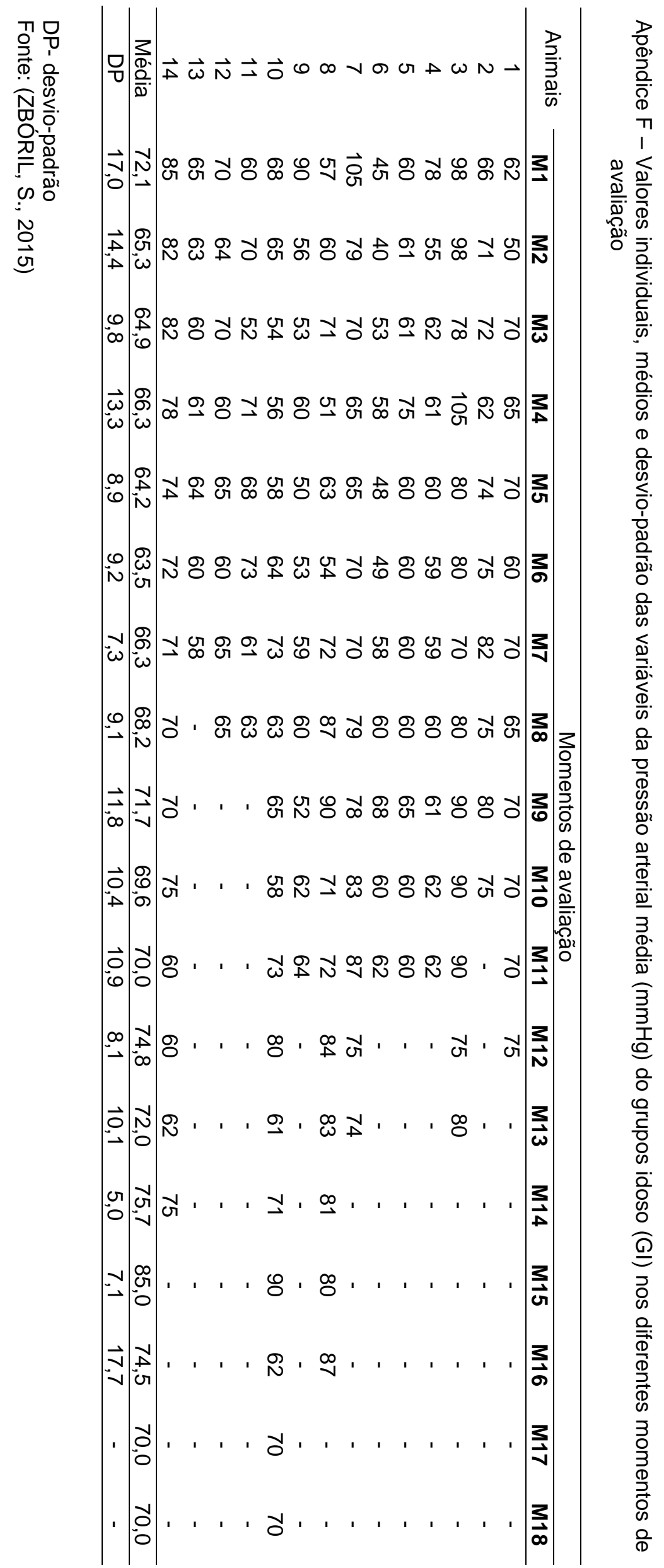




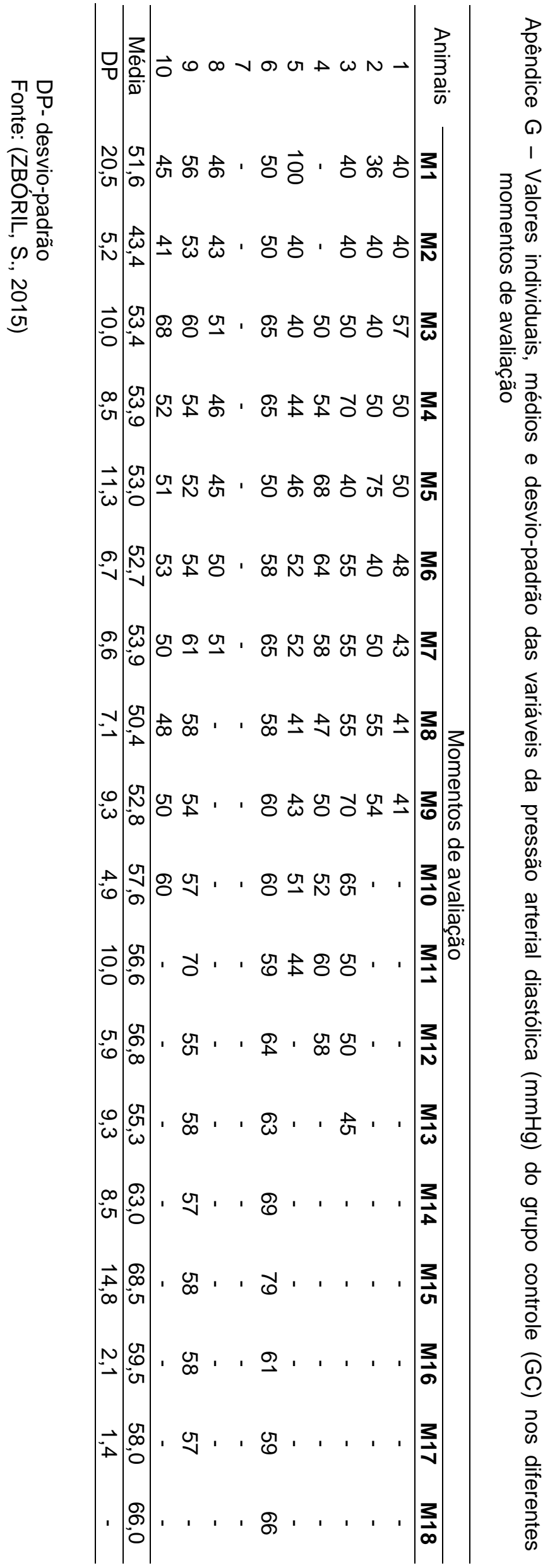




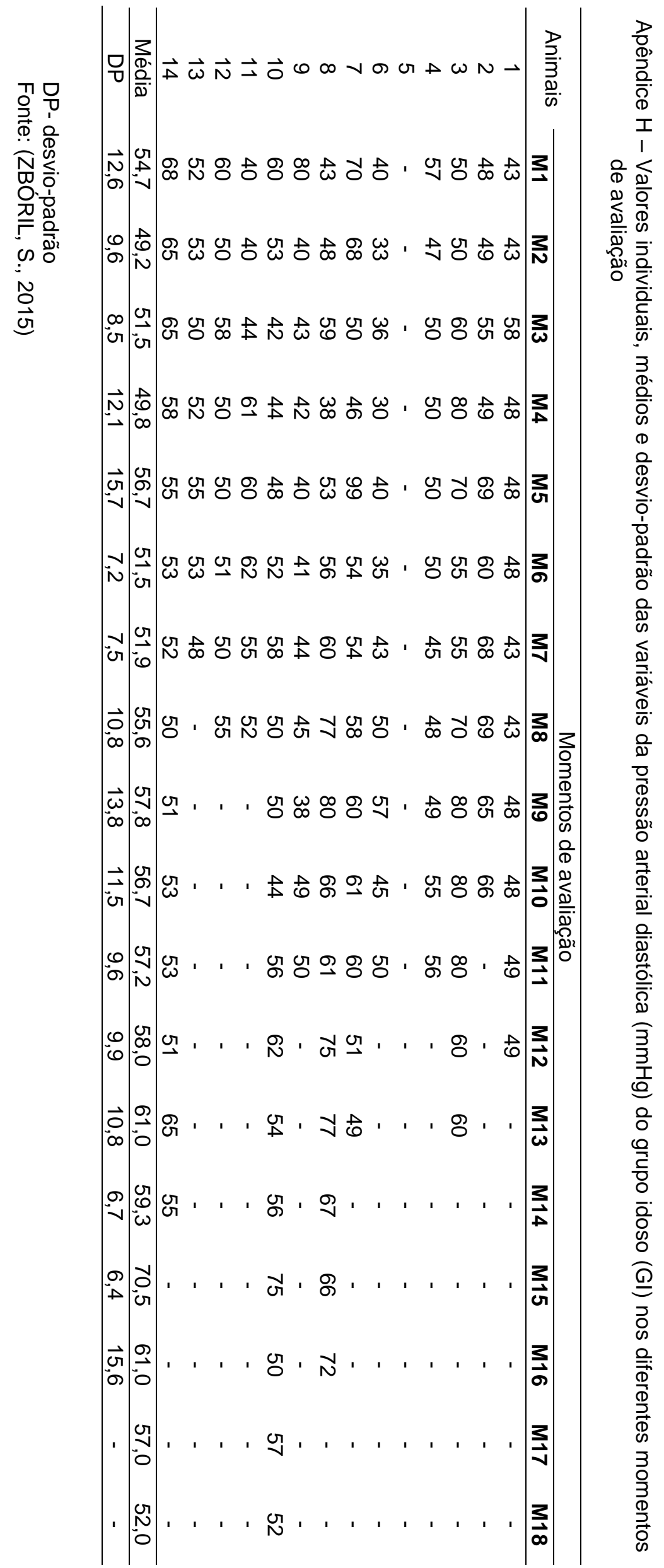




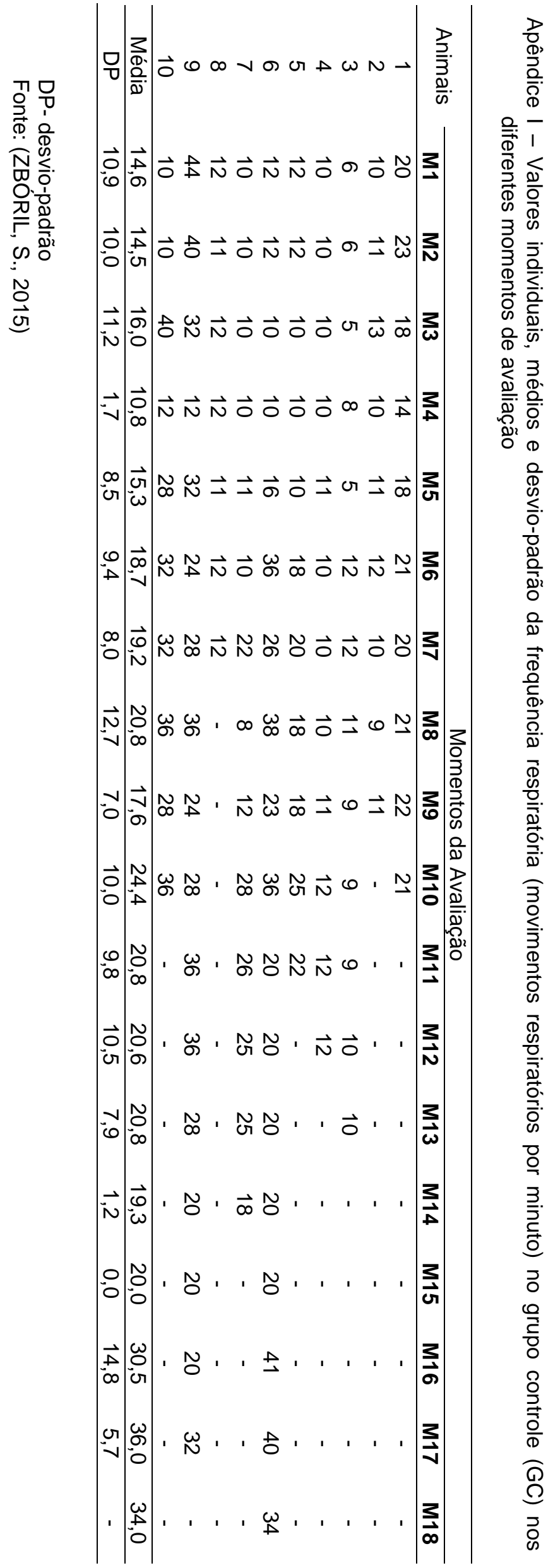




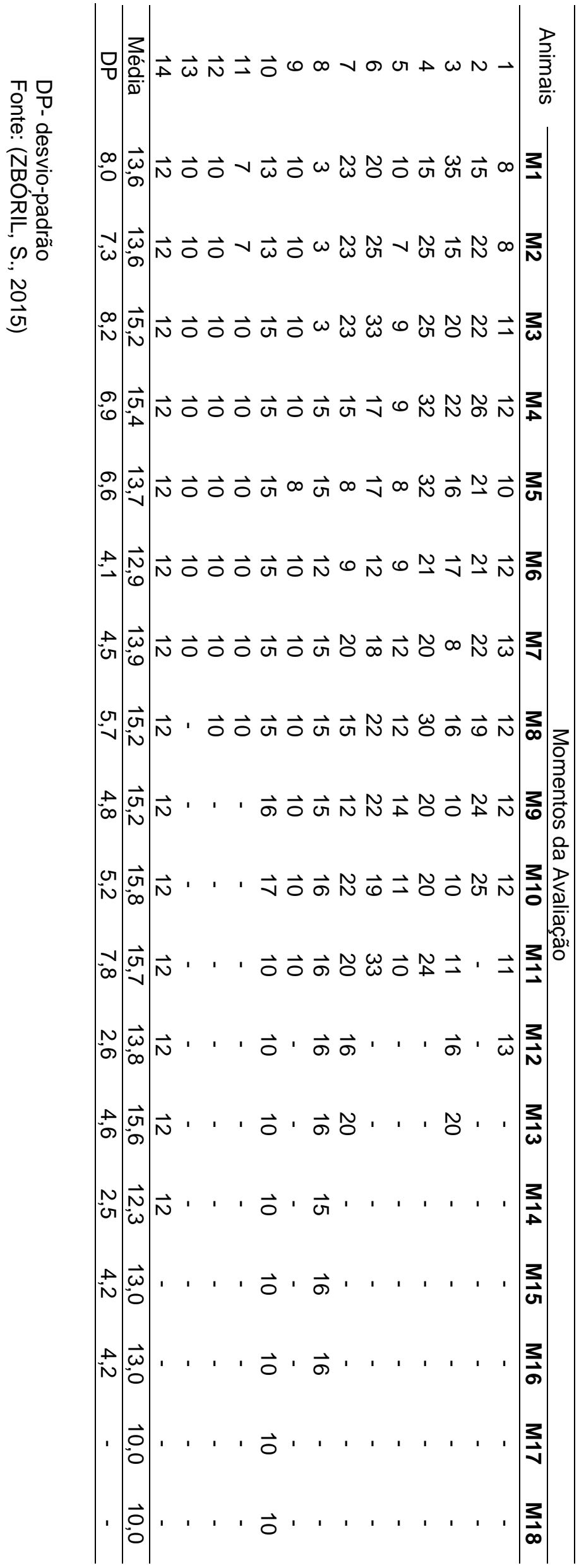

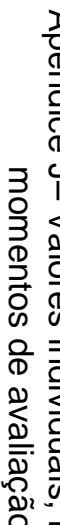




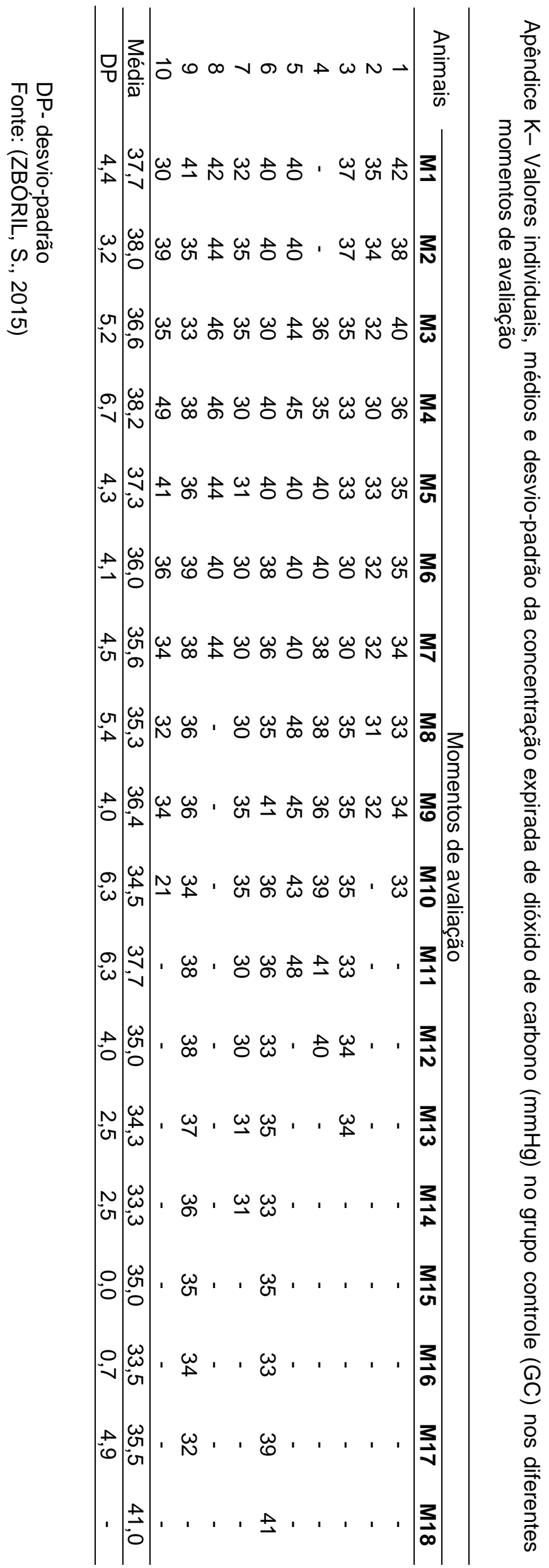




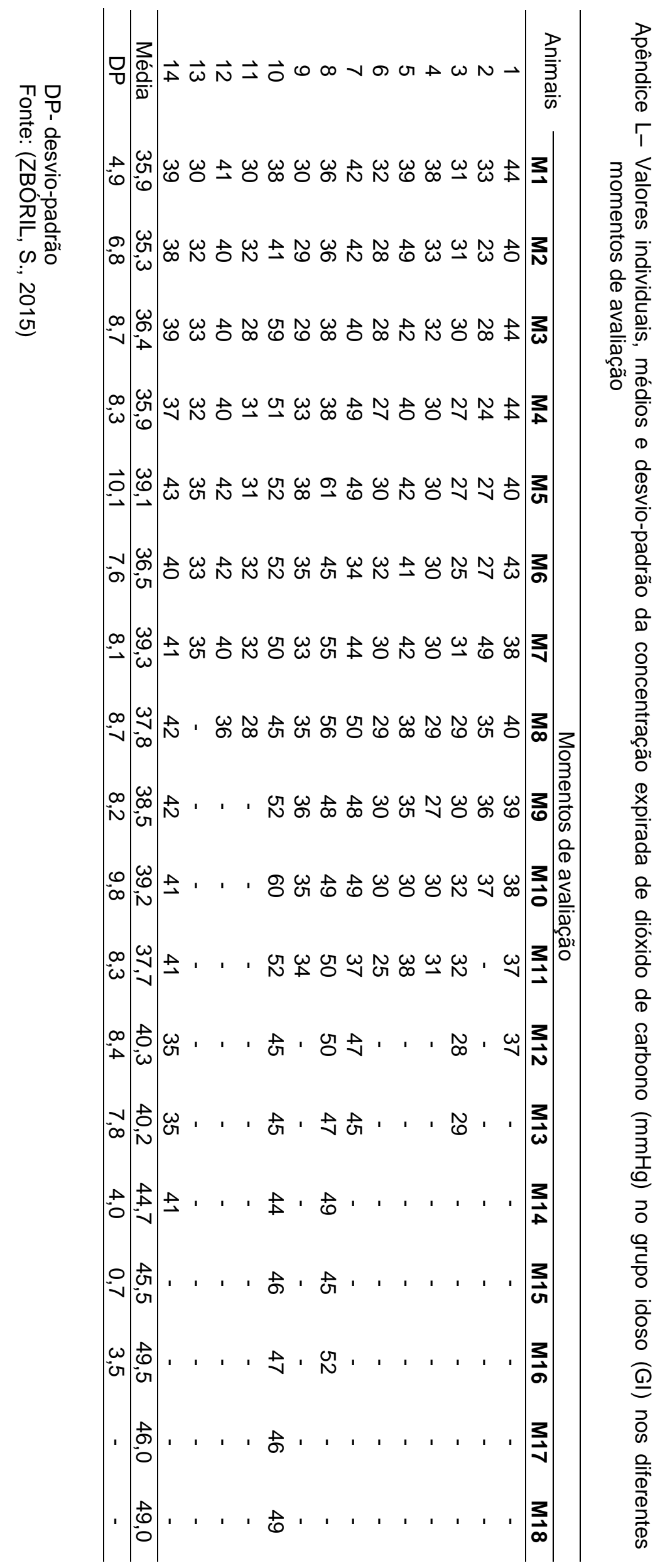




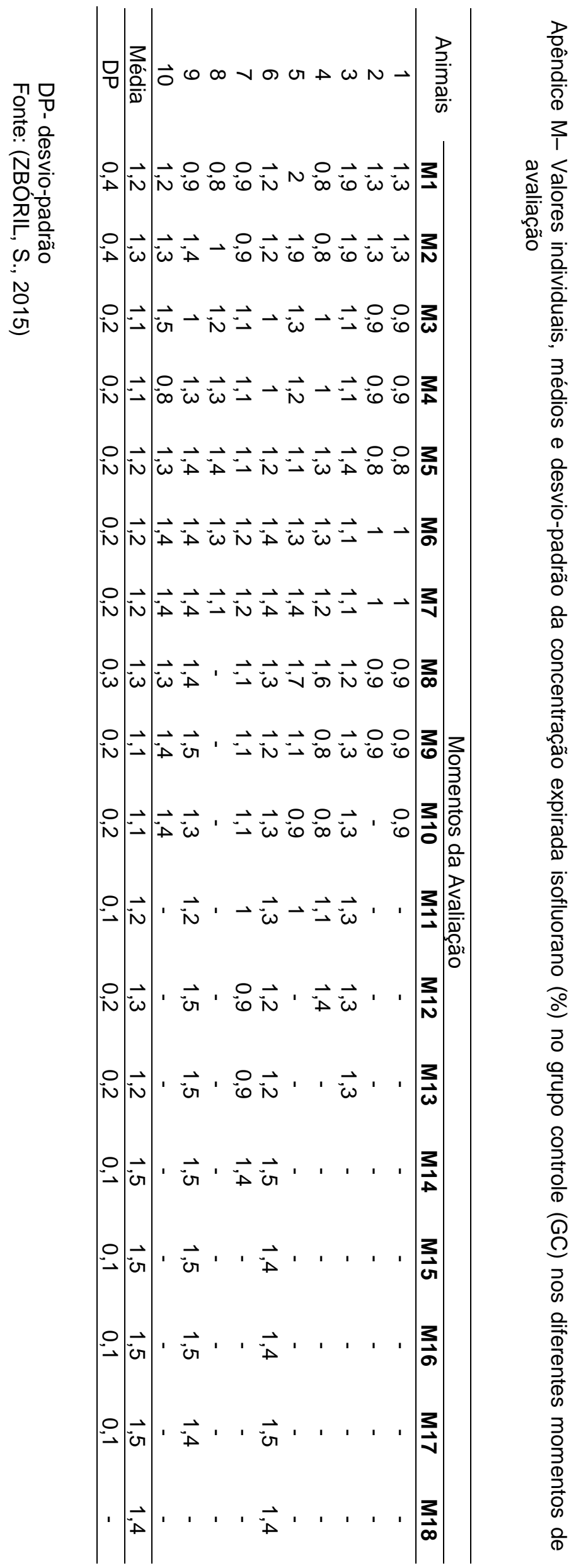




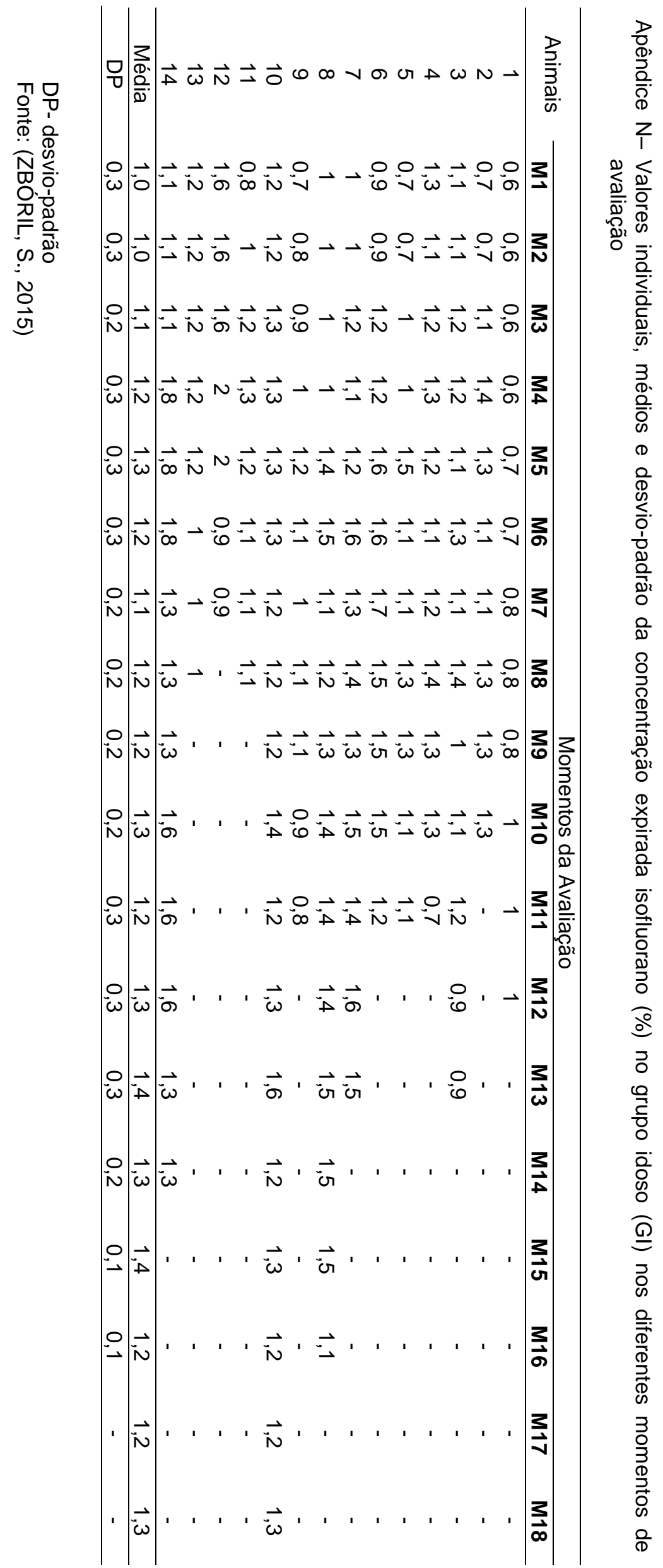




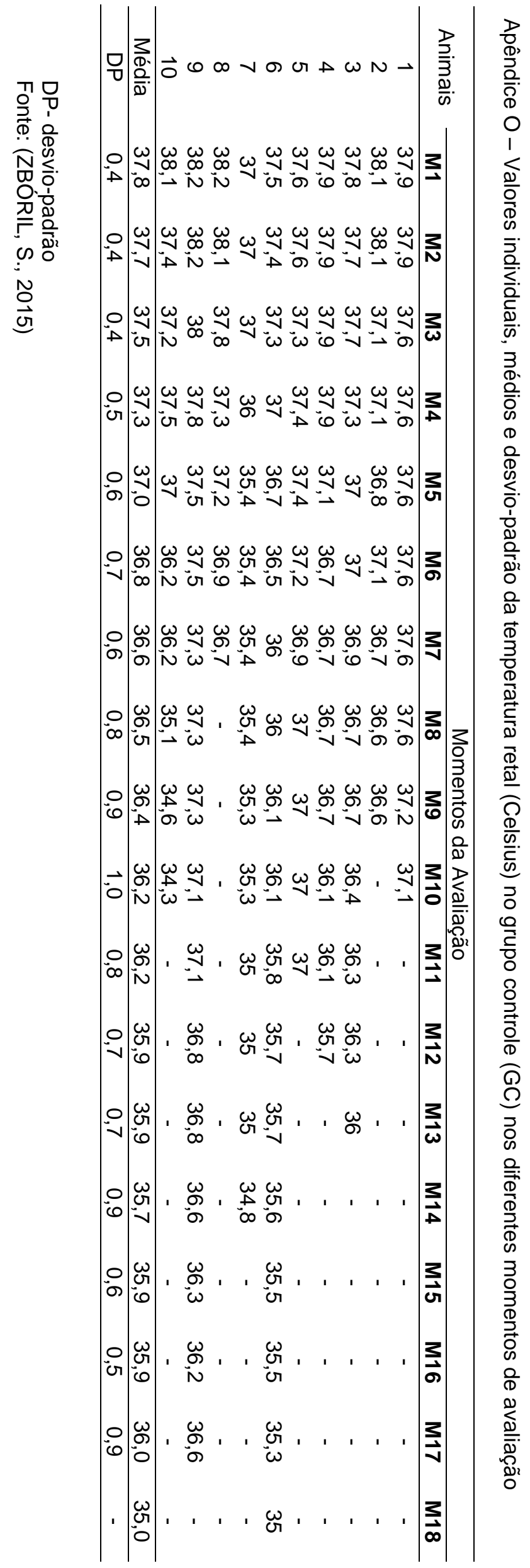




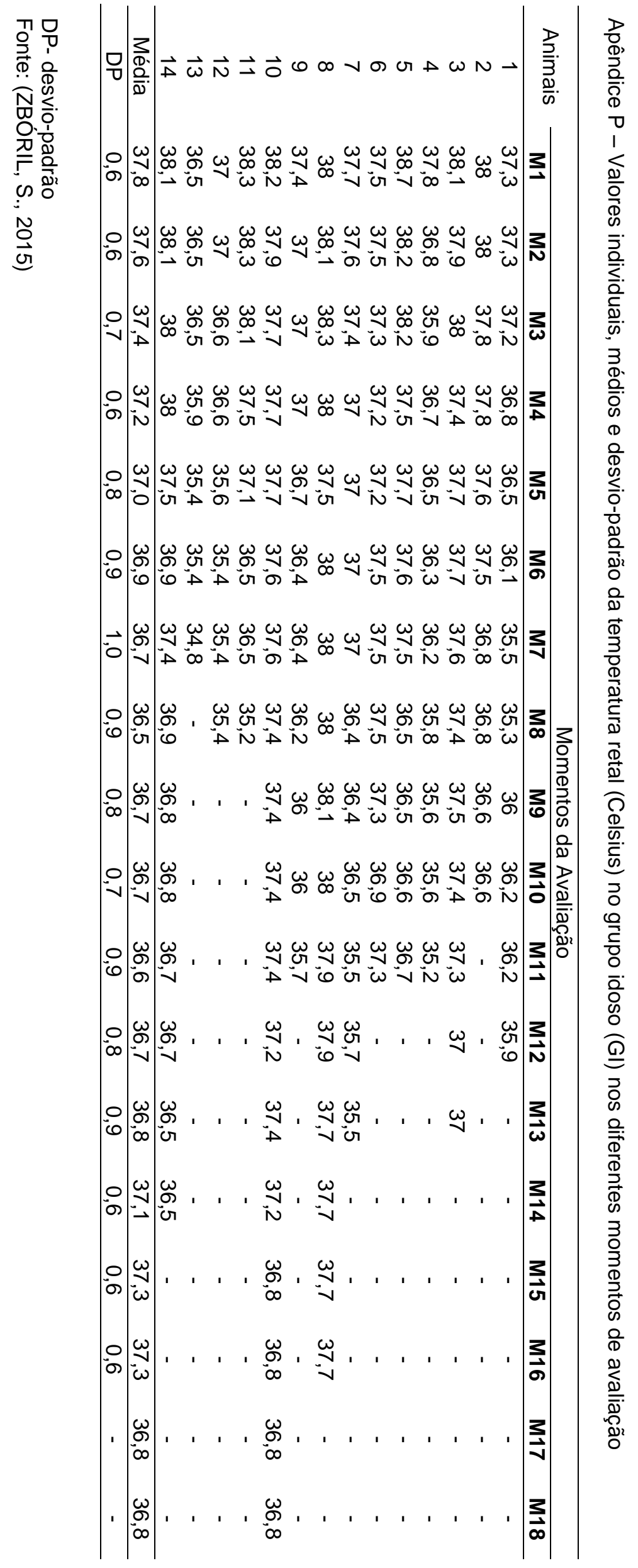




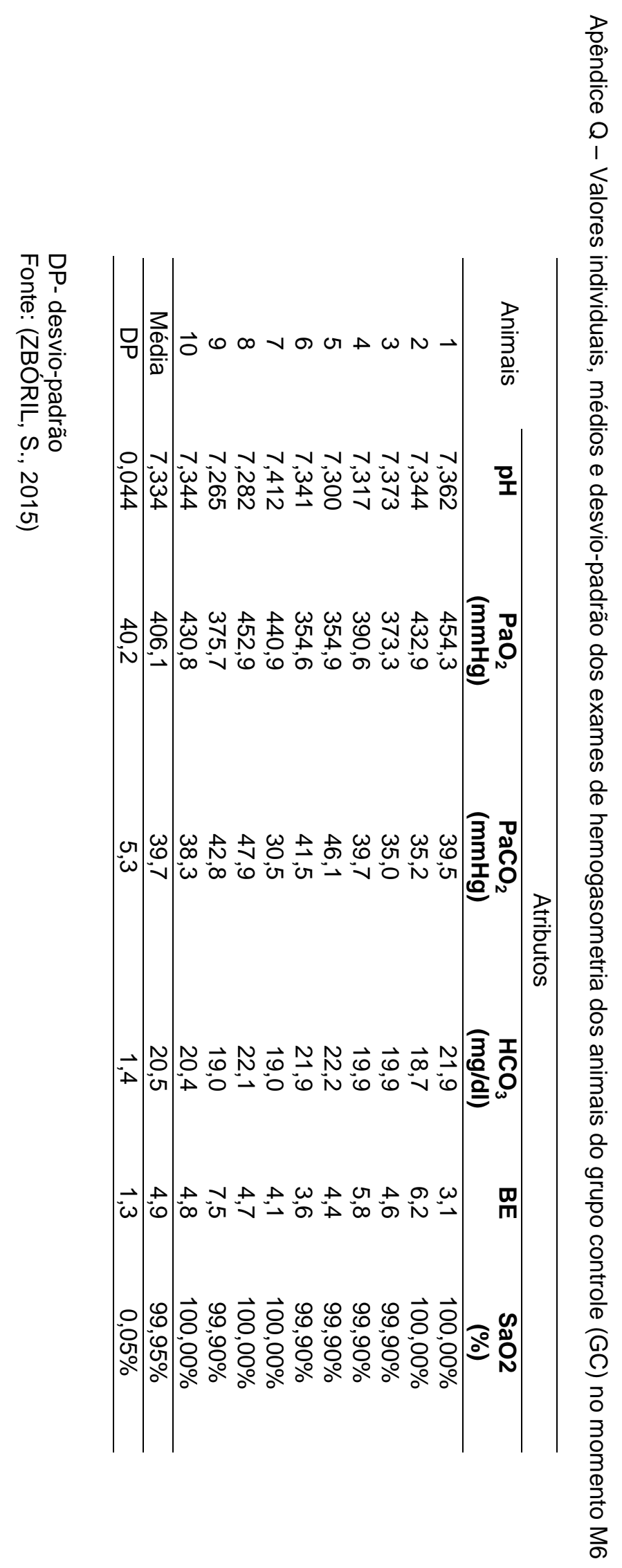




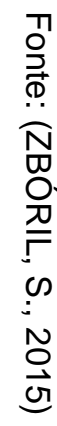

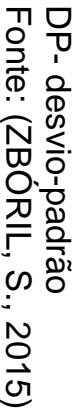

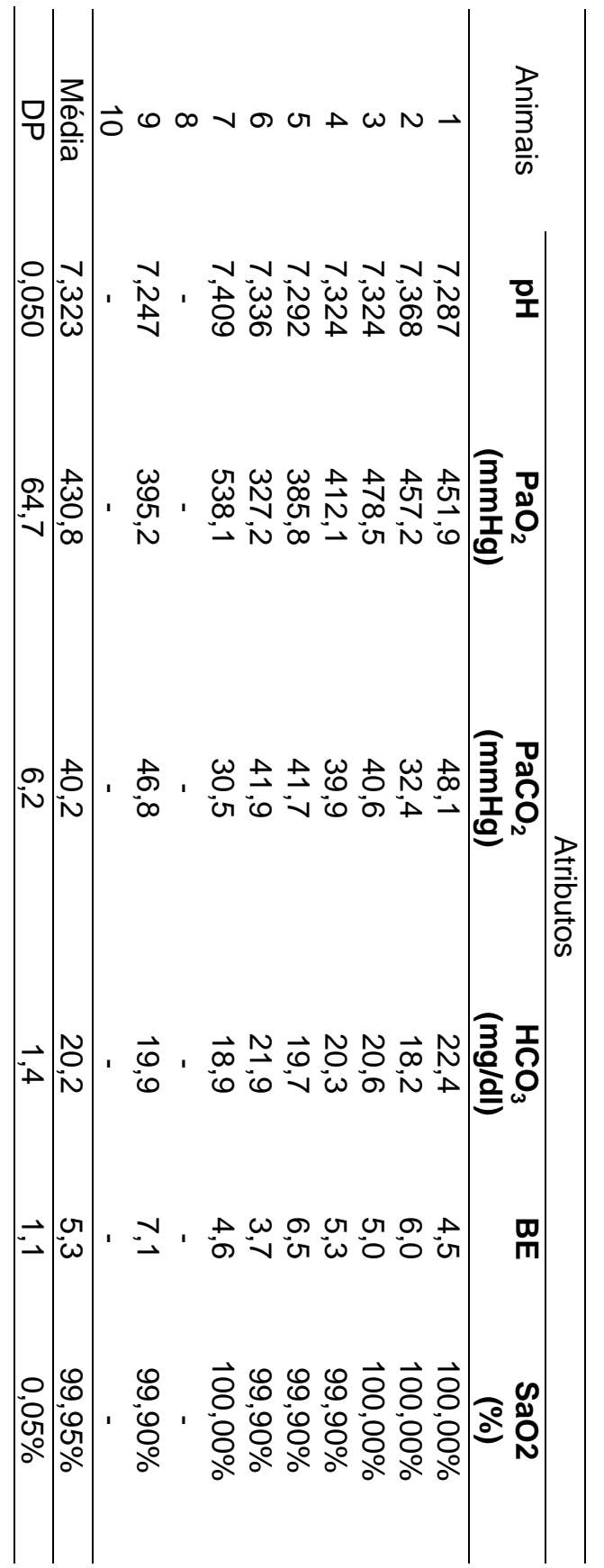

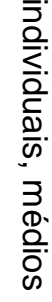

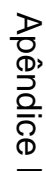

7

$<$

$\frac{0}{\circ}$

음

ㄴ.

ֻั1

음

응 


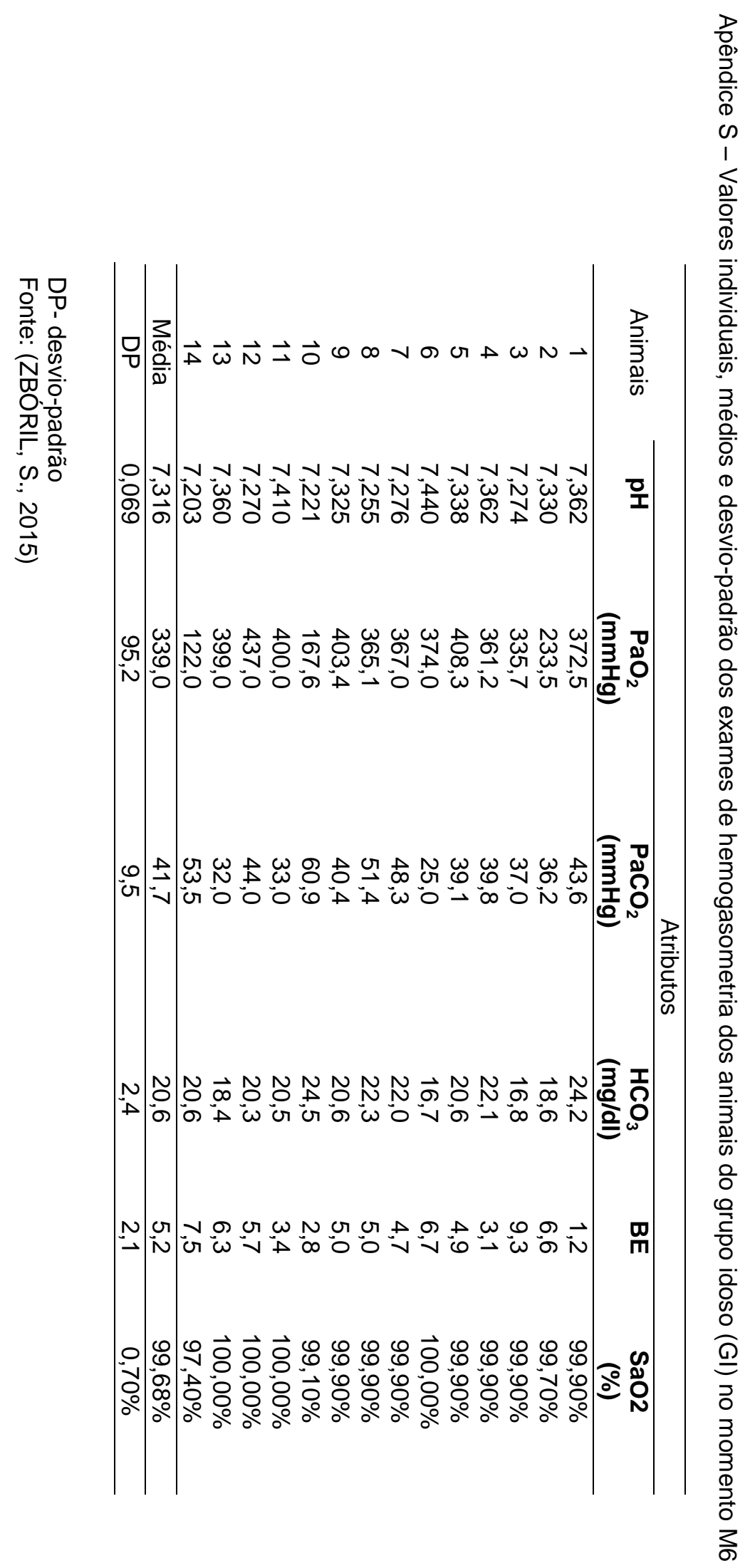




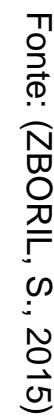

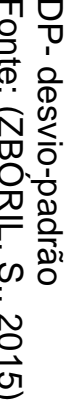

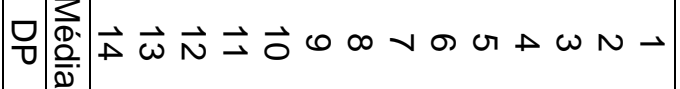

产.

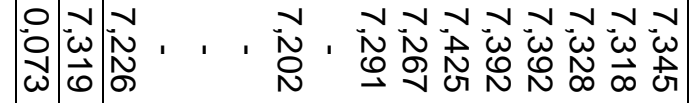

오

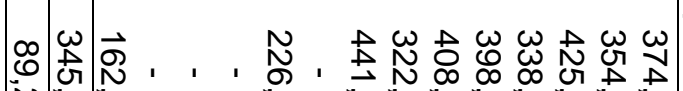

N N G

$\circ$ म

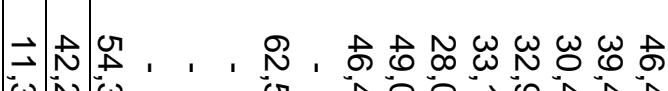

$\omega \tilde{\omega}$

ज 10000

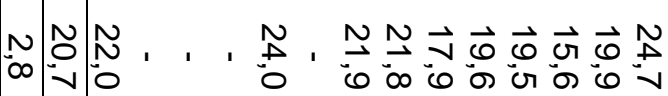

$\widehat{3}$ ำ

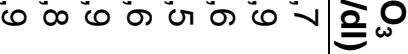

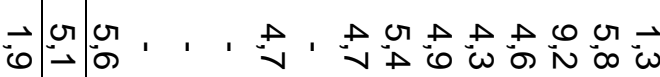

$\boldsymbol{m}$
$\mathbf{m}$

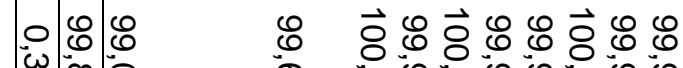

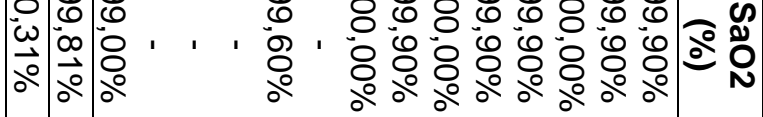

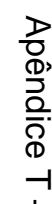

$<$

음

क

홀

$\frac{\text { की }}{\frac{2}{2}}$

ㄱ.

क

离

ำ.

$\stackrel{0}{0}$

จำ

웅

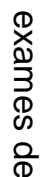

$\bar{\sigma}$

$\stackrel{\mathbb{1}}{3}$ 


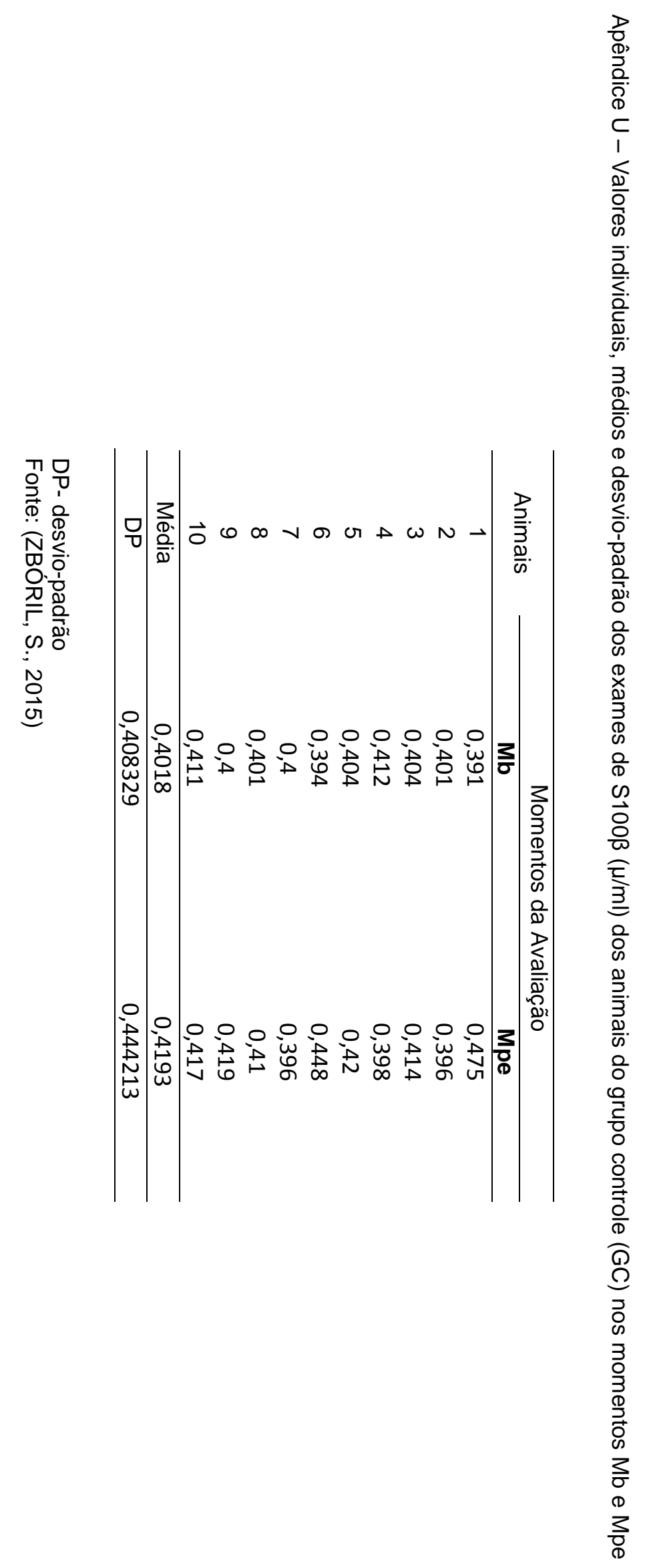




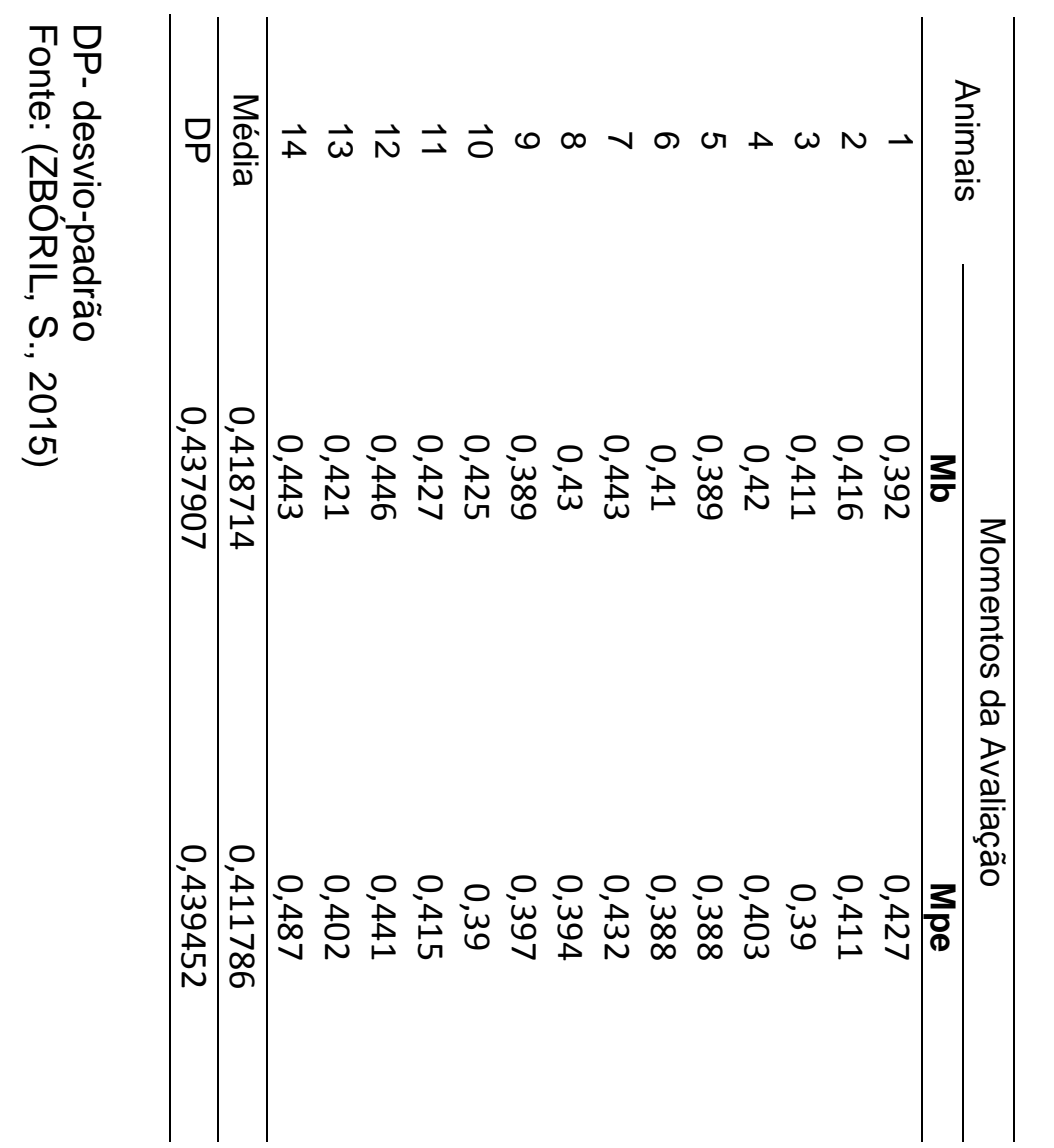




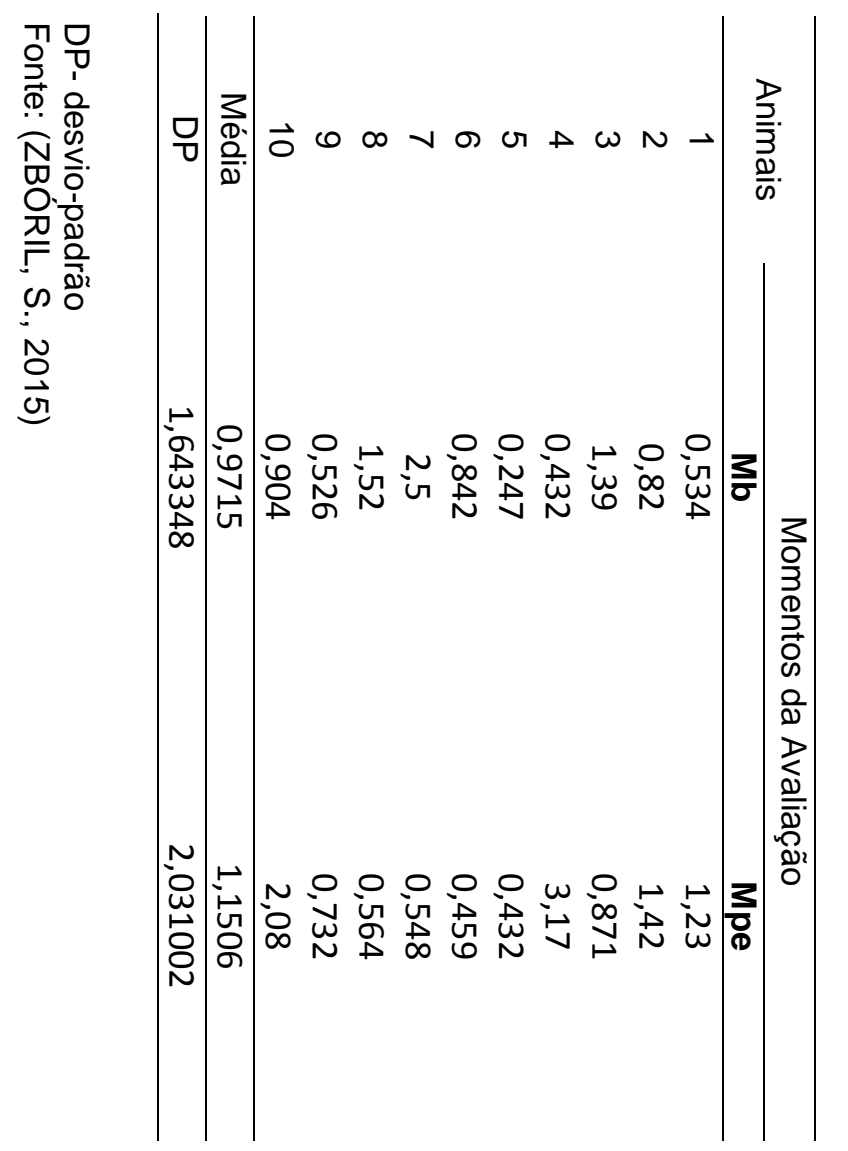

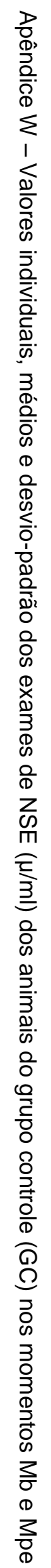




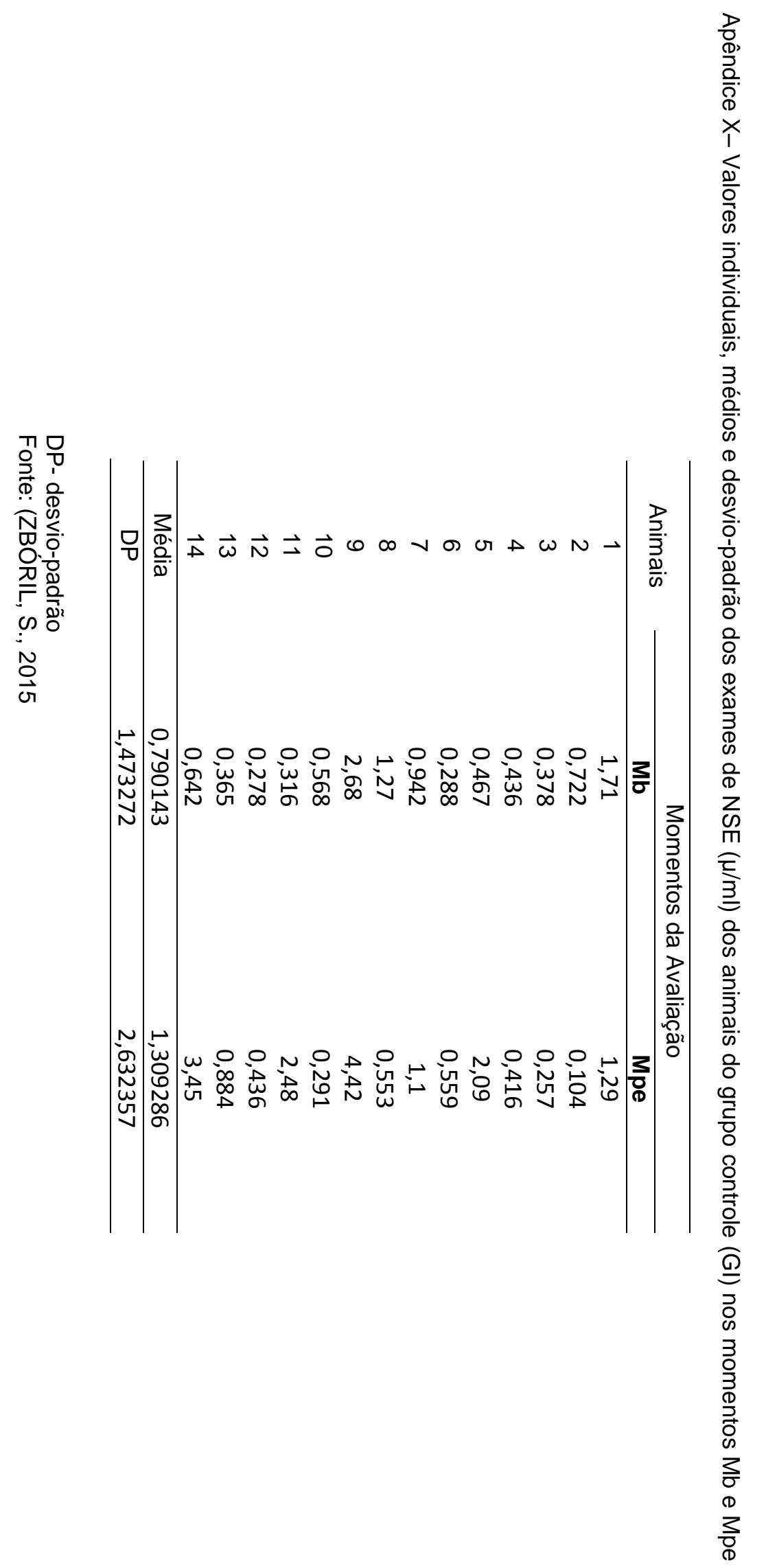

